\title{
MicroRNAs orchestra the cellular processes driving failure of the heart
}

Citation for published version (APA):

Verjans, R. H. K. O. (2018). MicroRNAs orchestra the cellular processes driving failure of the heart.

[Doctoral Thesis, Maastricht University]. Maastricht University. https://doi.org/10.26481/dis.20180223rv

Document status and date:

Published: 01/01/2018

DOI:

10.26481/dis.20180223rv

Document Version:

Publisher's PDF, also known as Version of record

\section{Please check the document version of this publication:}

- A submitted manuscript is the version of the article upon submission and before peer-review. There can be important differences between the submitted version and the official published version of record.

People interested in the research are advised to contact the author for the final version of the publication, or visit the DOI to the publisher's website.

- The final author version and the galley proof are versions of the publication after peer review.

- The final published version features the final layout of the paper including the volume, issue and page numbers.

Link to publication

\footnotetext{
General rights rights.

- You may freely distribute the URL identifying the publication in the public portal. please follow below link for the End User Agreement:

www.umlib.nl/taverne-license

Take down policy

If you believe that this document breaches copyright please contact us at:

repository@maastrichtuniversity.nl

providing details and we will investigate your claim.
}

Copyright and moral rights for the publications made accessible in the public portal are retained by the authors and/or other copyright owners and it is a condition of accessing publications that users recognise and abide by the legal requirements associated with these

- Users may download and print one copy of any publication from the public portal for the purpose of private study or research.

- You may not further distribute the material or use it for any profit-making activity or commercial gain

If the publication is distributed under the terms of Article $25 \mathrm{fa}$ of the Dutch Copyright Act, indicated by the "Taverne" license above, 


\section{Promotor:}

Prof. Dr. S.R.B. Heymans

\section{Copromotores:}

Dr. B. Schroen

Dr. M. van Bilsen

\section{Beoordelingscommissie:}

Prof. dr. Harry Crijns (voorzitter)

Prof, dr. Jan de Boer

Dr. Ebba Brakenhielm (Inserm, French Institute of Health and Medical Research, France)

Prof. dr. Mauro Giacca (ICGEB, International Centre for Genetic Engineering and Biotechnology, Italy)

Dr. Joris Hoeks

Financial support by the Dutch Heart Foundation for the publication of this thesis is gratefully acknowledged.

\section{ISBN:}

ISBN/EAN 9789462957879

\section{Lay-out and print by:}

ProefschriftMaken | www.proefschriftmaken.nl 


\section{MicroRNAs Orchestrate the Cellular Processes Driving Failure of the Heart}

\section{PROEFSCHRIFT}

ter verkrijging van de graad van doctor aan de Universiteit Maastricht, op gezag van de Rector Magnificus, Prof dr. Rianne M. Letschert volgens het besluit van het College van Decanen, in het openbaar te verdedigen vrijdag 23 februari 2018 om 12.00

door

\section{Robin Henricus Karel Oliver Verjans}





\section{Contents}

$\begin{array}{lll}\text { Chapter 1: } & \text { General Introduction } & 7\end{array}$

Chapter 2: $\quad$ MiRNA Deregulation in Cardiac Aging and Associated Disorders 19

Chapter 3: $\quad$ MicroRNAs Act as Pleiotropic Regulators of Cellular Processes 75 Underlying Heart Failure: A High-Throughput Phenotypical Screen in Three Primary Cardiac Cell Types

Chapter 4: The MicroRNA-221/222 Family Counteracts Myocardial Fibrosis 145 in Pressure Overload-Induced Heart Failure.

Chapter 5: $\quad$ MiR-151 Represses Cardiomyocyte Hypertrophy and Oxidative Metabolism by Targeting PGC1a.

Chapter 6: Cardiomyocyte Cell Cycle Activity is Under the Control miR$125 \mathrm{a}$

Chapter 7: General Discussion

Valorisation 



\section{CHAPTER 1}

\section{General Introduction}





\subsection{Failure of the Heart}

Cardiovascular disease (CVD) is the leading global cause of death, accounting for more than 17.3 million deaths per year, representing 1 of every 3 deaths [1]. In the Netherlands only, more than 100 people die from cardiovascular disease each day, an average of 1 death every 15 minutes [2]. This life-threatening disease is accompanied with enormous global costs, reaching $\$ 863$ billion in 2010 [3]. Almost half of the patients with newly diagnosed CVD have heart failure (HF) [4], representing the only cardiovascular disease that has increased in prevalence over the last 20 years [5]. In the Netherlands, currently 142.000 patients suffer from HF [2]. Especially the elderly population is at risk to develop HF. The incidence rates in males approximately doubles with each 10-year age increase from 65 to 85 years, while even tripling for females between ages 65 to 74 and 75 to 84 years [1]. These numbers mark that HF currently forms a major global health problem but HF will form an even greater health problem in the future, since the general population ages and affective treatment is still lacking. According to the American Heart Failure Association, the prevalence of HF will increase with 46\% from 2012 to 2030, resulting in more than 8 million people with an age of 18 years or older with HF [6]. Similarly, the total cost for HF in the US was $\$ 30.7$ billion in 2012 and are expected to increase to $\$ 69.7$ billion by 2030 [3, 6]. Strikingly, the high five-year mortality of HF patients (52.6\%) did not decline since 2000, highlighting the ineffectiveness of traditional therapeutics and the urgent need to develop novel treatment strategies.

\subsection{MicroRNAs}

MicroRNAs (miRNAs) are small endogenous regulatory RNAs belonging to a family of short single-stranded ribonucleic acids. These critical posttranscriptional regulators are tightly regulated in a temporally restrained and tissue-specific manner during development and pathological conditions. MiRNAs were first discovered in the early 1990s but only after 2001 a dedicated field focused on the study of these regulatory RNAs, following the identification of numerous endogenously expressed small RNAs [7-9]. In the ensuing decade, miRNA biology has attracted remarkable attention, resulting in rapid advances in understanding their function during development and disease. We have learned that mammalian genome encodes 300 conserved miRNA genes, and high-throughput sequencing studies have identified 1000 or more additional loci that produce small RNAs structurally resembling miRNAs $[10,11]$. At least $30 \%$ of all human genes are thought to be regulated by miRNAs [12], marking the importance of miRNA-regulated networks in maintaining homeostasis.

\subsection{MiRNA Biogenesis}

The generation of miRNAs is a multistage process (Figure 1). Although some miRNAs are individually transcribed by RNA polymerase II/II from separate transcription units, many 
more miRNAs are produced from transcription units that make more than one product. A transcript may encode clusters of distinct miRNAs, or it may encode a miRNA and a protein [13-15]. The resulting $\sim 60-80$ nucleotide long hairpin structures contain a terminal loop and flanking segments from the miRNA sequence, forming the primary miRNA (pri-miRNA) transcript [14]. Two sequential processing reactions are required to excise the transcript into the mature miRNA.

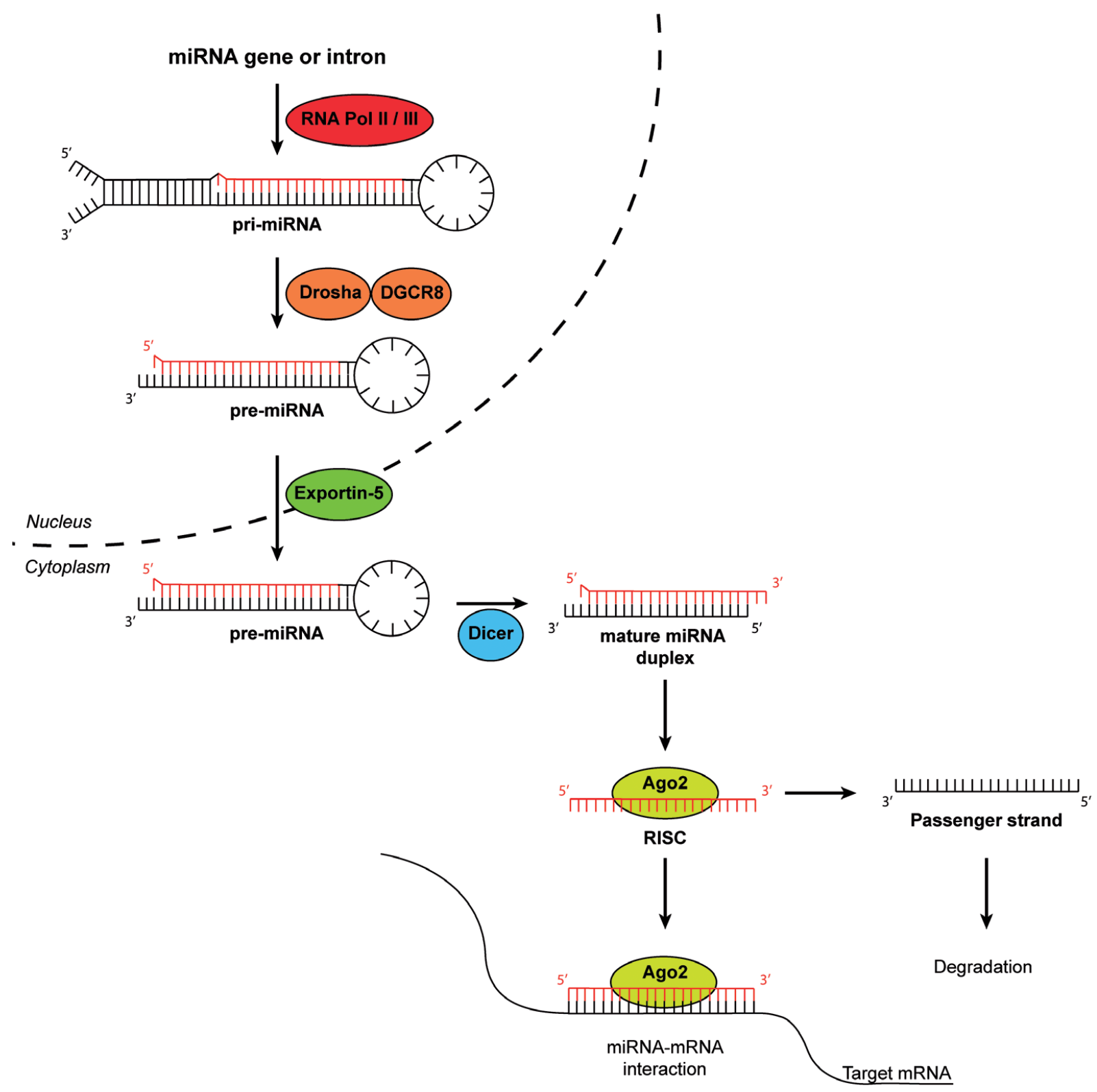

Figure 1 MicroRNA biogenesis. The miRNA biogenesis pathway includes the production of the primary miRNA transcript (pri-miRNA) by RNA polymerase II or III and cleavage of the pri-miRNA by the microprocessor complex Drosha with the aid of DGCR8 in the nucleus. The resulting precursor hairpin, the pre-miRNA, is exported from the nucleus by Exportin-5. In the cytoplasm, the RNase Dicer cleaves the pre-miRNA hairpin to its mature length. The functional strand of the mature miRNA is loaded together with Argonaute (Ago2) proteins into the RNA-induced silencing complex (RISC), where it functions as a guide to silence target mRNAs, whereas the passenger strand (black) is degraded. 
The first processing step occurs in the nucleus and is performed by Drosha with the aid of DGCR8 (DiGeorge critical region 8). DGCR8 directly interacts with the pri-miRNA to serve as a molecular ruler that properly positions Drosha to form the Microprocessor complex $[16,17]$. With the help of DGCR8, the catalytic site of Drosha is positioned 11 nucleotides from the base of the hairpin structure, allowing Drosha to excises the stem-loop to create a $\sim 70$ nucleotide stem-loop precursor miRNA (pre-miRNA) [15, 18]. However, microprocessormediated cleavage is not the only way to produce pre-miRNAs. Alternatively, splicing of pri-miRNA transcripts can take place to liberate introns that precisely mimic the structural features of pre-miRNAs $[19,20]$. These mirtrons then enter the miRNA-processing pathway without the aid of the Microprocessor.

The pre-miRNA is subsequently exported to the cytoplasm via Exportin-5 to undergo the second processing step. This reaction is catalysed by Dicer, excising the terminal loop from the pre-miRNA stem to yield a mature miRNA duplex of approximately 22 nucleotides in length $[13,15]$. The processed miRNA duplex comprises characteristic 5' and 3' ends, carrying a monophosphate group and a dinucleotide overhang, respectively that ensure efficient loading onto Argonaute 2 (AGO2) to form the RISC complex (RNA-induced silencing complex)[21-23]. Subsequent to loading, the so-called guide strand is selected to form the miRNA effector as part of the RISC, while the remaining passenger strand is released and degraded [24-30].

\subsection{MiRNA-induced posttranscriptional repression}

The miRNA strand incorporated into RISC acts as a sequence-specific adaptor to recognize and regulate complementary target messengerRNAs (mRNAs). Typically, miRNA-binding sites in mRNAs reside in the 3' untranslated region and are usually present in multiple copies. Although the degree of miRNA-mRNA complementarity has been considered a key determinant of the regulatory mechanism, most miRNAs bind with imperfect complementarity. The "seed" sequence (nucleotides 2-8 at the 5' end) of miRNAs is most critical in determination of target recognition, and in some cases fully sufficient for target selection [31-35].

Although target recognition is greatly understood, the mechanisms of miRNA-mediated silencing have been subject to on-going debate. Different possible mechanisms of RISCmediated repression of translation have been postulated. Normally, translation initiation begins with the recognition of the mRNA 5' terminal cap by elF4E, one of the subunits of the elF4F complex. Subsequently, the eIF4F complex recruits the $40 \mathrm{~S}$ ribosomal subunit and joins with the 605 ribosomal subunit at the AUG codon to begin elongation. RISC is postulated to repress initiation of translation by competing with elF4E to bind to the $5^{\text {' }}$ terminal cap [36, 37], and by blocking the association of the 605 ribosomal subunit with the 40 S pre-initiation complex [38]. 
The elF4F complex additionally interacts with the poly(A)-binding protein PABP1 that decorates the 3 ' end of the message. The ability of the elF4F complex to interact simultaneously with elF4E and PAB1 effectively circularizes the mRNA molecule and greatly enhances translation efficiency [39]. However, RISC can interfere with this process by deadenylation of the mRNA, limiting the circularization of the cap and PABP1-free tail of the deadenylated mRNA [40]. Alternatively, RISC is suggested to promote premature ribosome dissociation from mRNAs. Rapid dissociation of ribosomes in a miRNA-dependent manner represses elongation and prevents mRNA translation [41]. The current paradigm prevails that miRNAmRNA target interaction may lead to reductions in mRNA abundance due to an increase in mRNA degradation because of deadenylation, decapping, and exonucleolytic digestion of the mRNA [42, 43]. In support of this model, many repressed mRNAs are deadenylated by miRNAs in vivo [42] and in vitro [40].

\subsection{MiRNAs in Cardiovascular Disease}

Irrespective of the precise mechanism of MiRNA-induced repression of mRNA translation, miRNAs profoundly influence the responses of tissues to physiologic and pathophysiologic stress [44]. This suggests a central role for miRNA-regulated networks in disease states, which often represent an insufficient or aberrant response under conditions of stress or injury. MiRNAs are involved in many disease states, including the aging and failing heart $[45,46]$. Numerous miRNA profiling studies in mouse models of cardiovascular disease and in human biopsies has revealed deregulated expression patterns of miRNAs in various cardiovascular disorders, including atherosclerosis [47], myocardial infarction [48], and heart failure [49]. Gain- and loss-of-function studies in rodents have also validated the importance of specific miRNAs in the pathophysiology of many of these cardiovascular disorders $[46,50]$. Taken together, these studies indicate an altered miRNA profile during cardiac pathophysiology and the ability to regulate disease progression, highlighting their potential as therapeutic target.

\subsection{Aims and Outline of this Thesis}

The main aims of this thesis are: 1 ) to identify miRNAs that regulate cellular processes driving failure of the myocardium, and 2) to explore if the manipulation of some promising miRNA candidates (identified under aim 1) is able to retard heart failure progression. Thereto, we first performed a literature review and an in vitro high-throughput phenotypical screen to identify miRNAs that potentially play a role in the development of heart failure. Subsequently, we aimed to probe their efficacy in retarding heart failure progression in more detail through their manipulation in vitro and in various animal models. 
In chapter 2, we review the cardiac molecular and cellular processes driving myocardial aging, and describe the regulating role of senescence-associated miRNAs in these processes. Given the high similarity in molecular mechanisms of cardiac aging and HF, we additionally discuss miRNAs implicated in HF, focussing on miRNAs that show differential expression in the aged heart.

Chapter $\mathbf{3}$ describes an in vitro high-throughput screening approach in which we selected 194 miRNAs associated with HF development, and assessed their regulatory function in different cellular processes underlying HF, namely cardiomyocyte hypertrophy, cardiac fibrosis, and inflammation, in parallel. I have done this research was performed at Cenix BioScience, Dresden, Germany, where I have worked for 2 years. Cenix Biosciencse was a company that was renowned internationally for its expertise in high-throughput screening.

Chapter 4 through 6 will provide the experimental studies performed to determine the effect of individual miRNAs or miRNAs families on cellular processes underlying heart failure development. Chapter 4 focuses on the important role of the miRNA-221/222 family in the process of myocardial fibrosis formation as an underlying factor of HF progression. Chapter $\mathbf{5}$ elaborates on the function of miR-151a in cardiomyocyte hypertrophy and its ability to modulate cardiomyocyte metabolism by targeting PGC-1a. Chapter $\mathbf{6}$ addresses the effect of miR-125a on cardiomyocyte cell cycle activity and the hypertrophic response.

Finally, chapter $\mathbf{7}$ provides a summary of the described research and will discuss the value, limitations, and opportunities of these findings in a broader perspective, as well as its clinical utility. 


\section{References}

1. Benjamin EJ, Blaha MJ, Chiuve SE, Cushman M, Das SR, Deo R, de Ferranti SD, Floyd J, Fornage M, Gillespie C, Isasi CR, Jimenez MC, Jordan LC, Judd SE, Lackland D, Lichtman JH, Lisabeth L, Liu S, Longenecker CT, Mackey RH, Matsushita K, Mozaffarian D, Mussolino ME, Nasir K, Neumar RW, Palaniappan L, Pandey DK, Thiagarajan RR, Reeves MJ, Ritchey M, Rodriguez CJ, Roth GA, Rosamond WD, Sasson C, Towfighi A, Tsao CW, Turner MB, Virani SS, Voeks JH, Willey JZ, Wilkins JT, Wu JH, Alger HM, Wong SS, Muntner P, American Heart Association Statistics C and Stroke Statistics S. Heart disease and stroke statistics-2017 update: A report from the american heart association. Circulation. 2017;135:e146-e603

2. Feiten en cijfers hart- en vaatziekten. Dutch Heart Foundation. 2017; https://www.hartstichting. $\mathrm{nl} /$ hart-vaten/cijfers

3. Bloom DE, Ca ero, E.T., Jané-Llopis, E., Abrahams-Gessel, S., Bloom, L.R., Fathima, S., Feigl, A.B., Gaziano, T., Mowa, M., Pandya, A., Prettner, K., Rosenberg, L., Seligman, B., Stein, A.Z., \& Weinstein, C. . The global economic burden of noncommunicable diseases. Geneva: World Economic Forum. 2011

4. Sliwa K, Wilkinson D, Hansen C, Ntyintyane L, Tibazarwa K, Becker A and Stewart S. Spectrum of heart disease and risk factors in a black urban population in south africa (the heart of soweto study): A cohort study. Lancet. 2008;371:915-922

5. Braunwald E and Bristow MR. Congestive heart failure: Fifty years of progress. Circulation. 2000; 102:IV14-23

6. Heidenreich PA, Albert NM, Allen LA, Bluemke DA, Butler J, Fonarow GC, Ikonomidis JS, Khavjou O, Konstam MA, Maddox TM, Nichol G, Pham M, Pina IL, Trogdon JG, American Heart Association Advocacy Coordinating C, Council on Arteriosclerosis T, Vascular B, Council on Cardiovascular R, Intervention, Council on Clinical C, Council on E, Prevention and Stroke C. Forecasting the impact of heart failure in the united states: A policy statement from the american heart association. Circulation. Heart failure. 2013;6:606-619

7. Lagos-Quintana M, Rauhut R, Lendeckel W and Tuschl T. Identification of novel genes coding for small expressed rnas. Science. 2001;294:853-858

8. Lau NC, Lim LP, Weinstein EG and Bartel DP. An abundant class of tiny rnas with probable regulatory roles in caenorhabditis elegans. Science. 2001;294:858-862

9. Lee RC and Ambros V. An extensive class of small rnas in caenorhabditis elegans. Science. 2001; 294:862-864

10. Chiang HR, Schoenfeld LW, Ruby JG, Auyeung VC, Spies N, Baek D, Johnston WK, Russ C, Luo S, Babiarz JE, Blelloch R, Schroth GP, Nusbaum C and Bartel DP. Mammalian micrornas: Experimental evaluation of novel and previously annotated genes. Genes Dev. 2010;24:992-1009

11. Landgraf P, Rusu M, Sheridan R, Sewer A, Iovino N, Aravin A, Pfeffer S, Rice A, Kamphorst AO, Landthaler M, Lin C, Socci ND, Hermida L, Fulci V, Chiaretti S, Foa R, Schliwka J, Fuchs U, Novosel A, Muller RU, Schermer B, Bissels U, Inman J, Phan Q, Chien M, Weir DB, Choksi R, De Vita G, Frezzetti D, Trompeter HI, Hornung V, Teng G, Hartmann G, Palkovits M, Di Lauro R, Wernet P, Macino G, Rogler CE, Nagle JW, Ju J, Papavasiliou FN, Benzing T, Lichter P, Tam W, Brownstein MJ, Bosio 
A, Borkhardt A, Russo JJ, Sander C, Zavolan M and Tuschl T. A mammalian microrna expression atlas based on small rna library sequencing. Cell. 2007;129:1401-1414

12. Lewis BP, Burge CB and Bartel DP. Conserved seed pairing, often flanked by adenosines, indicates that thousands of human genes are microrna targets. Cell. 2005;120:15-20

13. Bartel DP. Micrornas: Genomics, biogenesis, mechanism, and function. Cell. 2004;116:281-297

14. Kim YK and Kim VN. Processing of intronic micrornas. EMBO J. 2007;26:775-783

15. Kim VN. Microrna biogenesis: Coordinated cropping and dicing. Nature reviews. Molecular cell biology. 2005;6:376-385

16. Lee Y, Ahn C, Han J, Choi H, Kim J, Yim J, Lee J, Provost P, Radmark O, Kim S and Kim VN. The nuclear rnase iii drosha initiates microrna processing. Nature. 2003;425:415-419

17. Denli AM, Tops BB, Plasterk RH, Ketting RF and Hannon GJ. Processing of primary micrornas by the microprocessor complex. Nature. 2004;432:231-235

18. Han J, Lee Y, Yeom KH, Nam JW, Heo I, Rhee JK, Sohn SY, Cho Y, Zhang BT and Kim VN. Molecular basis for the recognition of primary micrornas by the drosha-dgcr8 complex. Cell. 2006;125:887901

19. Okamura K, Hagen JW, Duan H, Tyler DM and Lai EC. The mirtron pathway generates micrornaclass regulatory rnas in drosophila. Cell. 2007;130:89-100

20. Ruby JG, Jan CH and Bartel DP. Intronic microrna precursors that bypass drosha processing. Nature. 2007;448:83-86

21. Nykanen A, Haley B and Zamore PD. Atp requirements and small interfering rna structure in the rna interference pathway. Cell. 2001;107:309-321

22. Elbashir SM, Lendeckel W and Tuschl T. Rna interference is mediated by 21- and 22-nucleotide rnas. Genes Dev. 2001;15:188-200

23. Elbashir SM, Martinez J, Patkaniowska A, Lendeckel W and Tuschl T. Functional anatomy of sirnas for mediating efficient rnai in drosophila melanogaster embryo lysate. EMBO J. 2001;20: 6877-6888

24. Miyoshi K, Tsukumo H, Nagami T, Siomi H and Siomi MC. Slicer function of drosophila argonautes and its involvement in risc formation. Genes Dev. 2005;19:2837-2848

25. Matranga C, Tomari Y, Shin C, Bartel DP and Zamore PD. Passenger-strand cleavage facilitates assembly of sirna into ago2-containing rnai enzyme complexes. Cell. 2005;123:607-620

26. Rand TA, Petersen S, Du F and Wang X. Argonaute2 cleaves the anti-guide strand of sirna during risc activation. Cell. 2005;123:621-629

27. Leuschner PJ, Ameres SL, Kueng S and Martinez J. Cleavage of the sirna passenger strand during risc assembly in human cells. EMBO Rep. 2006;7:314-320

28. Bernstein E, Caudy AA, Hammond SM and Hannon GJ. Role for a bidentate ribonuclease in the initiation step of rna interference. Nature. 2001;409:363-366

29. MacRae IJ and Doudna JA. An unusual case of pseudo-merohedral twinning in orthorhombic crystals of dicer. Acta Crystallogr D Biol Crystallogr. 2007;63:993-999 
30. Hutvagner G and Simard MJ. Argonaute proteins: Key players in rna silencing. Nature reviews. Molecular cell biology. 2008;9:22-32

31. Bartel DP. Micrornas: Target recognition and regulatory functions. Cell. 2009;136:215-233

32. Djuranovic S, Nahvi A and Green R. A parsimonious model for gene regulation by mirnas. Science. 2011;331:550-553

33. Stark A, Brennecke J, Russell RB and Cohen SM. Identification of drosophila microrna targets. PLOS Biol. 2003;1:E60

34. Lewis BP, Shih $1 H$, Jones-Rhoades MW, Bartel DP and Burge CB. Prediction of mammalian microrna targets. Cell. 2003;115:787-798

35. Doench JG and Sharp PA. Specificity of microrna target selection in translational repression. Genes Dev. 2004;18:504-511

36. Mathonnet G, Fabian MR, Svitkin YV, Parsyan A, Huck L, Murata T, Biffo S, Merrick WC, Darzynkiewicz E, Pillai RS, Filipowicz W, Duchaine TF and Sonenberg N. Microrna inhibition of translation initiation in vitro by targeting the cap-binding complex eif4f. Science. 2007;317:1764-1767

37. Kiriakidou M, Tan GS, Lamprinaki S, De Planell-Saguer M, Nelson PT and Mourelatos Z. An mrna m7g cap binding-like motif within human ago2 represses translation. Cell. 2007;129:1141-1151

38. Chendrimada TP, Finn KJ, Ji X, Baillat D, Gregory RI, Liebhaber SA, Pasquinelli AE and Shiekhattar R. Microrna silencing through risc recruitment of eif6. Nature. 2007;447:823-828

39. Carthew RW and Sontheimer EJ. Origins and mechanisms of mirnas and sirnas. Cell. 2009;136: 642-655

40. Wakiyama M, Takimoto K, Ohara O and Yokoyama S. Let-7 microrna-mediated mrna deadenylation and translational repression in a mammalian cell-free system. Genes Dev. 2007;21:18571862

41. Petersen CP, Bordeleau ME, Pelletier J and Sharp PA. Short rnas repress translation after initiation in mammalian cells. Mol Cell. 2006;21:533-542

42. Behm-Ansmant I and Izaurralde E. Quality control of gene expression: A stepwise assembly pathway for the surveillance complex that triggers nonsense-mediated mrna decay. Genes Dev. 2006;20:391-398

43. Wu L, Fan J and Belasco JG. Micrornas direct rapid deadenylation of mrna. Proc Natl Acad Sci U SA. 2006;103:4034-4039

44. Leung AK and Sharp PA. Microrna functions in stress responses. Mol Cell. 2010;40:205-215

45. Greco S, Gorospe M and Martelli F. Noncoding rna in age-related cardiovascular diseases. J Mol Cell Cardiol. 2015;83:142-155

46. Mendell JT and Olson EN. Micrornas in stress signaling and human disease. Cell. 2012;148:11721187

47. Han H, Wang YH, Qu GJ, Sun TT, Li FQ, Jiang W and Luo SS. Differentiated mirna expression and validation of signaling pathways in apoe gene knockout mice by cross-verification microarray platform. Exp Mol Med. 2013;45:e13 
48. van Rooij E, Sutherland LB, Thatcher JE, DiMaio JM, Naseem RH, Marshall WS, Hill JA and Olson EN. Dysregulation of micrornas after myocardial infarction reveals a role of mir-29 in cardiac fibrosis. Proc Natl Acad Sci U S A. 2008;105:13027-13032

49. van Rooij E, Sutherland LB, Liu N, Williams AH, McAnally J, Gerard RD, Richardson JA and Olson EN. A signature pattern of stress-responsive micrornas that can evoke cardiac hypertrophy and heart failure. Proc Natl Acad Sci U S A. 2006;103:18255-18260

50. Thum T, Catalucci D and Bauersachs J. Micrornas: Novel regulators in cardiac development and disease. Cardiovasc Res. 2008;79:562-570 



\title{
CHAPTER 2
}

\section{MiRNA Deregulation in Cardiac Aging and Associated Disorders}

\section{Adapted from International Review of Cell and Molecular Biology}

\author{
Robin Verjans ${ }^{1}$, Marc van Bilsen ${ }^{1,2}$, Blanche Schroen ${ }^{1}$ \\ ${ }^{1}$ Department of Cardiology, Cardiovascular Research Institute Maastricht (CARIM), \\ Maastricht University, 6200 MD Maastricht, the Netherlands. \\ 2 Department of Physiology, Cardiovascular Research Institute Maastricht (CARIM), \\ Maastricht University, 6200 MD Maastricht, the Netherlands
}




\section{Abstract}

The prevalence of age-related diseases is increasing dramatically, among which cardiac disease represents the leading cause of death. Aging of the heart is characterised by various molecular and cellular hallmarks impairing both cardiomyocytes and non-cardiomyocytes, and resulting in functional deteriorations of the cardiac system. The aging process includes desensitization of $\beta$-adrenergic receptor ( $\beta A R$ )signalling and decreased calcium handling, altered growth signalling and cardiac hypertrophy, mitochondrial dysfunction and impaired autophagy, increased programmed cell death, low-grade inflammation of non-canonical inflammatory cells, and increased ECM deposition.

MiRNAs play a fundamental role in regulating the processes underlying these detrimental changes in the cardiac system, indicating that miRNAs are crucially involved in aging. Among others, miR-34, miR-146a, and members of the miR-17-92 cluster, are deregulated during senescence and drive cardiac aging processes. It is therefore suggested that miRNAs form possible therapeutic targets to stabilize the aged failing myocardium.

\section{Keywords:}

Aging / Autophagy / Extracellular matrix / Fibrosis / Hypertrophy / Inflammation / Mitochondria / MicroRNA. 


\section{Introduction}

The global population ages dramatically as the average life expectancy increased the past century. In the United States, currently $\pm 12 \%$ of the population is over 65 years, and is estimated to further increase to $\pm 20 \%$ by 2030 [1]. This increase in global age is accompanied by a decrease in quality of life in the elderly population and a dramatically growing prevalence of age-related diseases. Cardiac disease represents the leading cause of death among these age-related diseases, accounting for $\pm 40 \%$ of all deaths in the elderly population [1, 2]. Heart failure (HF), the inability of the heart to pump sufficient blood into the body, is associated with frequent hospitalizations [3], resulting in high consummation of medical resources and a poor 5-year survival rate [4]. Heart failure (HF) in particular is generally accepted as a typical age-associated cardiac disease and is reaching epidemic proportions, with $\pm 88 \%$ of HF deaths and $>75 \%$ of all HF hospitalizations in the United States occurring in adults aged over 65 years $[5,6]$. HF is estimated to form an even greater problem in the future since, besides the fact that the increasing aged population has a high HF prevalence, effective treatment is still lacking. Besides the increasing age-associated prevalence of several cardiac risk factors including hypertension, obesitas, and insulin resistance, aging itself is a major independent risk factor for cardiac disease [7, 8], stressing the importance of understanding the processes underlying intrinsic myocardial aging.

MicroRNAs (miRNAs) are a class of small \pm 22 nucleotides long non-coding RNA molecules that negatively regulate target gene expression [9, 10]. MiRNAs are implicated in cardiac disease and increasing evidence links miRNAs to cardiac aging. Regulatory functions of age-associated miRNAs may potentially explain observed age-related deleterious phenotypes.

\section{Cardiac aging}

Due to the lack of proliferative capacity of cardiomyocytes, it is suggested that the heart is one of the organs most affected by detrimental age-associated changes. The senescent heart is characterized by structural remodelling at both organ, cellular, and molecular level. Remodelling of the aging cardiac system includes an increase in left ventricular wall thickness, stiffening of the heart, increased deposition of collagen, and collagen cross-linking [11]. On a cellular level, aging is associated with prolongation of cardiomyocyte action potential [12], decreased cardiomyocyte survival, as well as a decline in the number of mitochondria and cardiac stem cells [13-15]. Furthermore, endothelial dysfunction, migration/ proliferation of vascular smooth muscle cells (VSMCs), increased fibroblast proliferation, and pro-inflammatory signalling of inflammatory cells are additional cellular processes underlying cardiac aging $[16,17]$. These structural changes lead to an altered function of the aged myocardium, including an increase in the prevalence of atrial fibrillation [6], a lowered cardiac reserve [15], as well as declined diastolic function due to increased left ventricular diastolic stiffness, decreased filling [14, 18], and decreased contraction and relaxation velocity [12, 19-21]. 
The associated molecular processes include 1 ) desensitization of $\beta$-adrenergic receptor (BAR)-signalling and decreased calcium handling, 2) altered growth signalling, 3) mitochondrial dysfunction and impaired autophagy, 4) increased programmed cell death, 5) low-grade inflammation of non-canonical inflammatory cells, and 6) increased extracellular matrix (ECM) deposition [6, 14, 15, 22]. Thus, the intrinsic mechanisms associated with age-induced impairment of the myocardium are identified and mimic those implicated in HF. Unfortunately, precise knowledge on what initiates these cellular changes and the role of miRNAs therein is still lacking. This review provides an overview of the cardiac molecular and cellular processes driving myocardial aging listed above, and describes the regulating role of senescence-associated miRNAs in these processes. Given the similarity in molecular mechanisms of the aging and failing heart, we will as well discuss miRNAs implicated in HF of other causes than aging, focussing on miRNAs that show differential expression in the aged heart.

\section{BAR desensitization and calcium handling}

The sympathetic nervous system undergoes a series of rearrangements with aging. With normal aging, circulating norepinephrine levels increase by $10-15 \%$ per decade [23] and cardiac norepinephrine levels increase due to diminished reuptake and increased tissue spill over [24]. Chronically increased $\beta A R$ occupancy by norepinephrine leads to $\beta A R$ desensitization [25-27] and impairs cardiomyocyte calcium handling, eventually leading to deficits in cellular contraction and relaxation $[28,29]$. Prolonged myocardial relaxation time forms a hallmark of age-related diastolic dysfunction and is caused, among others, by impaired active relaxation of cardiomyocytes due to depressed $\mathrm{Ca}^{2+}$-uptake and $\mathrm{Ca}^{2+}$-release activities in the aging heart [30-32]. In the normal situation, $\beta A R$ activation regulates $\mathrm{Ca}^{2+}$ homeostasis and contraction through accumulation of the second messenger CAMP, which activates protein kinase A (PKA). In its turn, PKA phosphorylates phospholamban (PLB) and relieves its inhibitory effect on calcium-transporter SERCA2a, promoting sarcoplasmic reticulum cycling [33, 34] (Figure 1). Decreased expression [18] and activity [27] of SERCA2a are thought to be the primary mechanisms for the impaired cardiac relaxation in the aged myocardium. In addition, age-associated alterations in proteins able to regulate SERCA2a activity, including PLB, [35-38], PKA [39], and CAMKII [40] have also been documented in the aged heart. Thus, $\beta A R$ signalling plays a crucial role in maintaining a balanced calcium homeostasis and regulating cardiomyocyte contraction and relaxation, and dysregulated BAR signalling forms one of the major cellular hallmarks of the senescent myocardium.

Evidence shows that altered $\beta A R$ activity shapes cardiac miRNA profiles while specific miRNAs, including $\beta A R$-responsive ones, are able to influence $\beta A R$ signalling. This implies an important role for miRNAs in age-associated desensitization of $\beta A R$ signalling. Hou et al. [41] profiled rat cardiac miRNA expression under conditions of $\beta A R$ activation and inhibition, identifying miRNAs controlling $\beta A R$ pathway activity. Activation of $\beta A R$ signal- 
ling upregulated 43 while downregulating 9 miRNAs. On the other hand, $\beta A R$ inhibition upregulated and downregulated 5 and 28 miRNAs, respectively [41]. Similarly, Carrillo et al. [42] found that the expression of 33 miRNAs was significantly changed in cardiac lysates from rats stimulated with the $\beta A R$ agonist isoproterenol (ISO). The expression levels of miR21, miR-132, miR-214, and miR-222 were more than 7-fold increased. MiR-21, miR-132 and miR-222 are also directly involved in controlling calcium levels via targeting, beta-2 subunit of the voltage-dependent calcium channel (CACNB2) [42]. Moreover, Ling et al. [43] have shown that miR-26b, miR-21, and miR-320 levels are affected by changes in $\beta A R$ activity.

BAR signalling is shown to control one of the most abundantly cardiac expressed miRNA clusters, the miR-1/133 cluster via a cAMP response element in the promoter region of muscle specific miRNA cluster miR-1/miR-133a [44-47]. Intriguingly, miR-1 potentiates $\beta A R$ signalling, causing hyperphosphorylation of ryanodine receptor 2 (RyR2) channels thereby increasing excitation contraction coupling [48]. On the contrary, miR-133 inhibits ßAR-signalling at multiple levels. Transgenic cardiac specific miR-133 expression preserves cardiac performance and attenuates cardiac remodelling upon pressure overload [49]. This protective miR-133 effect is associated with decreased CAMP/PKA-dependent phosphorylation of PLB, and resulting from miR-133 directed targeting of the $\beta 1 A R$ (ADBR1) and several other components of the $\beta 1 A R$ signalling cascade [49]. Thus, while both miRNAs are under the regulation of $\beta A R$-signalling, these miRNAs have opposite roles. Exactly how their balance is regulated requires further investigation.

The cardio-protective effect of biased $\beta$-blocker carvedilol (Carv) involves enhanced $\beta$-arrestin-mediated signalling, thereby affecting pri-miRNA processing of specific miRNAs by Drosha. As a consequence, the maturation of miR-125a-5p, miR-125b-5p, miR-150, miR199a-3p, and miR-214 is upregulated in the mouse heart [50, 51]. These Carv-responsive miRNAs may potentially explain the cardio-protective effect of biased $\beta A R$ signalling [52]. In addition, their expression is altered in the aged heart [51,53], suggesting their potential involvement in the cardiac aging process.

Collectively, the aging-myocardium is characterised by $\beta A R$ desensitization and impaired calcium handling. Particularly miR-1/133a seem to function in opposite $\beta A R$ feedback loops, and the exact biological reasoning remains to be clarified. 


\section{Altered growth signalling and hypertrophy}

Cardiac hypertrophy is a hallmark of cardiac aging. Although this adaptive response minimizes myocardial wall stress and maintains cardiac function on the short term, persistent hypertrophic signalling on the long-term is detrimental and underlies cardiac pathology $[54,55]$. Cellular changes of cardiac hypertrophy are characterized by increased cardiomyocyte volume, expression of the fetal gene program and increased protein synthesis [56-58].

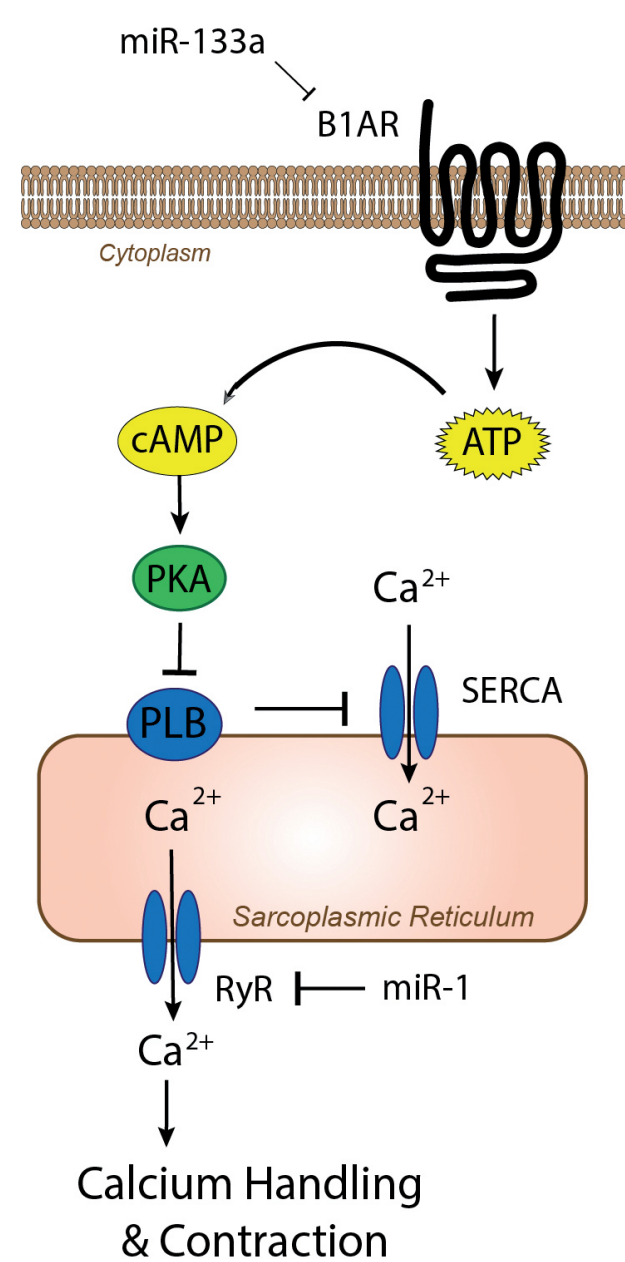

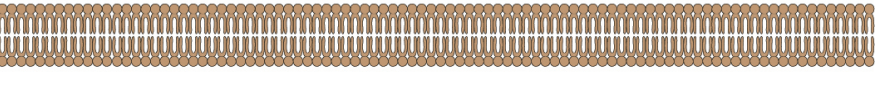

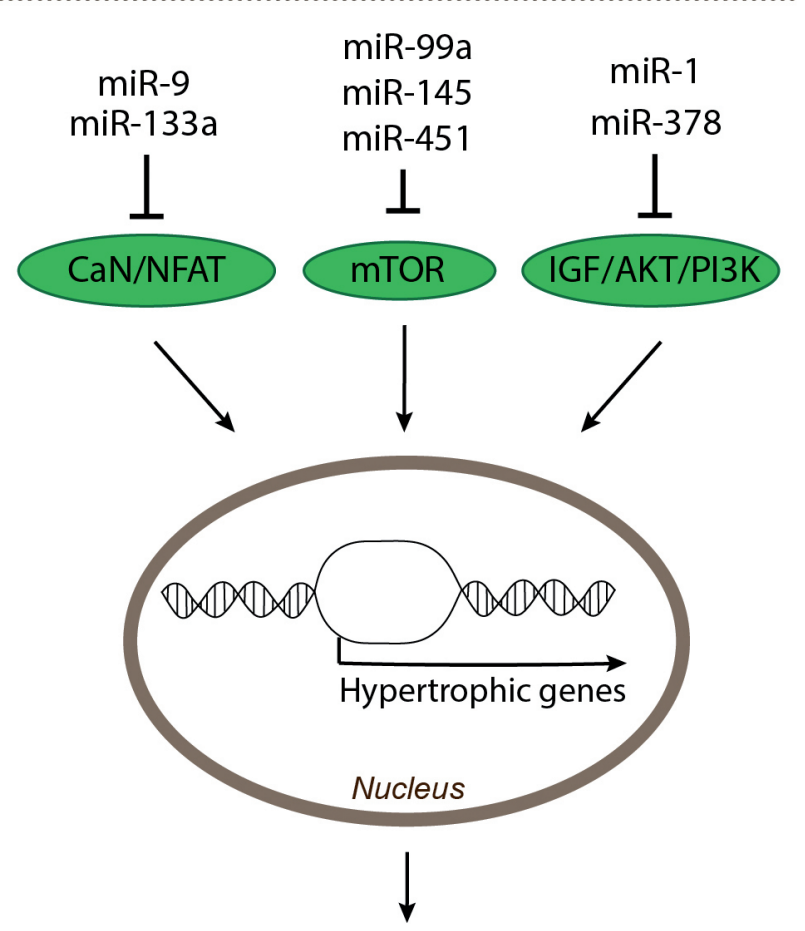

Hypertrophic Response

Figure 1) Age-associated miRNAs in control of the cardiomyocyte $\beta$-Adrenergic signalling and the hypertrophic response. Activation of $\beta 1$-adrenergic receptor ( $\beta 1-A R)$ controls cardiomyocyte calcium homeostasis via accumulation of the second messenger CAMP, which activates the phospholamban (PLB) inhibitor, protein kinase A (PKA). Inhibition of PLB de-represses the calcium-transporter SERCA2a and promotes calcium $\left(\mathrm{Ca}^{2+}\right)$ entry into the sarcoplasmic reticulum. Sarcoplasmic $\mathrm{Ca}^{2+}$ is in its turn exported to the cytoplasm by ryanodine receptor 2 (RyR2) to regulate cardiomyocyte contraction. Stimulation of major growth signalling pathways, including the Calcineurin/NFAT, mTOR, and IGF/AKT/PI3K pathway induces a hypertrophic response characterised by transcription of hypertrophic genes: atrial natriuretic factor (ANF), brain natriuretic factor (BNP), and $\beta$-Myosin Heavy chain $(\beta-M H C)$. At every level, miRNAs are implicated in regulating these processes. 
Numerous miRNA profiling studies have been performed in human hypertrophic patients and rodent models of cardiac hypertrophy, identifying various miRNAs which actively participate in cardiomyocyte hypertrophic signalling, including miR-1/miR-133 [59] miR-208 [60-62], miR-18 [63], miR-98/let-7 [64], miR-9 [65], miR-214 [66, 67], miR-199a [68, 69], miR-199b [70], miR-23a [71], and more recently the miR-212/132 family [72-74].

Deregulation of major growth signalling pathways, including the mTOR/P70/S6K [75], IGF/AKT/PI3K [76, 77], and Calcineurin/NFAT pathway [78], have been implicated in hypertrophic growth of aging cardiomyocytes (Figure 1).

\section{MiRNAs affecting mTOR/P70/S6K signalling}

The mammalian target of rapamycin (mTOR) pathway plays a critical role in cardiomyocyte hypertrophy, function, and structure via integration of nutrient and hormonal signals to regulate growth and is a major modulator of aging and age-related disease [75]. Inhibition of the pro-hypertrophic mTOR/P70/S6k signalling pathway has cardioprotective effects when the heart ages or suffers from ischaemia or overload [79-82]. These findings suggest that miRNAs targeting mTOR signalling in the failing or senescent heart could protect the heart from detrimental remodelling. Indeed, several different miRNAs are shown to suppress mTOR, directly or indirectly, thereby exerting cardioprotective functions in vitro and in vivo.

For example, miR-99a was shown to negatively regulate mTOR expression and P70/S6K activation, preventing cardiomyocyte hypertrophy under stress conditions in vitro and in vivo [83]. MiR-145 also exerts its anti-hypertrophic effect by decreasing the activity of the mTOR/P70/S6K signalling cascade. MiR-145 expression is proven to be significantly upregulated in end-stage HF patients [84]. Li et al. [85] have shown that miR-145 attenuates hypertrophy of cardiomyocytes induced by the $\beta A R$ agonist ISO by suppressing the expression and nuclear translocation of GATA6. In its turn, pro-hypertrophic transcription factor GATA6 has been found to be involved in the mTOR-induced pathological hypertrophy [86, 87] activating transcription of the fetal genes ANF, BNP, and $\beta-M H C$ [88] (Figure 1). These results indicate that miR-145 attenuates the cardiac hypertrophic response by decreasing mTOR activity indirectly. MiR-451 levels were significantly increased in type 2 diabetes mellitus (DM) murine hearts and in neonatal rat cardiac myocytes stimulated with palmitic acid. Loss of miR-451 function reduced palmitate-induced lipotoxicity in nRCMs. HFD-fed, cardiomyocyte-specific, miR-451 knockout mice were protected from hypertrophy and displayed lower levels of phosphorylated mTOR, implying that miR-451 is involved in diabetic cardiomyopathy, at least partly, through suppression of mTOR activity [89].

Thus, different studies suggest that miRNA-exerted regulation of mTOR plays an important role in cardiac aging and its inhibition protects the heart from detrimental hypertrophic remodelling under pathological conditions. 


\section{MiRNAs affecting IGF/AKT/PI3K signalling}

Insulin/IGF signalling plays a critical role in aging. Human serum IGF-1 levels decline over time, correlating with increased risk of HF [90]. Both Akt as well as the class IA isoform of phophoinositide 3-kinase (PI3K) are important factors downstream of insulin and IGF receptors, and regulate cell growth, survival and metabolism [91].

Muscle-specific miR-1 is one of the most cardiac abundant miRNAs, and different studies have shown an inverse correlation between miR-1 expression and cardiac hypertrophy $[45,92]$. Several miR-1 cardiac targets involved in the control of hypertrophy have been identified, including HDAC4 [93], Hand2 [94], ras GTPase-activating protein (Ras-GAP), and ras homolog enriched in brain (Rheb) [92]. Besides, miR-1 additionally modulates the cardiac hypertrophic response via direct targeting of IGF-1 [95, 96] and IGFR-1 [96], influencing insulin signalling. The pro-hypertrophic IGF-1 acts as a negative regulator of cardiac enriched miRNA-378. In turn, this miRNA regulates cardiac remodelling by both direct targeting of IGF-1R and indirect inhibition of IGF/PI3K/AKT signalling through targeting of Grb-2, a known cardiac hypertrophy modulator and an essential component of the Ras signalling pathway that is downstream of IGF-1 and other growth factors $[97,98]$. In the end, miR-378 blocks growth activity, leading to suppression of fetal gene expression and inhibition of hypertrophy of cardiomyocytes [97, 98].

\section{MiRNAs affecting Calcineurin/NFAT signalling}

Calcineurin-dependent NFAT (nuclear factor of activated T cells) activation is part of a central pro-hypertrophic signalling cascade. NFAT functions as a calcineurin effector, trafficking between the cytosol and the nucleus to regulate the cardiac hypertrophic response [78, 99]. Increased cardiac activation of calcineurin/NFAT signalling is observed in aging mice [18]. Two miRNAs, miR-133a and miR-9, have so far been shown to be able to decrease Calcineurin/NFAT signalling and ameliorate hypertrophic cell growth. Firstly, myocardial expression of miR-133a is decreased in human and animal hypertrophy [45, 92, 100], and is inversely related to cardiac hypertrophy [45]. MiR-133a directly targets calcineurin [101] and NFAT [102], preventing phenylephrine-induced hypertrophic cell growth and repression of the fetal gene programm [103]. In line, loss of miR-133a increased angiotensinogen expression and hypertrophy [104]. The second calcineurin/NFAT associated miRNA, miR-9 indirectly suppresses NFAT through translational suppression of myocardin, which is necessary for nuclear activation of NFAT [65].

Although the majority of identified hypertrophy-regulating miRNAs has not been studied in the process of aging, these reports indicate that many miRNAs play a crucial role in controlling the hypertrophic response in cardiomyocytes. MiRNAs exert their hypertrophyregulatory function via impacting major growth signalling pathways, which are also associated with age-related diseases. Cellular hypertrophic signalling as a result of senescence could potentially be caused by dysregulation of these hypertrophy-regulating miRNAs. Further research should be conducted to determine if the age-associated hypertrophic response is directly caused by altered expression of these miRNAs, or a secondary result. 


\section{Maintaining metabolic \& mitochondrial function with age}

Metabolic dysfunction is associated with aging and many age-related disease [105]. Whereas fatty acid oxidation is the primary source of energy in the adult healthy myocardium, both the senescent and failing heart display a striking impairment of mitochondrial fatty acid oxidation and oxidative phosphorylation and an increased reliance on glucose metabolism [106, 107]. Despite intense research in this area, there is little consensus on the causes of this "metabolic substrate shift" or whether the shift in substrate utilization in failing and aging myocardium is detrimental nor compensatory [108]. Also the role of miRNAs in the metabolic shift needs further clarification.

By feeding mice different diets it was demonstrated that high fat feeding induced distinct cardiac miRNA expression patterns as assessed by RNA deep sequencing [109]. This included downregulation of senescense-associated miRNAs, miR-29b and miR-15. Moreover, high fat feeding upregulated expression levels of aging miRNAs miR-21a, miR-29c, miR-22, and miR-223 [109]. Not only fatty acid levels affect miRNA profiles, recent studies have shown that high glucose significantly reduced expression levels of miR-126 and miR-375 [110-112]. These findings suggest that age-associated alterations in the metabolic environment may cause a distinct miRNA profile. More importantly, a growing body of evidence suggests that numerous miRNAs are implicated in the regulation of metabolic homeostasis by targeting genes with a prominent role in 1) fatty acid or 2) glucose metabolism, and 3) energy production via controlling mitochondrial-biogenesis, -function, and -autophagy.

\section{MiRNAs regulating fatty acid metabolism}

The healthy adult myocardium relies primarily on mitochondrial fatty acid oxidation for its energy production. Numerous mitochondrial enzymes involved in fatty acid $\beta$-oxidation have been shown to be under the control of miRNAs (Figure 2). The miR-199a/214 cluster has been shown to play a regulatory role in the metabolic switch from mitochondrial fatty acid oxidation in the healthy myocardium towards glucose utilization at the onset of HF, by actively repressing PPAR $\beta / \delta$ [113]. In addition, MiR-199a suppresses PPARa indirectly, resulting in repression of different PPARa-target genes involved within the $\beta$-oxidation [114]. Both miR-199a and miR-214 are increased in failing human and rodent hearts [100], and both decrease reliance on fatty acid oxidation through inhibition of PPAR $\delta$ [113]. Overexpression results in mitochondrial dysfunction and decreased mitochondrial fatty acid oxidation. Conversely, silencing of miR-199a/214 in mice subjected to pressure overload de-repressed cardiac PPAR $\delta$ levels, normalized mitochondrial fatty acid oxidation and ultimately lead to improved cardiac function [113].

MiR-370 regulates the rate of $\beta$-oxidation by suppressing expression of carnitine palmitoyltransferase 1a (CPT1a), an enzyme involved in the import of fatty acids into the mitochondria. In addition, other genes important for fatty acid utilization, such as Diacylglycerol O-Acyltransferase 2 (DGAT2), and fatty Acid Synthase (FAS) are also targeted by miR-370 strengthening its functional participation in fatty acid metabolism [115]. Also, 
miR-132 and miR-212 decreased the transporting rate of long-chain acylcarnitines into the mitochondria for $\beta$-oxidation via translational regulation of CPT1a expression [116, 117]. MiR-33a and miR-33b inhibit the expression of various metabolic enzymes, marking them as crucial players in controlling fatty acid $\beta$-oxidation [118]. MiR-1, which we already described as central in hypertrophy and contraction, negatively regulates the expression of heart-type fatty acid binding protein 3 (FABP3), leading to decreased transport of fatty acids within the cardiomyocyte and subsequent impaired $\beta$-oxidation [119]. MiR-27b targets PPARy thereby regulating the cardiac metabolic shift through suppression of fatty acid fuelling of mitochondria [120]. MiR-27b transgenic mice displayed lower cardiac levels of PPARy while silencing of endogenous miR-27b in mice showed a higher expression of cardiac PPARy, which resulted in increased fatty acid oxidation and attenuation of cardiac dysfunction in a pressure overload model [120].

These results reveal the intricate regulation of fatty acid $\beta$-oxidation by miRNAs, promoting the metabolic switch towards increased reliance on glycolysis. Whether similar processes are involved in the metabolic substrate shift driving myocardial aging, remains to be elucidated.

\section{MiRNAs regulating glucose metabolism}

In addition to fatty acid oxidation (Figure 2), various miRNAs able to impact cardiac glucose metabolism have been identified. Larger reliance on glucose utilization for energy production is a consistent feature of the failing and aging heart [121, 122] which has a major impact on the available energy levels due to the aerobic nature of the heart [123]. Interestingly, the age-associated miRNA, miR-34a, directly targets several glycolytic enzymes, including hexokinase 1 , hexokinase 2, glucose-6-phosphate isomerase, and pyruvate dehydrogenase kinase 1 , thereby repressing cellular glycolysis, potentially attempting to attenuate the age-associated increased cardiac reliance on glucose metabolism [124].

Additional miRNAs shown to inhibit glucose metabolism include let-7, miR-208, miR195, miR-143, miR-133, miR-93, and miR-103/107, while miR-223 stimulates glycolysis. The lin28/let 7 pathway functions as a central regulator of mammalian glucose metabolism. Expression of members of the let- 7 family was enhanced in the diabetic heart and overexpression induces glucose intolerance due to diminished glucose-induced insulin secretion as a result of translational inhibition of IGF-1R, insulin receptor (INSR) and GLUT4 [125-127]. Moreover, RNA-binding proteins Lin28a and Lin28b increase insulin sensitivity and resistance to diabetes through blocking of let-7 maturation and subsequent de-repression of multiple let-7 targets [125, 128-130]. Similarly, heart specific miR-208 negatively regulates med13, a regulator of energy expenditure and numerous other genes involved in energy balance in the heart. Indeed, inhibition of miR-208 in mice conferred resistance to obesity, improved systemic insulin sensitivity, and glucose tolerance [131]. MiR-195 suppresses the expression of INSR impairing insulin signalling cascade and glycogen synthesis [132]. Silencing of miR-103/107 modulates expression of insulin receptor regulator caveolin 1 


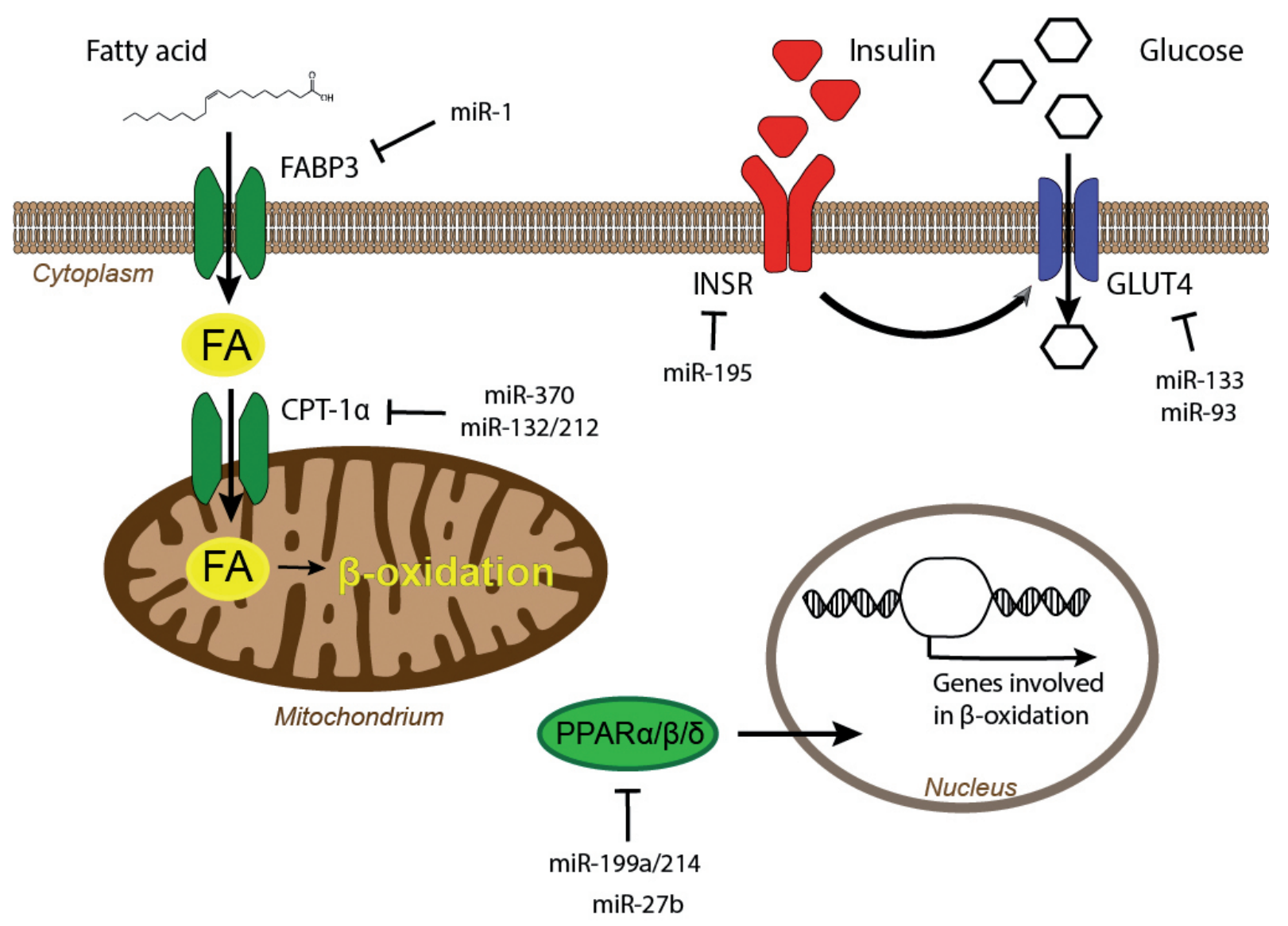

Figure 2) MiRNAs regulating fatty acid and glucose metabolism in the aging myocardium. Fatty acid (FA) metabolism is facilitated by fatty acid binding protein 3 (FABP3), which transports FAs into the cell. Here, FAs undergo $\beta$-oxidation after CPT-1a-dependent transport into the mitochondrion. Nuclear translocation of different peroxisome proliferator-activated receptors (PPARa/ $\beta / \delta$ ) induces transcription of various genes involved in $\beta$-oxidation, such as long chain- and very long chain - acyl-CoA dehydrogenase (ACADL and ACADVL), and Hydroxyacyl-CoA Dehydrogenase (HADH). Glucose metabolism is highly dependent on insluin-mediated activation of insulin receptor (INSR), which stimulates glucose transport by GLUT4. Central factors in these metabolic pathways are regulated by miRNAs.

(CAV1) and improves insulin sensitivity and glucose homeostasis, whereas forced expression of miR-103/107 impaired glucose homeostasis [133]. Moreover, miR-143 [134], miR133 [135], and miR-93 [136] have also been shown to control glucose homeostasis, in which the latter two are shown to inhibit cardiomyocyte glucose uptake via direct targeting of glucose transporter GLUT4.

On the other hand, miR-223 overexpression increased GLUT4 expression, resulting in an increase in glucose uptake and an adaptive response to restore normal glucose uptake in the diabetic heart. Conversely, systemic inhibitor-mediated silencing of miR-223 resulted in a significant decrease in cardiac GLUT4 expression [137]. Collectively, these studies highlight the central role of miRNAs in glucose metabolism. MiRNAs exerting a glucose-stimulating function may potentially be responsible for the observed age-induced increased reliance on glucose metabolism. 


\section{Mitochondrial biogenesis and function under the control of miRNAs}

Not only the "metabolic substrate shift" plays a prominent role in the aging heart, mitochondrial dysfunction and dysregulation are also associated with aging and many age-related disease [138]. Due to the constant demand for high ATP levels for maintaining contractile activity in the heart, the loss of mitochondrial number and function during cellular aging has adverse impact on cardiac muscle $[139,140]$. The main causes of age-associated mitochondrial impairment are reduced mitochondrial biogenesis and increased number of dysfunctional mitochondria, the latter being partly due to decreased autophagy [141]. Mitochondrial biogenesis is regulated by several pathways, most of which rely on peroxisome proliferator-activated receptor y co-activator 1 a (PCG-1a) [142]. PCG-1a enhances mitochondrial function but cardiac expression is repressed in the failing heart [143]. PGC-1a is regulated by miR-696 is skeletal muscle in response to physical activity, and mitochondrial biogenesis and fatty acid oxidation were decreased following miR-696 overexpression [144]. Further research needs to be conducted using cardiomyocytes to interrogate the possible detrimental impact of miR-696 on mitochondrial biogenesis during myocardial senescence.

In addition to decreased formation of mitochondria, impaired mitochondrial functioning forms a driving factor of cellular aging in the heart. Different miRNAs have been identified to influence ATP generation by inhibiting mitochondrial function (Figure 3). Members of the aging-miRNA family, miR-15a and miR-15b, reduced ATP generation and mitochondrial integrity in rat cardiomyocytes $[145,146]$. Also, miR-181 family members, affect ATP generation. MiR-181c causes electron transport chain complex IV remodelling through regulation of the mitochondrial cytochrome c oxidase subunit 1 ( $m$ t COX1) at the translational level [147], while miR-181a modulates the citric acid cycle [148]. Moreover, both miR-338 and miR-210 modulate ATP production by depressing the expression of the main components in the electron transfer chain, cytochrome c oxidase IV (COXIV) and cytochrome c oxidase assembly protein 10 (COX10)[149]. Finally, miR-484 negatively regulates mitochondrial fission in the heart via targeting mitochondrial fission protein (Fis1), thereby disrupting maintenance of normal mitochondrial function [150].

Impaired mitochondrial function does not only limit ATP production, dysfunctional mitochondria also form the most important source of ROS (Figure 3). Although generation of ROS is an inevitable by-product of aerobic metabolism and low levels of ROS are necessary for intracellular signalling [151], the aged and failing myocardium are characterised with an excess of ROS produced by various types of cardiac cells, that seems to be under the control of miRNAs as well [152-154]. MiR-210, which expression is induced in senescent fibroblasts [155], induces the generation of ROS through impairment of mitochondrial function via suppressing activity of OXPHOS complex I and II [156, 157]. Similarly, miR-494 induction in senescent fibroblasts increases ROS production [155]. ROS can also be generated by various enzymes, including the nicotinamide adenine dinucleotide phosphate (NADPH)-oxidases [158]. MiR-448 is shown to be in control of ROS production through 
repression of the NOX2 regulatory subunit Ncf1. Downregulation of cardiac miR-448 led to increased Ncf1 expression and abnormally elevated ROS production and ultimately dilated cardiomyopathy and arrhythmias [158].

The cellular defense mechanism to counter the overproduction of ROS is the scavenging of free radicals by an array of antioxidants, such as superoxide dismutase (SOD) [159, 160]. Both miR-34a and miR-335 are up-regulated in kidneys of old rodents and target ROS scavenging enzymes SOD2 and Thrioredoxin Reductase 2 (Txnrd2), thereby causing oxidative stress [161]. Similarly, miR-21 increases oxidative stress via targeting of SOD2 in angiogenic progenitor cells [162]. MiR-146a downregulates the expression of NOX4, the major catalytic subunit of NADPH oxidase [163]. Aged cells display increased expression of NOX4 and decreased miR-146a levels and overexpression of miR-146a decreases the rate of HUVEC senescence [163]. Moreover, miR-1 modulates oxidative stress in cardiomyocytes via targeting multiple antioxidant enzymes, including SOD1, the catalytic subunit of the glutamate cysteine ligase (Gclc), and glucose-6-phosphate dehydrogenase (G6PD) [164]. Gclc is a positive regulator of glutathione (GSH), promoting scavenging of ROS. MiR-1 transgenic mice hearts display repressed expression of SOD1, Gclc, and G6PD, contributing to the increased ROS level and susceptibility to oxidative stress within these hearts [164]. In addition, miR-144 levels are repressed in cultured cardiomyocytes exposed to highglucose and in hearts of streptozotocin (STZ)-induced diabetic mice. MiR-144 promotes ROS-induced oxidative damage through directly targeting of the central regulator of the response to oxidative stress, nuclear factor-erythroid 2-related factor 2 (Nrf2)[165].

Remarkably, miRNAs themselves can become oxidatively modified by ROS, which may in turn alter their stability, integrity, binding affinity, and functionality, thereby contributing to altered redox signalling and disease mechanisms [166, 167]. More specifically, miR-184 is shown to interact with the 3' UTRs of Bcl-xL and Bcl-w only after being subjected to oxidative modification, initiating apoptosis in the heart cell line H9c2 [167]. These results suggest that miRNAs have a pivotal role in maintaining cardiac mitochondrial function and energy metabolism in the presence and absence of oxidative stress, preserving myocardial homeostasis.

\section{MiRNAs orchestrating autophagy}

As described earlier, the senescent myocardium is associated with defective mitochondria $[14,168,169]$ due to the infrequent replacement of cardiomyocytes and their high susceptibility to mitochondrial damage $[170,171]$. Senescent cardiomyocytes counteract this detrimental process via autophagy, which is characterized by the delivery of intracellular components to the lysosome, maintaining cardiomyocyte homeostasis and mitochondrial activity through the renewal/recycling of cytoplasmic materials and organelles, removal of aggregated proteins, and the provision of energy and biomolecules to cells [172-174] (Figure 3). Although autophagy plays a relatively minor role in proliferating non-cardiomyocyte cells (such as endothelial cells and fibroblasts), it has been shown that a progressive 
decline in autophagy efficiency in senescent cardiomyocytes plays an important role in age-related cardiac diseases [175]. Due to the loss of autophagy, dysfunctional mitochondria accumulate as the cells ages, and promote the formation of ROS, leading to further accumulation of damaged mitochondria and ROS creating a positive feedback loop that results in the "aging" phenotype with a decline in autophagy at its core $[170,176]$.

Strikingly, Gibbings and co-workers have shown that autophagic activity is crucial in regulating miRNA processing through engaging post-transcriptional regulation of DICER and establishes a checkpoint required for continued loading of miRNAs into AGO2 [177]. Autophagy-deficient cells exhibit decreased ago-loading with miRNAs, diminished miRNA levels and reduced silencing activity of exogenous siRNA duplexes [177]. Thus, autophagy is required for continued loading of miRNA duplexes into AGO and for their durable activity. This is supported by the fact that DICER protein accumulates in cells depleted of different autophagy related genes [178]. These results suggest that autophagy influences the expression of genes crucial in miRNA processing and thereby maturation of miRNAs. An age-related decline in autophagy may therefore affect miRNA processing and thus mature miRNA profiles in the heart.

The role of miRNAs in autophagy is gaining more interest and one examples of an age-associated miRNA that promotes autophagy is miR-155. MiR-155 negatively regulates the autophagy-inhibitor mTOR through targeting of multiple genes involved within this pathway, including RHEB, RPTOR Independent Companion Of MTOR Complex 2 (RICTOR), and Ribosomal Protein S6 Kinase B2 (RPS6KB2)[179]. These results suggest that miR-155 possesses the potential to exert a beneficial role in the aging myocardium via prevention of an age-induced deleterious decrease in autophagy.

On the other hand, several studies report that different forms of stress can provoke an increase in cardiomyocyte autophagic activity, and link this prolonged/excessive upregulation of autophagy with the development of cardiac hypertrophy [180, 181]. In these situations, miRNAs functioning as negative regulators of autophagy may benefit cardiac remodelling and function. Furthermore, miR-30a decreases auto phagic activity through suppression of Beclin 1 (Becn1) expression, which is able to regulate the expression of the main autophagy gene LC3B $[182,183]$. Strikingly, miR-30 family members are down-regulated in human and mouse hypertrophic hearts $[184,185]$ and Angll-treatment is shown to result in autophagy-induced myocardial hypertrophy, at least partly, via decreasing the expression of miR-30 [182]. Initiation of autophagy by the unc-51 like autophagy activating kinase 1 (ULK1) complex is suppressed by miR-20a and miR-106b [186]. Other negative regulators of autophagy include miR-101 [187, 188], miR-199a [189], miR-221 [190, 191], miR-222 [192], ,and miR-374a [193]. Collectively, miRNAs able to increase autophagic activity potentially have beneficial a role during myocardial aging whereas autophagy suppressing-miRNAs may aggravate age-related myocardial phenotypes. 


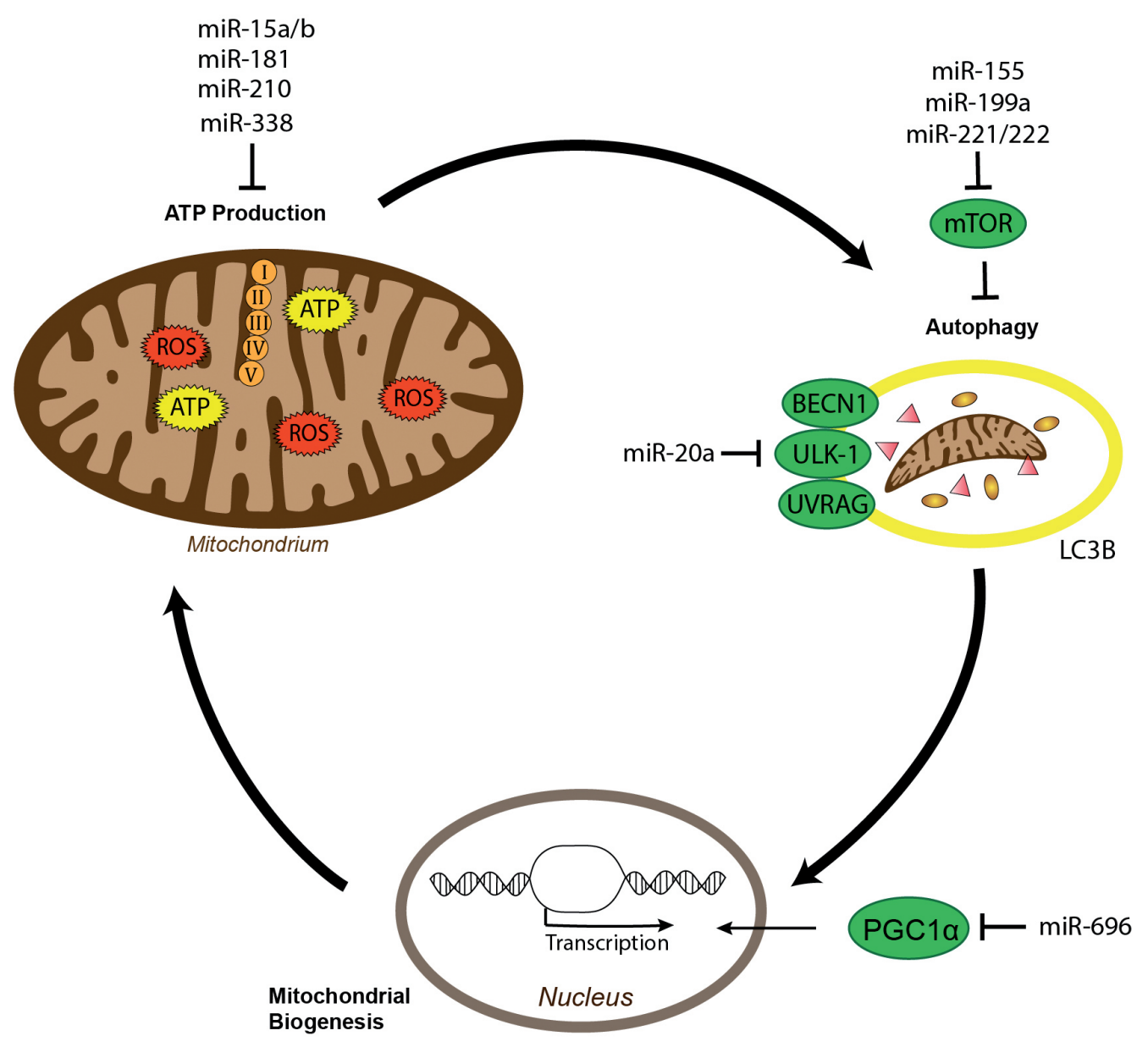

Figure 3) Aging miRNAs negatively regulate mitochondrial function via controlling mitochondrial ATP production, biogenesis, and autophagy. Mitochondria generate energy in the form of ATP, which is accompanied by the production of reactive oxygen species (ROS). Beclin 1 (BECN1) and unc-51 like autophagy activating kinase 1 (ULK-1) initiate the formation of autophagosomes to protect the cell against dysfunctional, ROS-producing mitochondria. Autophagosomal content undergoes lysation after fusion with a lysosome. Degraded components can be recycled during PPARG Coactivator 1 Alpha (PGC1-a)-mediated mitochondrial biogenesis.

\section{Programmed cell death}

Cardiomyocyte renewal occurs at a low rate ( $\pm 1 \% / y e a r)$ in youth and seems to slow down even further with advancing age [194]. This non-mitotic nature of cardiomyocytes marks the importance of a balanced homeostasis to prevent cell death. Aging in the mammalian heart is characterized by a gradual loss of myocytes and hypertrophy of the remaining myocytes [54]. Cardiomyocyte loss is primarily due to necrosis and apoptosis (Figure 4). Deregulation of both cell death pathways has been observed in heart disease [195] as well as during normal myocardial senescence [196, 197].

\section{MiRNAs regulating necrotic cell death}

Necrosis is morphologically characterized by an increase in cell volume, dilation of organelles, rupture of the plasma membrane and subsequent loss of intracellular contents [198, 
199]. Cardiomyocytes can undergo necrosis when being exposed to excessive stress due to, for example the lack of oxygen and nutrients, as during myocardial ischemia [200]. So far, only limited evidence has been gathered on the role of miRNAs in regulation of cardiac necrosis. Age-associated miR-155 was reported to attenuate hydrogen peroxide $\left(\mathrm{H}_{2} \mathrm{O}_{2}\right)$ induced necrotic cell death in cardiomyocyte progenitor cells (CMPCs)[201]. Strikingly, transplantation of CMPCs overexpressing miR-155 in the infarcted myocardium induced an anti-necrotic response through repression of receptor interacting protein 1 (RIP1)[201]. Although certain miRNAs have been shown to influence cardiac necrotic cell death in vitro as well as in vivo, the role of miRNAs in regulation of necrotic cell death pathways is underinvestigated, especially in the context of age-associated necrosis.

\section{MiRNAs promoting apoptotic cell death}

Unlike necrosis, myocardial apoptotic cell death and the role of miRNAs therein have been well documented. Apoptosis is a highly regulated process in which signalling is mediated by the mitochondria [202], regulated by a family of both pro-apoptotic and anti-apoptotic member proteins called Bcl-2 [203], and executed by a family of cysteine proteases, called caspases [204].

A large body of work describes the impact of miRNAs on cardiac apoptosis, including miRNAs implicated in myocardial aging, such as miR-34a. MiR-34a is upregulated in cardiomyocyte apoptosis induced by doxorubicin or excessive ROS accumulation [205], and its inhibition has cardioprotective effects, partially diminishing apoptosis both in vitro and in vivo [205-208]. Interestingly, miR-34a has been identified as a predictive plasma marker of future HF in patients after acute MI [205]. Moreover, miR-92a, a member of the aging miRNA cluster miR-17-92, has been proven to regulate cardiomyocyte apoptosis. Circulating expression of miR-92a is elevated in acute MI patients as well as in post-MI cardiac and blood samples of rodents [209]. Knock down of miR-92a has cardio-protective effects through reduction of apoptosis while overexpression has the opposite effect [209-212].

Two different age-associated miRNA families, the miR-15- and miR-29 family are proven to regulate apoptotic signalling through direct inhibition of anti-apoptotic gene BCL-2. Various miR-15 family members were found to be up-regulated in the overloaded heart [213] while being downregulated in both border and infarct zone of mice subjected to MI [214]. Several of these members are proven to promote apoptosis, including miR-15a, miR-15b, miR-16, miR-195, and miR-497, and worsen myocardial ischemia-induced cardiac injury [100, 215-218]. Furthermore, miR-29 family members, miR-29a/c protect cultured cardiomyocytes from I/R injury, evidenced by increased cell survival and decreased Casp3 activity after inhibition [219].

Various other miRNAs have been identified to modify cell death via targeting of additional negative regulators of the apoptotic pathway. For eample, apoptosis-induced miR-140 promotes apoptosis via targeting of anti-apoptitc mitofusin 1 [220]. Silencing of 
miR-140 in vitro and in vivo attenuates apoptosis and reduces infarct size in a mouse model of I/R injury [220].

MiR-155 is, in addition to prevention of necrosis, suggested to stimulate apoptosis. Inhibition of miR-155 in LPS-treated mice attenuated cardiac apoptosis and preserved cardiac function, while forced expression of miR-155 aggravated cardiac dysfunction [221]. These results are indicative for a pro-apoptotic function of miR-155 in the heart during sepsis. The discrepancy between the observed anti-necrotic and pro-apoptotic effect can possibly be explained by the fact that the role of miR-155 was investigated in different cell types. Next to that, Wang et al. studied the effect of the well-known pro-inflammatory miR-155 on cardiomyocyte apoptosis in a LPS-induced sepsis model. It is possible that the decreased apoptosis after inhibition of miR-155 is rather due to a diminished inflammatory response than a direct effect on apoptotic signalling.

Additional miRNAs enhancing apoptosis via targeting negative regulators/factors of the intrinsic apoptotic pathway include miR-1 [222], miR-100 [223], and miR-132 [224]. These results suggest that various miRNAs are able to provoke apoptosis in cardiomyocytes, in most, but not all, cases via direct or indirect suppression of activity of anti-apoptotic gene $\mathrm{BCL}-2$, thereby aggravating myocardial function.

\section{MiRNAs inhibiting apoptotic cell death}

Other miRNA have been shown to inhibit apoptosis, including the senescence-associated miRNA cluster miR-17-92. Hypoxia decreases expression of various miR-17-92 cluster members, and overexpression of this cluster markedly attenuates apoptosis [225]. For example, miR-17 exert its anti-apoptotic function through suppression of Casp9 and apoptotic protease-activating factor 1 (Apaf-1)[226] while miR-19b prevents apoptosis via phosphatase and tensin homolog (PTEN) suppression [227].

One of the best-studied anti-apoptotic miRNAs is miR-21. MiR-21 displays increased expression levels in border areas in infarcted hearts while being down-regulated in infarcted areas $[228,229]$. Silencing of miR-21 aggravates $\mathrm{H}_{2} \mathrm{O}_{2}$-induced apoptotis whereas overexpression of miR-21 protects against apoptosis and subsequently decreases $\mathrm{MI}$ size and myocardial remodelling [229, 230]. The anti-apoptitic effect of miR-21 is established via targeting of different pro-apoptotic genes, such as PTEN [231, 232], PDCD4 [233, 234], and TPM1 [235]. Interestingly, Huang and co-workers showed that miR-21/miR-146a synergistically reduced ischemia/hypoxia-induced cardiomyocyte apoptosis in vitro and in a murine MI-model, the combination of the miRNAs being superior to each miRNA alone [236].

Similarly, miR-24 and miR-93 are reported to target, among others, PTEN and attenuate cardiomyocyte apoptosis and myocardial injury in vivo [237-239]. Although miR-24 prevents apoptosis in cardiomyocytes, forced expression of miR-24 in endothelial cells promotes apoptosis through direct targeting of GATA2 and PAK4, which in their turn, impinge on BCL2-associated agonist of cell death [240] Silencing of endothelial miR-24 in in mice 
with $\mathrm{MI}$ attenuated cardiac endothelial cell apoptosis, reduced infarct size and preserved cardiac function [240].

Caspases are crucial in apoptotic signalling and miR-133 is in control of multiple of these key players, exerting an anti-apoptotic function. Hearts from cardiac-specific miR-133 transgenic mice displayed reduced Casp3 activation and apoptosis during pressure overload [49]. In addition, miR-133 protects cardiomyocytes from cell death through suppression of Casp9 explaining, at least partly, the beneficial effect of ischemic post-conditioning [241, 242].

Several members of the miR-30 family, miR-30e in particular, display reduced expression in response to doxorubicin-induced cardiotoxicity and were found to mediate apoptosis through inhibition of apoptotic signalling by mitochondria [243, 244]. In addition, miR-30e inhibits the expression of BCL2/adenovirus E1B-interacting protein 3-like (BNIP3L or NIX)[243].

Many additional miRNAs have been shown to attenuate apoptotic cell death in cardiomyocytes exposed to $\mathrm{H}_{2} \mathrm{O}_{2}$ or doxorubicin, including miR-199a [245], miR-22 [246, 247], miR-23a [248, 249], miR-125b [250], miR-132 [224], miR-150 [251], and miR-206 [252]. These reports demonstrate that many different miRNAs are able to inhibit apoptotic cell death in the myocardium, including various age-associated miRNAs. Decreased expression of these anti-apoptotic miRNAs in the aging heart may explain the observed increase in apoptotic cell death.

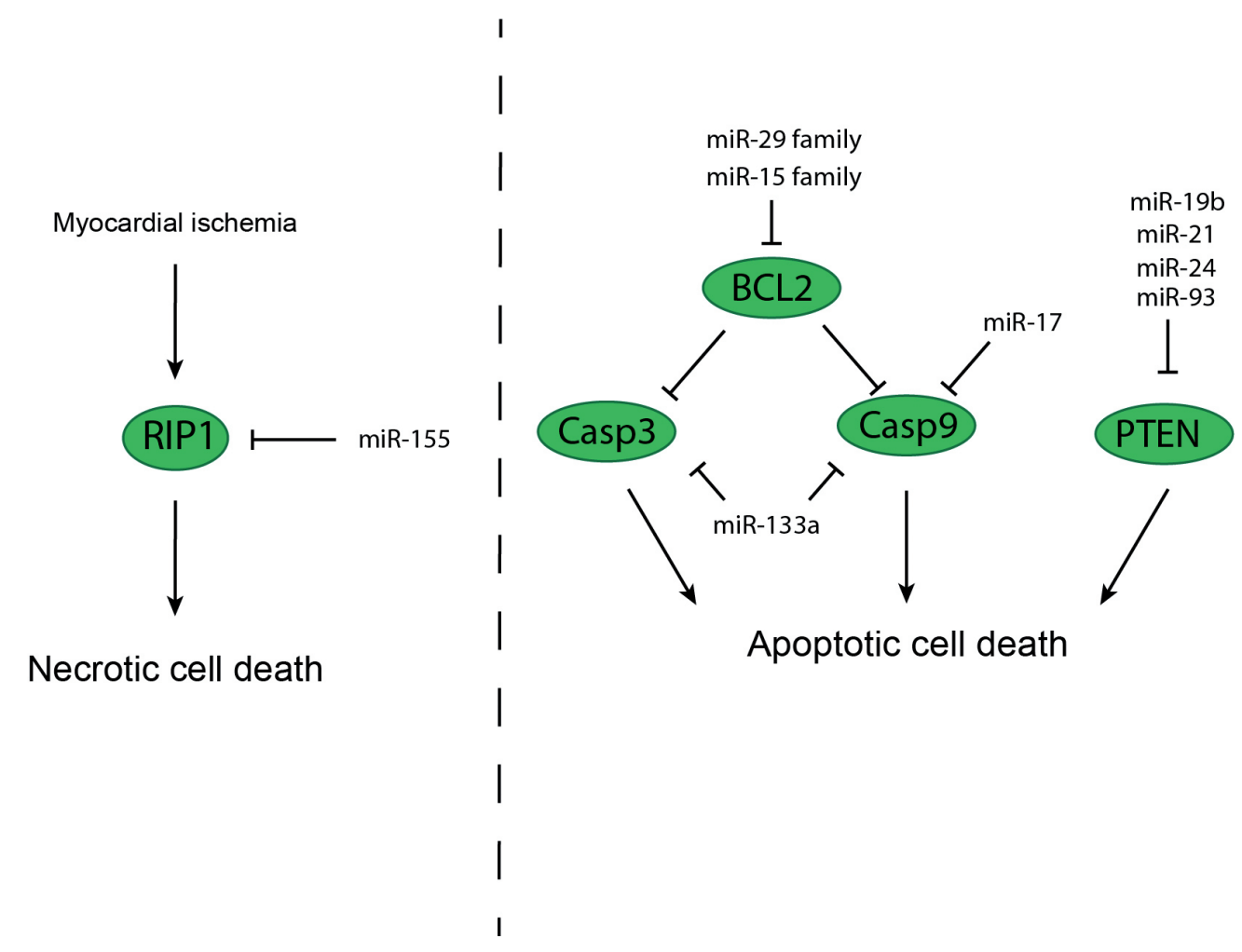

Figure 4) Both cell death signalling pathways, apoptosis and necrosis, are affected by aging miRNAs. Necrotic cell death can be caused by myocardial ischemia via activation of receptor interacting protein 1 (RIP1). Apoptotic cell death is regulated by B-cell lymphoma 2 (BCL-2) and executed by various caspases, including Casp3 and Casp9, and pro-apoptotic gene phosphatase and tensin homolog (PTEN). 


\section{Inflammatory endothelial activation and macrophage recruitment}

Aging is associated with a systemic proinflammatory state, sometimes referred to as "inflammaging", which can activate signalling cascades leading to structural and functional remodelling of the heart [253-255]. A growing body of evidence indicates that proinflammatory signalling is a key factor driving remodelling of the heart with advancing age (reviewed in [256]). Allostatic-associated proinflammatory signalling molecules are upregulated whereas anti-inflammatory molecules are down-regulated in the myocardium. Importantly, the aging-associated pro-inflammatory response is not performed by "professional immune cells"; aged cardiac cells, including endothelial cells, smooth muscle cells and fibroblasts, acquire a senescence-associated secretory pro-inflammatory phenotype $[17,257]$. In particular, senescence of endothelial cells (ECs) and the accompanying dysfunction promotes, the pathogenesis of age-related coronary disease, including atherosclerosis [258-260]. Disturbed flow enhances cell senescence and primes endothelial cells for inflammatory gene expression, and might promote accumulation of monocyte-derived macrophages at damaged areas in the arterial intima [261-263]. Thus, miRNAs controlling endothelial activation/senescence and the potential following recruitment of macrophages can influence cellular aging and the progression of age-related cardiac diseases (Figure 5).

\section{MiRNAs regulating endothelial activation}

Interestingly, among the most abundant miRNAs in endothelial cells are age-deregulated miRNAs such as miR-146a, miR-21, miR-126a, and members of the miR-17-92 cluster [264]. Moreover, shear stress forms the main cause of accelerated cellular senescence and shapes the miRNA signature of endothelial cells [265-267], altering the expression of senescence miRNAs $[268,269]$. Among these miRNAs, miR-146a represses NFkB signalling via direct inhibition of IRAK 1 and TRAF6 and, thus, cellular en richment of miR-146a through systemic delivery of mimetics suppresses NFkB activation and reduces macrophage recruitment [270]. In addition, miR-146a $\%$ mice are resistant to endothelial activation following treatment with IL-1 $\beta$ because of reduced induction of pro-inflammatory adhesion molecules [271]. Conversely, overexpression of miR-146a suppresses both chemokine production and monocyte adhesion to the endothelium, supporting the hypothesis that miR-146a ameliorates endothelial inflammation and the progression of atherosclerosis [272]. Similarly, EC-enriched miRNA miR-126a is shown to be involved in endothelial activation via targeting vascular cell adhesion molecule-1 expression (VCAM-1), preventing leukocyte adhesion to endothelial cells [264, 273, 274].

Shear stress-inducible miR-19a and miR-21 promote endothelial inflammation and disease progression. Circulating miR-21 may be an inflammatory biomarker linking the aging process to cardiac disease [275], displaying an age-related increase in the plasma miR-21 levels [276]. Here, miR-21 expression and IL-6 and IL-8 levels correlated, suggesting a potential role of miR-21 in inflammatory gene expression. On the contrary, disturbed blood 
flow-induced upregulation of miR-21 in endothelial cells suppresses translation of PPARa, inducing the expression of vascular VCAM-1 and CCL2, and promoting endothelial inflammation [277]. Moreover, miR-19a is upregulated in atherosclerotic ECs, and increases NFkB activity by targeting several negative regulators of NFkB, functioning as a pro-atherogenic factor [278].

Additional senescent-associated miRNAs induced by endothelial shear stress include miR-181b, miR-23b, and miR-150, whereas shear stress downregulates expression of miR24, miR-103, miR-210, and miR-221 [269, 279-281]. MiR-181b dampens the inflammatory response in the endothelium by limiting the translocation of NFkB from the cytoplasm to the nucleus, decreasing NFkB activity and contributing to the anti-inflammatory phenotype of endothelial cells at athero-protected regions of (coronary) arteries [272, 282, 283]. Furthermore, members of the let-7 miRNA family are upregulated in endothelial cells at athero-protected sites, whereas miR-103 and miR-221 are upregulated at athero-prone sites [284]. More specifically, overexpression of let-7g and let-7i has been shown to suppress endothelial and cardiac inflammatory activation, whereas a pro-inflammatory phenotype was acquired in the absence of let-7g or let-7i $[285,286]$. Similarly, increased miR-103 expression enhances endothelial inflammation, while blocking of miR-103 reduces macrophage accumulation and chemokine expression, suggesting a pro-inflammatory role for miR-103 [287, 288]. Finally, miR-221 is able to decrease the expression of NFkB target genes such as VCAM-1 and CCL2 via targeting transcription factor ETS-1 [289].

\section{MiRNAs influence macrophage polarization and function}

Acquisition of a senescence-associated secretory pro-inflammatory phenotype during endothelial aging is followed by recruitment of inflammatory cells. Following their adhesion to the endothelium, inflammatory cells can migrate into the intima, differentiate into macrophages and enhance the local inflammatory response. Aging is associated with changes in cardiac tissue macrophage composition, gene expression, and function, altering the inflammatory response and increasing myocardial susceptibility [290]. More specifically, senescent mice show a suppressed post-infarct inflammatory response, evidenced by a decreased and delayed neutrophil and macrophage infiltration, markedly reduced cytokine and chemokine expression and impaired phagocytosis of death cardiomyocytes [291]. It is now recognized that miRNAs can profoundly influence the biology of inflammatory cells, in particular the differentiation of monocytes into polarized macrophages. A large number of age-associated miRNAs are differentially regulated during the differentiation of monocytes into macrophages, for example miR-24, miR-30b, miR-142-3p, and miR-199a-5p are down regulated in this process $[292,293]$. In particular, miR-24, miR-30b, and miR-142-3p impair macrophage differentiation and activation, as evidenced by reduced macrophage phagocytosis and reduced expression of inflammatory cytokines upon overexpression [292, 294, 295].

Once differentiated, recruited macrophages can take on two extreme states [296, 297]. The initiation phase of an inflammatory response is characterized by pro-inflammatory 
macrophages, also known as classically activated or M1 macrophages, which secrete inflammatory cytokines, such as IL-12, IL-1 $\beta$ and tumor necrosis factor (TNF)- $\alpha$ [297, 298]. Anti-inflammatory macrophages, also known as alternatively activated or M2 macrophages, play important roles in inflammation resolution and tissue repair by secreting anti-inflammatory cytokines such as IL-10 [298]. Pro-inflammatory M1 macrophages have increased expression of age-associated miRNAs miR-29b, miR-125a, miR-26a-2, miR-147, and miR-155-5p, whereas anti-inflammatory M2 macrophages have increased expression of miR-193b or miR-27a, miR-29b-1, miR-132, miR-222 and miR-155-3p respectively [299-301] (Figure 5). Moreover, forced expression of miRNAs affects macrophage polari-

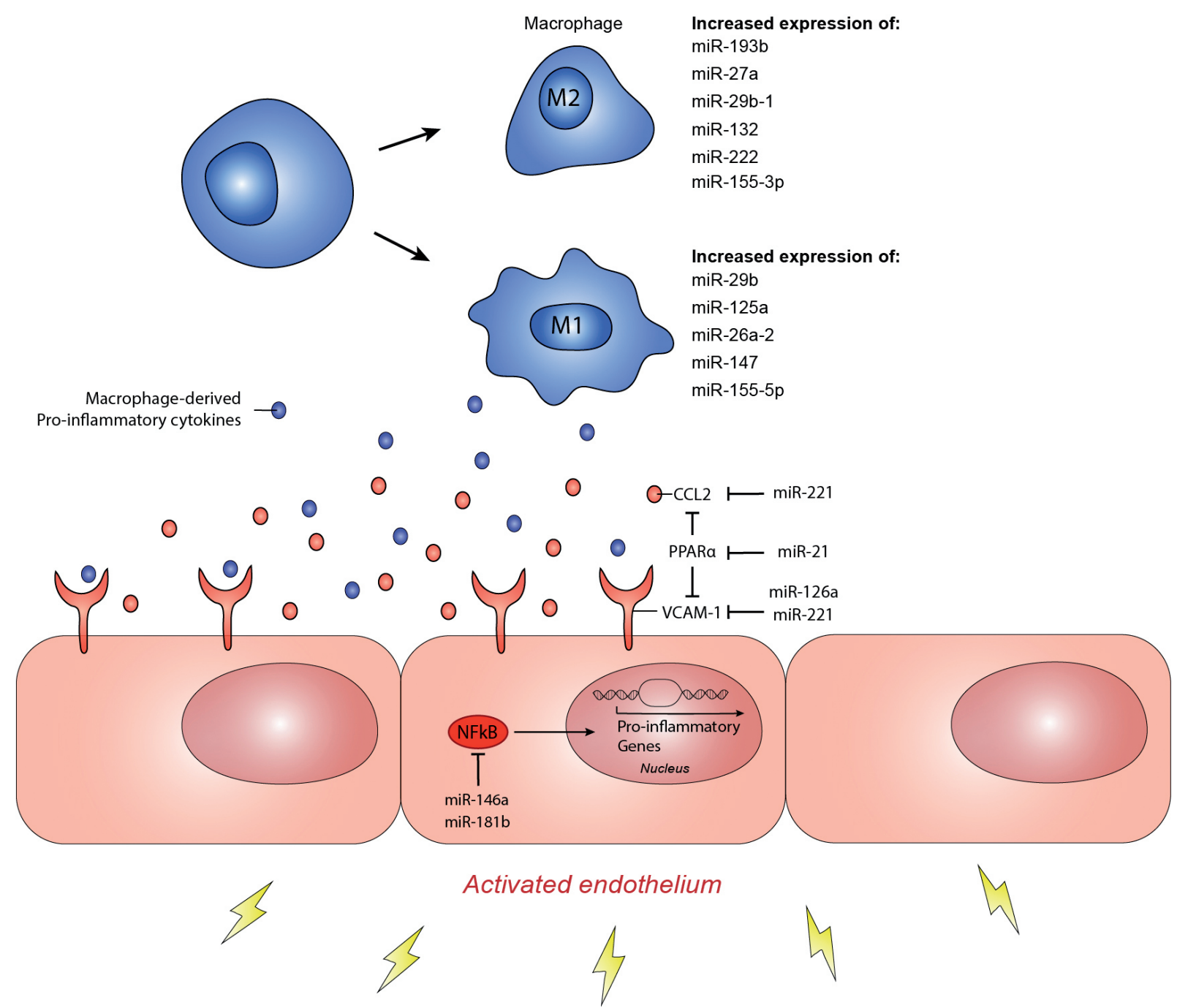

Figure 5) Macrophage polarisation shapes their miRNA profile, subsequently affecting endothelium activation and their inflammatory response. Macrophages can polarise into either pro-inflammatory M1 macrophages, or anti-inflammatory M2 macrophages, which display distinct miRNA profiles. NFKB signalling plays a central role in endothelium activation, increasing the expression of pro-inflammatory cytokines and chemokines, including Vascular Cell Adhesion Molecule-1 (VCAM-1), and C-C Motif Chemokine Ligand 2 (CCL2). Expression of CCL2 leads to the recruitment of M1 macrophages, which in their turn secrete pro-inflammatory cytokines to promote further endothelial activation. 
sation status. For example, in vitro overexpression of miR-155-5p and miR-29b induced differentiation towards a M1 macrophage expression pattern [299, 301].

One of the most well-investigated miRNAs in cardiac inflammatory disease, miR-155, is upregulated in the peripheral blood of aged women [302], in human B cells from elderly individuals [303] and is suggested to form a senescence associated secretory marker [304]. Moreover, Corsten et al. [305] have shown that elevated miR-155 levels were found in cardiac tissue of both human and mice with viral-induced myocarditis [305]. MiR-155 functions, among others, as a positive regulator of TLR-signalling and its silencing during viral-induced myocarditis mice models resulted in attenuation of cardiac inflammation [306]. MiR-155 is highly expressed in both mouse and human aortic atheroscletoric lesions but is reported to have a controversial role in atherosclerotic inflammation, reported to

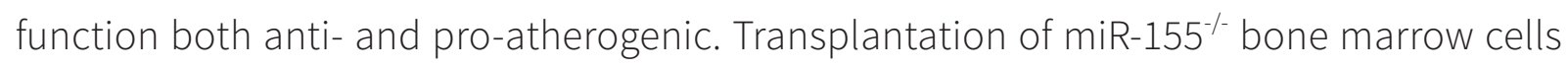
into LDLr/- mice was reported to amplify macrophage inflammation, increase atheroscle-

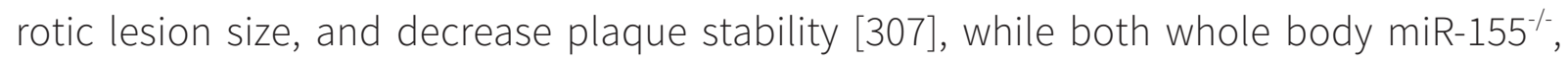

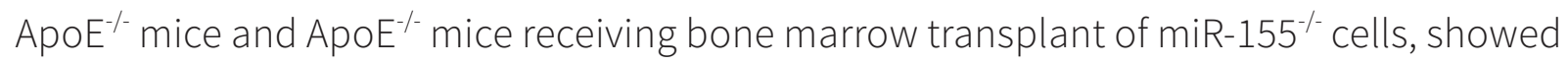
markedly reduced macrophage inflammation and decreased atherosclerotic lesions [301, 308]. Importantly, the differences in the ability of macrophage miR-155 to reduce lesion progression may greatly depend on the stage of atherosclerotic development (i.e. early versus advanced) when the expression of key target genes is stage-specific [309].

Aging-related miRNAs miR-21 and miR-146b were found to be upregulated in myocarditis patients. These miRNAs also have a central role in immune activation and inflammation [305]. Silencing of these miRNAs by specific inhibitors showed a strong attenuation of viral-induced myocarditis mice [310]. The exact role of these miRNAs in the pathology of myocarditis is not elucidated, however it is shown that the expression of miR-21 and miR-146b is correlated with IL-17 expression, implicating an immune modulating function for both age-associated miRNAs [310].

Additionally, anti-inflammatory miRNAs, miR-106a and miR-93 were downregulated in the acute phase of human myocarditis [305], while being upregulated in the senescent heart [311]. Both are involved in anti-inflammatory responses by inhibiting the production of inflammatory cytokines [312, 313].

Strikingly, miR-181b is also increased in EC-extracellular vesicles-treated monocytic cells, while this miRNAs is shown to supress monocyte activation upon overexpression [314]. These results suggest that crosstalk between the endothelium and monocytes/macrophages may be mediated via secreted extracellular vesicles containing anti-inflammatory miRNAs. This finding marks the important function of miRNAs in controlling endothelial activation and the inflammatory response. We can conclude from these studies that miRNA are key regulators of endothelial activation, monocyte differentiation, and macrophage activation and polarization. Dysregulation of these miRNAs affect the aging process of the myocardium, potentially aggravating the processes driving cellular senescence. 


\section{Extracellular matrix (ECM) remodelling}

The extracellular matrix (ECM) is a complex collection of proteins, including fibronectin and different types of collagens, and functions as the structural backbone of the heart in addition to being a critical regulator of cellular processes like proliferation, migration, and differentiation, through the control of signalling via growth factors and bioactive molecules [315]. Importantly, excessive ECM hallmarks the senescent myocardium, increasing cardiac stiffness and mediating diastolic dysfunction [316-318]. In the heart, fibroblasts are the most abundant cell type [319, 320] and they play a crucial role in myocardial homeostasis by preserving the balance of ECM synthesis and degradation [321]. In response to various stresses, such as myocardial injury and exposure to cytokines or growth factors, fibroblasts undergo transformation to myofibroblasts [322-326], which control ECM composition by regulating the secretion and activity of proteolytic enzymes, including members of the ECM degrading superfamily of matrix metalloproteinase (MMPs) and their tissue inhibitors (TIMPs)[327, 328]. The main pro-fibrogenic growth factor identified as a central player of myofibroblasts transformation and ECM remodelling is transforming growth factor $\beta$ (TGF $\beta$ ) $[328,329]$, which signals through MAPK or SMAD proteins to drive fibrotic gene expression (Figure 6).

TGF $\beta$ signalling does not only induce fibroblast activation and differentiation, it also shapes the fibroblast miRNA profile. SMAD proteins, have a dual function; 1 ) they bind to the DNA to regulate the transcription of miRNAs and 2) they interact with the Drosha/ DGCR8 complex to influence miRNA maturation [330]. For example, TGF $\beta 1$ induces expression of miR-21 [331], while reducing expression of the miR-30 family [332]. Additionally, miR-212/132 levels were increased after TGF $\beta$ treatment in endothelial cells [333]. These results suggest a possible link between the fibrotic response and miRNAs. Different miRNAs have been shown to posses the ability to regulate pathological fibrosis, including miRNAs displaying an age-associated dysregulation.

\section{MiRNAs suppressing ECM production}

Members of the age-associated miR-17-92 miRNA cluster, including miR-18a and miR-19b, have been implicated as potential regulators of ECM production during aging cardiomyopathy, through their targets CTGF and TSP-1 [334]. Moreover, miR-19a/b are shown to be a negative regulator of TGF $\beta$ signalling via direct targeting of TGF $\beta R 2$, resulting in inhibition of interstitial fibrosis and attenuation of cardiac remodelling [335]. MiR-22, another age-associated miRNA, is one of the most abundantly expressed miRNAs in the heart [336] whose expression increases during aging [337]. This miRNA promotes senescence and activation of cultured cardiac fibroblasts via repression of its target, the small leucine rich proteoglycan osteoglycin (OGN)[337]. Although miR-22 knockout mice do not display any cardiac abnormalities under basal conditions, upon cardiac stress, they quickly develop dilated cardiomyopathy accompanied with excessive cardiac fibrosis [338, 339]. MiR-22 
inhibition might therefore be a potential therapeutic target, to block fibrosis development in the elderly heart patient.

The well-documented miR-34a has been implicated in cardiac aging and fibrosis formation. It is part of a positive feedback loop, induced by TGF $\beta$ and itself promoting TGF $\beta$-induced activation of cardiac fibroblasts by targeting co-smad and SMAD4 [340]. MiR-34a is upregulated in senescent murine hearts as well as in aged human myocardial biopsies [207]. Silencing of miR-34a protected the heart against excessive cardiac fibrosis and remodelling upon pressure overload or MI [207, 341-343].

The most well studied miRNA for its role in fibrosis is age-associated miR-21. This cardiac fibroblast-enriched miRNA is increased in human and murine HF [100, 344, 345], and both its myocardial and plasma levels correlated with intra-cardiac fibrosis in aortic stenosis patients [344]. MiR-21 has multiple targets implicated in matrix deposition, including sprout homologue 1 [345], PTEN [346], SMAD7 [347] and TGFßR3 [348], and their inhibition synergizes to provoke a pronounced cardiac fibrosis phenotype.

Furthermore, the aging-associated miR-29 family is downregulated in response to cardiac stress [100,349]. Notably, circulating levels of miR-29a correlated inversely with cardiac fibrosis [350, 351]. This family protects against cardiac fibrosis via direct targeting of a number of ECM genes and subsequent inhibition of MAPK- and TGF $\beta / S M A D 3-s i g n a l l i n g$, preventing fibroblast activation and proliferation [352-355]. Strikingly, rescue of miR-29b expression 14 days after Angll treatment reduced cardiac fibrosis and restored cardiac function, indicating the therapeutic potential in established hypertensive heart disease [354].

The miR-15 family (miR-15a, miR-15b, miR-16, miR-195, miR-497, and miR-322) is induced in response to cardiac stress [100, 216] and targets TGFBR1, SMAD3, and SMAD7 among others, presumably to counteract TGF $\beta$ activity and to inhibit ECM remodelling [213]. Indeed, inhibition of miR-15b specifically aggravated fibrosis in pressure overloaded mice [213]. On the other hand, upon experimental ischemia-reperfusion, inhibition of the complete miR-15 family yielded smaller infarct sizes and less fibrosis [216]. The basis for the different outcomes of miR-15 inhibition remains unclear, but may be owed to the different nature of the insults to the heart and inhibition of the complete miR-15 family versus only one of the family members.

Cardiac fibrosis during experimental pressure overload is, associated with the downregulation of miR-133a [356] and concomitant de-repression of its targets fibronectin, Colla1, and Col4a1 [46, 356, 357]. Also, the senescence-associated miR-30 is a fibroblastenriched miRNA, downregulated in the failing human and rodent heart [100], exerting its anti-fibrotic function via targeting of CTGF [185].

Many other miRNAs associated with aging have been identified as negative regulators of the cardiac fibrotic response by inhibiting crucial pro-fibrotic signalling cascades, such as the TGF $\beta$ and MAPK/ERK pathways, including miR-24, miR-122, miR-101, miR-19a/b, and miR-150. MiR-24 is downregulated shortly after MI and negatively regulates cardiac fibrosis 
by controlling the expression of Furin, which is necessary for TGF $\beta$ excretion [358]. Overexpression of miR-24 into the mouse myocardium before inducing MI led to a reduced infarct size and improved cardiac function [358]. The same protective effect of miR-122 on myocardial fibrosis in human AOS was revealed and was dependent on the targeting of TGF $\beta 1$

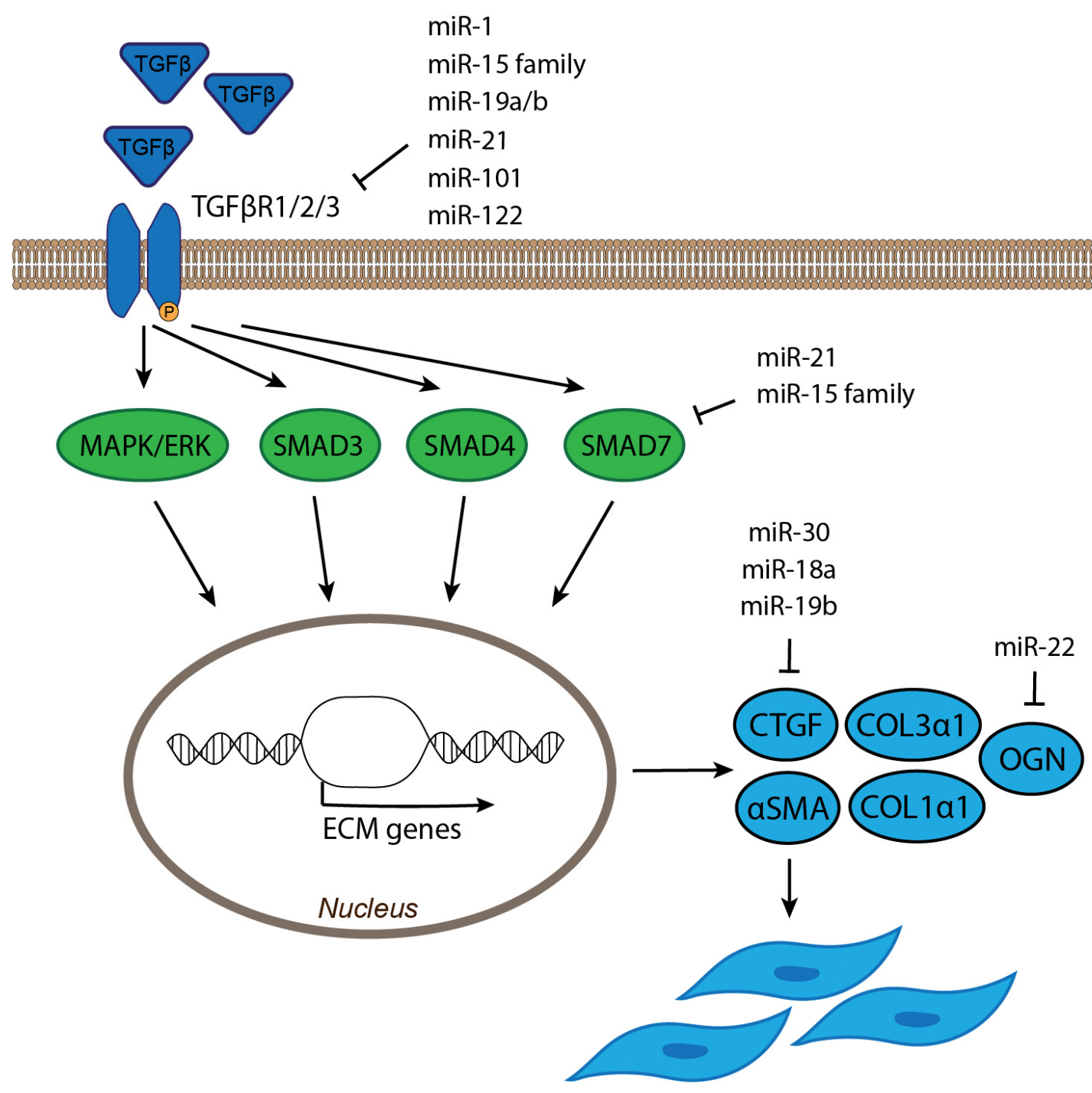

Fibroblast activation \& proliferation

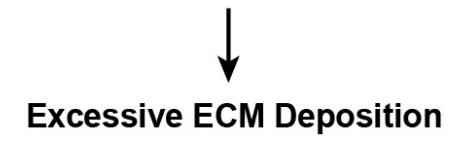

Figure 6) Senescence-associated miRNAs alter cardiac fibroblast activation and proliferation via targeting of the MAPK and TGF $\beta$ pathway, resulting in disbalance of the extracellular matrix. Activation of transforming growth factor beta receptors (TGF $\beta R 1 / 2 / 3$ ) promotes MAPK/ ERK and/or SMAD signalling. Both pathways stimulate the fibrotic response, which is characterised by increased transcription of connective tissue growth factor (CTGF), alpha smooth muscle actin (aSMA), osteoglycin (OGN), and different collagens (COL1a1 and COL3a1). Increased expression of these pro-fibrotic genes leads to excessive extracellular matrix (ECM) deposition through activation and proliferation of cardiac fibroblasts. 
[359]. Adenovirus-mediated overexpression of miR-101 can attenuate interstitial fibrosis formation and inhibits MI-induced cardiac dysfunction in rats via silencing of TGF $\beta R 1$ and the transcription factor c-Fos, suppressing proliferation of cardiac fibroblasts [360, 361].

Next to TGF $\beta$, MAPK/ERK signalling plays a critical role in activation of cardiac fibroblasts and collagen formation [362]. Interestingly, miR-7a/b inhibits both the TGF $\beta$ and MAPK pathways and subsequently reduces collagen I expression and inhibits cardiac fibroblast proliferation and migration [363]. MiR-150 is decreased in murine hearts suffering form pressure overload and inhibits cardiac fibroblast activation upon overexpression in vitro, while miR-150 KO mice display a more severe deterioration of cardiac function due to excessive cardiac fibrosis in comparison with wild-type mice [364].

\section{MiRNAs promoting ECM production}

Age-associated and TGFß-induced miR-125b promotes fibrosis through inhibition of the antifibrotic secreted frizzled-related protein 5 (SFRP5), resulting in both proliferation and activation of cardiac fibroblasts and derepression of aSMA and collagen I and III [365].

Overall, age-associated changes in the molecular environment, such as increased TGF $\beta$ signalling, are accompanied with altered miRNA expression profiles. In turn, these miRNAs are able to influence fibroblast activation, differentiation, and collagen production, marking them as potential therapeutic targets to fine-tune ECM deposition.

\section{Conclusion \& Discussion}

Various cellular processes are identified to drive cardiac senescence resulting in age-associated functional deterioration. Therewith, described molecular hallmarks of cardiac aging also drive the progression of HF, implying that HF is an accelerated state of myocardial aging, involving similar processes. Still, "healthy aging" suggests the presence of a heart that is functional enough to meet the body's demand and such heart will by definition differ from a failing heart. Therefore, using HF-miRNA studies to understand the cardiac aging process better as we did here is acceptable. Notably, recent studies suggest that age-associated functional and structural changes in the heart are, at least partly, caused by exhaustion of the stem cell pool in the myocardium, leading to impaired repair and regeneration in the aged heart (reviewed in [366]). However, the role of stem cells in cardiac aging was not discussed within this review since the abundance and biological relevance of stem cells in the heart is still under debate. Future research should be conducted to study the role of miRNAs more extensively in the context of the healthy aging heart.

As highlighted throughout this review, cardiac and circulating miRNA expression profiles change during aging. The dysregulation of these responsive miRNAs can be the cause of age-induced alterations in the microenvironment, including desensitization of $\beta$-adrenergic signalling, local pro-inflammatory stimulation, ECM-deriving growth factors, and induction of apoptosis. In their turn, miRNAs are able to orchestrate the processes 
underlying senescence and potentially aggravate or counterbalance the cardiac aging phenotypes. This bidirectional connection between the cellular hallmarks of aging and miRNA function stresses the importance to gain knowledge about 1) the effect of microenvironmental aging on miRNA expression and 2) the exact regulatory function of miRNAs in cellular processes driving cardiac aging. 


\section{References}

1. Yazdanyar A and Newman AB. The burden of cardiovascular disease in the elderly: Morbidity, mortality, and costs. Clin Geriatr Med. 2009;25:563-577, vii

2. Go AS, Mozaffarian D, Roger VL, Benjamin EJ, Berry JD, Blaha MJ, Dai S, Ford ES, Fox CS, Franco S, Fullerton HJ, Gillespie C, Hailpern SM, Heit JA, Howard VJ, Huffman MD, Judd SE, Kissela BM, Kittner SJ, Lackland DT, Lichtman JH, Lisabeth LD, Mackey RH, Magid DJ, Marcus GM, Marelli A, Matchar DB, McGuire DK, Mohler ER, 3rd, Moy CS, Mussolino ME, Neumar RW, Nichol G, Pandey DK, Paynter NP, Reeves MJ, Sorlie PD, Stein J, Towfighi A, Turan TN, Virani SS, Wong ND, Woo D, Turner MB, American Heart Association Statistics C and Stroke Statistics S. Heart disease and stroke statistics--2014 update: A report from the american heart association. Circulation. 2014; 129:e28-e292

3. Jencks SF, Williams MV and Coleman EA. Rehospitalizations among patients in the medicare fee-for-service program. N Engl J Med. 2009;360:1418-1428

4. Stewart S, Jenkins A, Buchan S, McGuire A, Capewell S and McMurray JJ. The current cost of heart failure to the national health service in the uk. European journal of heart failure. 2002;4: 361-371

5. Fang J, Mensah GA, Croft JB and Keenan NL. Heart failure-related hospitalization in the U.S., 1979 to 2004. J Am Coll Cardiol. 2008;52:428-434

6. Lakatta EG and Levy D. Arterial and cardiac aging: Major shareholders in cardiovascular disease enterprises: Part ii: The aging heart in health: Links to heart disease. Circulation. 2003;107:346354

7. Lakatta EG. Cardiovascular regulatory mechanisms in advanced age. Physiological reviews. 1993; 73:413-467

8. Bursi F, Rocca WA, Killian JM, Weston SA, Knopman DS, Jacobsen SJ and Roger VL. Heart disease and dementia: A population-based study. Am J Epidemiol. 2006;163:135-141

9. Ha M and Kim VN. Regulation of microrna biogenesis. Nature reviews. Molecular cell biology. 2014;15:509-524

10. Kunz M, Xiao K, Liang C, Viereck J, Pachel C, Frantz S, Thum T and Dandekar T. Bioinformatics of cardiovascular mirna biology. J Mol Cell Cardiol. 2015;89:3-10

11. Vasan RS, Sullivan LM, Roubenoff R, Dinarello CA, Harris T, Benjamin EJ, Sawyer DB, Levy D, Wilson PW, D'Agostino RB and Framingham Heart S. Inflammatory markers and risk of heart failure in elderly subjects without prior myocardial infarction: The framingham heart study. Circulation. 2003;107:1486-1491

12. Liu SJ, Wyeth RP, Melchert RB and Kennedy RH. Aging-associated changes in whole cell $k(+)$ and l-type ca(2+) currents in rat ventricular myocytes. Am J Physiol Heart Circ Physiol. 2000;279: H889-900

13. Shih H, Lee B, Lee RJ and Boyle AJ. The aging heart and post-infarction left ventricular remodeling. J Am Coll Cardiol. 2011;57:9-17

14. Dai DF and Rabinovitch PS. Cardiac aging in mice and humans: The role of mitochondrial oxidative stress. Trends Cardiovasc Med. 2009;19:213-220 
15. Lakatta EG. Arterial and cardiac aging: Major shareholders in cardiovascular disease enterprises: Part iii: Cellular and molecular clues to heart and arterial aging. Circulation. 2003;107:490-497

16. Wang M, Zhao D, Spinetti G, Zhang J, Jiang LQ, Pintus G, Monticone R and Lakatta EG. Matrix metalloproteinase 2 activation of transforming growth factor-beta1 (tgf-beta1) and tgf-beta1type ii receptor signaling within the aged arterial wall. Arterioscler Thromb Vasc Biol. 2006;26: 1503-1509

17. Wang M, Jiang L, Monticone RE and Lakatta EG. Proinflammation: The key to arterial aging. Trends Endocrinol Metab. 2014:25:72-79

18. Dai DF, Santana LF, Vermulst M, Tomazela DM, Emond MJ, MacCoss MJ, Gollahon K, Martin GM, Loeb LA, Ladiges WC and Rabinovitch PS. Overexpression of catalase targeted to mitochondria attenuates murine cardiac aging. Circulation. 2009;119:2789-2797

19. Redfield MM, Jacobsen SJ, Borlaug BA, Rodeheffer RJ and Kass DA. Age- and gender-related ventricular-vascular stiffening: A community-based study. Circulation. 2005;112:2254-2262

20. Chen CH, Nakayama M, Nevo E, Fetics BJ, Maughan WL and Kass DA. Coupled systolic-ventricular and vascular stiffening with age: Implications for pressure regulation and cardiac reserve in the elderly. J Am Coll Cardiol. 1998;32:1221-1227

21. Bursi F, Weston SA, Redfield MM, Jacobsen SJ, Pakhomov S, Nkomo VT, Meverden RA and Roger VL. Systolic and diastolic heart failure in the community. Jama. 2006;296:2209-2216

22. Loffredo FS, Nikolova AP, Pancoast JR and Lee RT. Heart failure with preserved ejection fraction: Molecular pathways of the aging myocardium. Circ Res. 2014;115:97-107

23. Esler M, Jackman G, Leonard P, Skews H, Bobik A and Jennings G. Effect of propranolol on noradrenaline kinetics in patients with essential hypertension. Br J Clin Pharmacol. 1981;12:375-380

24. Esler M, Kaye D, Thompson J, Jennings G, Cox H, Turner A, Lambert G and Seals D. Effects of aging on epinephrine secretion and regional release of epinephrine from the human heart. J Clin Endocrinol Metab. 1995;80:435-442

25. White M, Roden R, Minobe W, Khan MF, Larrabee P, Wollmering M, Port JD, Anderson F, Campbell $D$, Feldman AM and et al. Age-related changes in beta-adrenergic neuroeffector systems in the human heart. Circulation. 1994;90:1225-1238

26. Xiao RP, Tomhave ED, Wang DJ, Ji X, Boluyt MO, Cheng H, Lakatta EG and Koch WJ. Age-associated reductions in cardiac beta1- and beta2-adrenergic responses without changes in inhibitory $g$ proteins or receptor kinases. J Clin Invest. 1998;101:1273-1282

27. Janczewski AM and Lakatta EG. Modulation of sarcoplasmic reticulum ca(2+) cycling in systolic and diastolic heart failure associated with aging. Heart Fail Rev. 2010;15:431-445

28. Davies CH, Ferrara N and Harding SE. Beta-adrenoceptor function changes with age of subject in myocytes from non-failing human ventricle. Cardiovasc Res. 1996;31:152-156

29. Xiao RP, Spurgeon HA, O'Connor F and Lakatta EG. Age-associated changes in beta-adrenergic modulation on rat cardiac excitation-contraction coupling. J Clin Invest. 1994;94:2051-2059

30. Kirchhefer U, Baba HA, Hanske G, Jones LR, Kirchhof P, Schmitz W and Neumann J. Agedependent biochemical and contractile properties in atrium of transgenic mice overexpressing junctin. Am J Physiol Heart Circ Physiol. 2004;287:H2216-2225 
31. Zhu X, Altschafl BA, Hajjar RJ, Valdivia HH and Schmidt U. Altered ca2+ sparks and gating properties of ryanodine receptors in aging cardiomyocytes. Cell Calcium. 2005;37:583-591

32. Zile MR and Brutsaert DL. New concepts in diastolic dysfunction and diastolic heart failure: Part ii: Causal mechanisms and treatment. Circulation. 2002;105:1503-1508

33. Rockman HA, Koch WJ and Lefkowitz RJ. Seven-transmembrane-spanning receptors and heart function. Nature. 2002;415:206-212

34. Ishikawa Y and Homcy CJ. The adenylyl cyclases as integrators of transmembrane signal transduction. Circ Res. 1997;80:297-304

35. Cain BS, Meldrum DR, Joo KS, Wang JF, Meng X, Cleveland JC, Jr., Banerjee A and Harken AH. Human serca2a levels correlate inversely with age in senescent human myocardium. J Am Coll Cardiol. 1998;32:458-467

36. Meyer M and Dillmann WH. Sarcoplasmic reticulum ca(2+)-atpase overexpression by adenovirus mediated gene transfer and in transgenic mice. Cardiovasc Res. 1998;37:360-366

37. Schmidt U, del Monte F, Miyamoto MI, Matsui T, Gwathmey JK, Rosenzweig A and Hajjar RJ. Restoration of diastolic function in senescent rat hearts through adenoviral gene transfer of sarcoplasmic reticulum ca(2+)-atpase. Circulation. 2000;101:790-796

38. Tschope C, Spillmann F, Rehfeld U, Koch M, Westermann D, Altmann C, Dendorfer A, Walther T, Bader M, Paul M, Schultheiss HP and Vetter R. Improvement of defective sarcoplasmic reticulum ca2+ transport in diabetic heart of transgenic rats expressing the human kallikrein-1 gene. Faseb J. 2004;18:1967-1969

39. Jiang MT, Moffat MP and Narayanan N. Age-related alterations in the phosphorylation of sarcoplasmic reticulum and myofibrillar proteins and diminished contractile response to isoproterenol in intact rat ventricle. Circ Res. 1993;72:102-111

40. Xu A and Narayanan N. Effects of aging on sarcoplasmic reticulum ca2+-cycling proteins and their phosphorylation in rat myocardium. Am J Physiol. 1998;275:H2087-2094

41. Hou Y, Sun Y, Shan H, Li X, Zhang M, Zhou X, Xing S, Sun H, Chu W, Qiao G and Lu Y. Beta-adrenoceptor regulates mirna expression in rat heart. Medical science monitor: international medical journal of experimental and clinical research. 2012;18:BR309-314

42. Carrillo ED, Escobar Y, Gonzalez G, Hernandez A, Galindo JM, Garcia MC and Sanchez JA. Posttranscriptional regulation of the beta2-subunit of cardiac l-type ca2+ channels by micrornas during long-term exposure to isoproterenol in rats. J Cardiovasc Pharmacol. 2011;58:470-478

43. Ling S, Nanhwan M, Qian J, Kodakandla M, Castillo AC, Thomas B, Liu H and Ye Y. Modulation of micrornas in hypertension-induced arterial remodeling through the beta1 and beta3-adrenoreceptor pathways. J Mol Cell Cardiol. 2013;65:127-136

44. Lu Y, Zhang Y, Shan H, Pan Z, Li X, Li B, Xu C, Zhang B, Zhang F, Dong D, Song W, Qiao G and Yang B. Microrna-1 downregulation by propranolol in a rat model of myocardial infarction: A new mechanism for ischaemic cardioprotection. Cardiovasc Res. 2009;84:434-441

45. Care A, Catalucci D, Felicetti F, Bonci D, Addario A, Gallo P, Bang ML, Segnalini P, Gu Y, Dalton ND, Elia L, Latronico MV, Hoydal M, Autore C, Russo MA, Dorn GW, 2nd, Ellingsen O, Ruiz-Lozano P, 
Peterson KL, Croce CM, Peschle C and Condorelli G. Microrna-133 controls cardiac hypertrophy. Nat Med. 2007;13:613-618

46. Matkovich SJ, Wang W, Tu Y, Eschenbacher WH, Dorn LE, Condorelli G, Diwan A, Nerbonne JM and Dorn GW, 2nd. Microrna-133a protects against myocardial fibrosis and modulates electrical repolarization without affecting hypertrophy in pressure-overloaded adult hearts. Circ Res. 2010; 106:166-175

47. Trajkovski M, Ahmed K, Esau CC and Stoffel M. Myomir-133 regulates brown fat differentiation through prdm16. Nat Cell Biol. 2012;14:1330-1335

48. Terentyev D, Belevych AE, Terentyeva R, Martin MM, Malana GE, Kuhn DE, Abdellatif M, Feldman DS, Elton TS and Gyorke S. Mir-1 overexpression enhances ca(2+) release and promotes cardiac arrhythmogenesis by targeting pp2a regulatory subunit b56alpha and causing camkiidependent hyperphosphorylation of ryr2. Circ Res. 2009;104:514-521

49. Castaldi A, Zaglia T, Di Mauro V, Carullo P, Viggiani G, Borile G, Di Stefano B, Schiattarella GG, Gualazzi MG, Elia L, Stirparo GG, Colorito ML, Pironti G, Kunderfranco P, Esposito G, Bang ML, Mongillo M, Condorelli $G$ and Catalucci D. Microrna-133 modulates the beta1-adrenergic receptor transduction cascade. Circ Res. 2014;115:273-283

50. Kim IM, Wang Y, Park KM, Tang Y, Teoh JP, Vinson J, Traynham CJ, Pironti G, Mao L, Su H, Johnson JA, Koch WJ and Rockman HA. Beta-arrestin1-biased beta1-adrenergic receptor signaling regulates microrna processing. Circ Res. 2014;114:833-844

51. Zhang X, Azhar G, Williams ED, Rogers SC and Wei JY. Microrna clusters in the adult mouse heart: Age-associated changes. BioMed research international. 2015;2015:732397

52. Noma T, Lemaire A, Naga Prasad SV, Barki-Harrington L, Tilley DG, Chen J, Le Corvoisier P, Violin JD, Wei H, Lefkowitz RJ and Rockman HA. Beta-arrestin-mediated beta1-adrenergic receptor transactivation of the egfr confers cardioprotection. J Clin Invest. 2007;117:2445-2458

53. Dimitrakopoulou K, Vrahatis AG and Bezerianos A. Integromics network meta-analysis on cardiac aging offers robust multi-layer modular signatures and reveals micronome synergism. BMC genomics. 2015;16:147

54. Olivetti G, Melissari M, Capasso JM and Anversa P. Cardiomyopathy of the aging human heart. Myocyte loss and reactive cellular hypertrophy. Circ Res. 1991;68:1560-1568

55. Anversa P, Hiler B, Ricci R, Guideri G and Olivetti G. Myocyte cell loss and myocyte hypertrophy in the aging rat heart. J Am Coll Cardiol. 1986;8:1441-1448

56. Berk BC, Fujiwara K and Lehoux S. Ecm remodeling in hypertensive heart disease. J Clin Invest. 2007;117:568-575

57. Chen F, Kook H, Milewski R, Gitler AD, Lu MM, Li J, Nazarian R, Schnepp R, Jen K, Biben C, Runke G, Mackay JP, Novotny J, Schwartz RJ, Harvey RP, Mullins MC and Epstein JA. Hop is an unusual homeobox gene that modulates cardiac development. Cell. 2002;110:713-723

58. Heineke J and Molkentin JD. Regulation of cardiac hypertrophy by intracellular signalling pathways. Nature reviews. Molecular cell biology. 2006;7:589-600 
59. Townley-Tilson WH, Callis TE and Wang D. Micrornas 1, 133, and 206: Critical factors of skeletal and cardiac muscle development, function, and disease. Int J Biochem Cell Biol. 2010;42:12521255

60. van Rooij E, Quiat D, Johnson BA, Sutherland LB, Qi X, Richardson JA, Kelm RJ, Jr. and Olson EN. A family of micrornas encoded by myosin genes governs myosin expression and muscle performance. Dev Cell. 2009;17:662-673

61. van Rooij E, Sutherland LB, Qi X, Richardson JA, Hill J and Olson EN. Control of stress-dependent cardiac growth and gene expression by a microrna. Science. 2007;316:575-579

62. Callis TE, Pandya K, Seok HY, Tang RH, Tatsuguchi M, Huang ZP, Chen JF, Deng Z, Gunn B, Shumate J, Willis MS, Selzman CH and Wang DZ. Microrna-208a is a regulator of cardiac hypertrophy and conduction in mice. J Clin Invest. 2009;119:2772-2786

63. Tatsuguchi M, Seok HY, Callis TE, Thomson JM, Chen JF, Newman M, Rojas M, Hammond SM and Wang DZ. Expression of micrornas is dynamically regulated during cardiomyocyte hypertrophy. J Mol Cell Cardiol. 2007;42:1137-1141

64. Yang Y, Ago T, Zhai P, Abdellatif M and Sadoshima J. Thioredoxin 1 negatively regulates angiotensin ii-induced cardiac hypertrophy through upregulation of mir-98/let-7. Circ Res. 2011;108: 305-313

65. Wang K, Long B, Zhou J and Li PF. Mir-9 and nfatc3 regulate myocardin in cardiac hypertrophy. J Biol Chem. 2010;285:11903-11912

66. Yang T, Zhang GF, Chen XF, Gu HH, Fu SZ, Xu HF, Feng Q and Ni YM. Microrna-214 provokes cardiac hypertrophy via repression of ezh2. Biochem Biophys Res Commun. 2013;436:578-584

67. Tang CM, Liu FZ, Zhu JN, Fu YH, Lin QX, Deng CY, Hu ZQ, Yang H, Zheng XL, Cheng JD, Wu SL and Shan ZX. Myocyte-specific enhancer factor 2c: A novel target gene of mir-214-3p in suppressing angiotensin ii-induced cardiomyocyte hypertrophy. Scientific reports. 2016;6:36146

68. Haghikia A, Missol-Kolka E, Tsikas D, Venturini L, Brundiers S, Castoldi M, Muckenthaler MU, Eder M, Stapel B, Thum T, Haghikia A, Petrasch-Parwez E, Drexler H, Hilfiker-Kleiner D and Scherr M. Signal transducer and activator of transcription 3-mediated regulation of mir-199a-5p links cardiomyocyte and endothelial cell function in the heart: A key role for ubiquitin-conjugating enzymes. Eur Heart J. 2011;32:1287-1297

69. Rane S, He M, Sayed D, Yan L, Vatner D and Abdellatif M. An antagonism between the akt and beta-adrenergic signaling pathways mediated through their reciprocal effects on mir-199a-5p. Cellular signalling. 2010;22:1054-1062

70. da Costa Martins PA, Salic K, Gladka MM, Armand AS, Leptidis S, el Azzouzi H, Hansen A, Coenende Roo CJ, Bierhuizen MF, van der Nagel R, van Kuik J, de Weger R, de Bruin A, Condorelli G, Arbones ML, Eschenhagen T and De Windt LJ. Microrna-199b targets the nuclear kinase dyrk1a in an auto-amplification loop promoting calcineurin/nfat signalling. Nat Cell Biol. 2010;12:12201227

71. Lin Z, Murtaza I, Wang K, Jiao J, Gao J and Li PF. Mir-23a functions downstream of nfatc3 to regulate cardiac hypertrophy. Proc Natl Acad Sci U S A. 2009;106:12103-12108 
72. Ucar A, Gupta SK, Fiedler J, Erikci E, Kardasinski M, Batkai S, Dangwal S, Kumarswamy R, Bang C, Holzmann A, Remke J, Caprio M, Jentzsch C, Engelhardt S, Geisendorf S, Glas C, Hofmann TG, Nessling M, Richter K, Schiffer M, Carrier L, Napp LC, Bauersachs J, Chowdhury K and Thum T. The mirna-212/132 family regulates both cardiac hypertrophy and cardiomyocyte autophagy. Nat Commun. 2012;3:1078

73. Strum JC, Johnson JH, Ward J, Xie H, Feild J, Hester A, Alford A and Waters KM. Microrna 132 regulates nutritional stress-induced chemokine production through repression of sirt1. Mol Endocrinol. 2009;23:1876-1884

74. Zhang L, Huang D, Wang Q, Shen D, Wang Y, Chen B, Zhang J and Gai L. Mir-132 inhibits expression of sirt1 and induces pro-inflammatory processes of vascular endothelial inflammation through blockade of the srebp-1c metabolic pathway. Cardiovasc Drugs Ther. 2014;28:303-311

75. Johnson SC, Rabinovitch PS and Kaeberlein M. Mtor is a key modulator of ageing and age-related disease. Nature. 2013;493:338-345

76. Naga Prasad SV, Esposito G, Mao L, Koch WJ and Rockman HA. Gbetagamma-dependent phosphoinositide 3-kinase activation in hearts with in vivo pressure overload hypertrophy. J Biol Chem. 2000;275:4693-4698

77. Antos CL, McKinsey TA, Frey N, Kutschke W, McAnally J, Shelton JM, Richardson JA, Hill JA and Olson EN. Activated glycogen synthase-3 beta suppresses cardiac hypertrophy in vivo. Proc Natl Acad Sci U S A. 2002;99:907-912

78. Molkentin JD, Lu JR, Antos CL, Markham B, Richardson J, Robbins J, Grant SR and Olson EN. A calcineurin-dependent transcriptional pathway for cardiac hypertrophy. Cell. 1998;93:215-228

79. Kato H, Nakajima S, Saito Y, Takahashi S, Katoh R and Kitamura M. Mtorc1 serves er stress-triggered apoptosis via selective activation of the ire1-jnk pathway. Cell death and differentiation. 2012;19:310-320

80. McMullen JR, Sherwood MC, Tarnavski O, Zhang L, Dorfman AL, Shioi T and Izumo S. Inhibition of mtor signaling with rapamycin regresses established cardiac hypertrophy induced by pressure overload. Circulation. 2004;109:3050-3055

81. Shioi T, McMullen JR, Tarnavski O, Converso K, Sherwood MC, Manning WJ and Izumo S. Rapamycin attenuates load-induced cardiac hypertrophy in mice. Circulation. 2003;107:1664-1670

82. Sen S, Kundu BK, Wu HC, Hashmi SS, Guthrie P, Locke LW, Roy RJ, Matherne GP, Berr SS, Terwelp M, Scott B, Carranza S, Frazier OH, Glover DK, Dillmann WH, Gambello MJ, Entman ML and Taegtmeyer H. Glucose regulation of load-induced mtor signaling and er stress in mammalian heart. J Am Heart Assoc. 2013;2:e004796

83. Li Q, Xie J, Wang B, Li R, Bai J, Ding L, Gu R, Wang L and Xu B. Overexpression of microrna-99a attenuates cardiac hypertrophy. PloS one. 2016;11:e0148480

84. Naga Prasad SV, Duan ZH, Gupta MK, Surampudi VS, Volinia S, Calin GA, Liu CG, Kotwal A, Moravec CS, Starling RC, Perez DM, Sen S, Wu Q, Plow EF, Croce CM and Karnik S. Unique microrna profile in end-stage heart failure indicates alterations in specific cardiovascular signaling networks. $J$ Biol Chem. 2009;284:27487-27499 
85. Li R, Yan G, Zhang Q, Jiang Y, Sun H, Hu Y, Sun J and Xu B. Mir-145 inhibits isoproterenol-induced cardiomyocyte hypertrophy by targeting the expression and localization of gata6. FEBS letters. 2013;587:1754-1761

86. van Berlo JH, Elrod JW, van den Hoogenhof MM, York AJ, Aronow BJ, Duncan SA and Molkentin JD. The transcription factor gata-6 regulates pathological cardiac hypertrophy. Circ Res. 2010; 107:1032-1040

87. Liang Q, De Windt LJ, Witt SA, Kimball TR, Markham BE and Molkentin JD. The transcription factors gata4 and gata6 regulate cardiomyocyte hypertrophy in vitro and in vivo. J Biol Chem. 2001;276:30245-30253

88. Charron F, Paradis P, Bronchain O, Nemer G and Nemer M. Cooperative interaction between gata-4 and gata-6 regulates myocardial gene expression. Mol Cell Biol. 1999;19:4355-4365

89. Kuwabara Y, Horie T, Baba O, Watanabe S, Nishiga M, Usami S, Izuhara M, Nakao T, Nishino T, Otsu K, Kita T, Kimura T and Ono K. Microrna-451 exacerbates lipotoxicity in cardiac myocytes and high-fat diet-induced cardiac hypertrophy in mice through suppression of the $1 \mathrm{~kb} 1 / \mathrm{ampk}$ pathway. Circ Res. 2015;116:279-288

90. Vasan RS, Sullivan LM, D'Agostino RB, Roubenoff R, Harris T, Sawyer DB, Levy D and Wilson PW. Serum insulin-like growth factor $i$ and risk for heart failure in elderly individuals without a previous myocardial infarction: The framingham heart study. Ann Intern Med. 2003;139:642-648

91. Cantley LC. The phosphoinositide 3-kinase pathway. Science. 2002;296:1655-1657

92. Sayed D, Hong C, Chen IY, Lypowy J and Abdellatif M. Micrornas play an essential role in the development of cardiac hypertrophy. Circ Res. 2007;100:416-424

93. Chen JF, Mandel EM, Thomson JM, WU Q, Callis TE, Hammond SM, Conlon FL and Wang DZ. The role of microrna-1 and microrna-133 in skeletal muscle proliferation and differentiation. Nat Genet. 2006;38:228-233

94. Zhao Y, Samal E and Srivastava D. Serum response factor regulates a muscle-specific microrna that targets hand2 during cardiogenesis. Nature. 2005;436:214-220

95. Shan ZX, Lin QX, Fu YH, Deng CY, Zhou ZL, Zhu JN, Liu XY, Zhang YY, Li Y, Lin SG and Yu XY. Upregulated expression of mir-1/mir-206 in a rat model of myocardial infarction. Biochem Biophys Res Commun. 2009;381:597-601

96. Elia L, Contu R, Quintavalle M, Varrone F, Chimenti C, Russo MA, Cimino V, De Marinis L, Frustaci A, Catalucci D and Condorelli G. Reciprocal regulation of microrna-1 and insulin-like growth factor-1 signal transduction cascade in cardiac and skeletal muscle in physiological and pathological conditions. Circulation. 2009;120:2377-2385

97. Nagalingam RS, Sundaresan NR, Gupta MP, Geenen DL, Solaro RJ and Gupta M. A cardiacenriched microrna, mir-378, blocks cardiac hypertrophy by targeting ras signaling. J Biol Chem. 2013;288:11216-11232

98. Ganesan J, Ramanujam D, Sassi Y, Ahles A, Jentzsch C, Werfel S, Leierseder S, Loyer X, Giacca M, Zentilin L, Thum T, Laggerbauer B and Engelhardt S. Mir-378 controls cardiac hypertrophy by combined repression of mitogen-activated protein kinase pathway factors. Circulation. 2013; 127:2097-2106 
99. Wilkins BJ and Molkentin JD. Calcium-calcineurin signaling in the regulation of cardiac hypertrophy. Biochem Biophys Res Commun. 2004;322:1178-1191

100. van Rooij E, Sutherland LB, Liu N, Williams AH, McAnally J, Gerard RD, Richardson JA and Olson EN. A signature pattern of stress-responsive micrornas that can evoke cardiac hypertrophy and heart failure. Proc Natl Acad Sci U S A. 2006;103:18255-18260

101. Dong DL, Chen C, Huo R, Wang N, Li Z, Tu YJ, Hu JT, Chu X, Huang W and Yang BF. Reciprocal repression between microrna-133 and calcineurin regulates cardiac hypertrophy: A novel mechanism for progressive cardiac hypertrophy. Hypertension. 2010;55:946-952

102. Li Q, Lin X, Yang X and Chang J. Nfatc4 is negatively regulated in mir-133a-mediated cardiomyocyte hypertrophic repression. Am J Physiol Heart Circ Physiol. 2010;298:H1340-1347

103. Liu N, Bezprozvannaya S, Williams AH, Qi X, Richardson JA, Bassel-Duby R and Olson EN. Microrna-133a regulates cardiomyocyte proliferation and suppresses smooth muscle gene expression in the heart. Genes Dev. 2008;22:3242-3254

104. Myers R, Timofeyev V, Li N, Kim C, Ledford HA, Sirish P, Lau V, Zhang Y, Fayyaz K, Singapuri A, Lopez JE, Knowlton AA, Zhang XD and Chiamvimonvat N. Feedback mechanisms for cardiacspecific micrornas and camp signaling in electrical remodeling. Circ Arrhythm Electrophysiol. 2015;8:942-950

105. Hu F and Liu F. Targeting tissue-specific metabolic signaling pathways in aging: The promise and limitations. Protein Cell. 2014;5:21-35

106. Taegtmeyer H, Golfman L, Sharma S, Razeghi P and van Arsdall M. Linking gene expression to function: Metabolic flexibility in the normal and diseased heart. Annals of the New York Academy of Sciences. 2004;1015:202-213

107. Stanley WC, Recchia FA and Okere IC. Metabolic therapies for heart disease: Fish for prevention and treatment of cardiac failure? Cardiovasc Res. 2005;68:175-177

108. van Bilsen M, van Nieuwenhoven FA and van der Vusse GJ. Metabolic remodelling of the failing heart: Beneficial or detrimental? Cardiovasc Res. 2009;81:420-428

109. Guedes EC, Franca GS, Lino CA, Koyama FC, Moreira Ldo N, Alexandre JG, Barreto-Chaves ML, Galante PA and Diniz GP. Microrna expression signature is altered in the cardiac remodeling induced by high fat diets. Journal of cellular physiology. 2016;231:1771-1783

110. Zampetaki A, Kiechl S, Drozdov I, Willeit P, Mayr U, Prokopi M, Mayr A, Weger S, Oberhollenzer F, Bonora E, Shah A, Willeit J and Mayr M. Plasma microrna profiling reveals loss of endothelial mir-126 and other micrornas in type 2 diabetes. Circ Res. 2010;107:810-817

111. Keller DM, Clark EA and Goodman RH. Regulation of microrna-375 by camp in pancreatic betacells. Mol Endocrinol. 2012;26:989-999

112. El Ouaamari A, Baroukh N, Martens GA, Lebrun P, Pipeleers D and van Obberghen E. Mir-375 targets 3'-phosphoinositide-dependent protein kinase-1 and regulates glucose-induced biological responses in pancreatic beta-cells. Diabetes. 2008;57:2708-2717

113. el Azzouzi H, Leptidis S, Dirkx E, Hoeks J, van Bree B, Brand K, McClellan EA, Poels E, Sluimer JC, van den Hoogenhof MM, Armand AS, Yin X, Langley S, Bourajjaj M, Olieslagers S, Krishnan J, Vooijs M, Kurihara H, Stubbs A, Pinto YM, Krek W, Mayr M, da Costa Martins PA, Schrauwen P 
and De Windt LJ. The hypoxia-inducible microrna cluster mir-199a approximately 214 targets myocardial ppardelta and impairs mitochondrial fatty acid oxidation. Cell Metab. 2013;18:341354

114. Li B, Zhang Z, Zhang H, Quan K, Lu Y, Cai D and Ning G. Aberrant mir199a-5p/caveolin1/pparalpha axis in hepatic steatosis. J Mol Endocrinol. 2014;53:393-403

115. Iliopoulos D, Drosatos K, Hiyama Y, Goldberg IJ and Zannis VI. Microrna-370 controls the expression of microrna-122 and cpt1alpha and affects lipid metabolism. J Lipid Res. 2010;51:1513-1523

116. Soni MS, Rabaglia ME, BhatnagarS, Shang J, Ilkayeva O, Mynatt R, Zhou YP, Schadt EE, Thornberry NA, Muoio DM, Keller MP and Attie AD. Downregulation of carnitine acyl-carnitine translocase by mirnas 132 and 212 amplifies glucose-stimulated insulin secretion. Diabetes. 2014;63:3805-3814

117. Spillmann F, Trimpert C, Peng J, Eckerle LG, Staudt A, Warstat K, Felix SB, Pieske B, Tschope C and Van Linthout S. High-density lipoproteins reduce palmitate-induced cardiomyocyte apoptosis in an ampk-dependent manner. Biochem Biophys Res Commun. 2015;466:272-277

118. Rottiers V, Najafi-Shoushtari SH, Kristo F, Gurumurthy S, Zhong L, Li Y, Cohen DE, Gerszten RE, Bardeesy N, Mostoslavsky R and Naar AM. Micrornas in metabolism and metabolic diseases. Cold Spring Harbor symposia on quantitative biology. 2011;76:225-233

119. Varrone F, Gargano B, Carullo P, Di Silvestre D, De Palma A, Grasso L, Di Somma C, Mauri P, Benazzi L, Franzone A, Jotti GS, Bang ML, Esposito G, Colao A, Condorelli G and Catalucci D. The circulating level of fabp3 is an indirect biomarker of microrna-1. J Am Coll Cardiol. 2013;61:88-95

120. Wang J, Song Y, Zhang Y, Xiao H, Sun Q, Hou N, Guo S, Wang Y, Fan K, Zhan D, Zha L, Cao Y, Li Z, Cheng X, Zhang Y and Yang X. Cardiomyocyte overexpression of mir-27b induces cardiac hypertrophy and dysfunction in mice. Cell Res. 2012;22:516-527

121. Razeghi P, Young ME, Alcorn JL, Moravec CS, Frazier OH and Taegtmeyer H. Metabolic gene expression in fetal and failing human heart. Circulation. 2001;104:2923-2931

122. Barger PM and Kelly DP. Ppar signaling in the control of cardiac energy metabolism. Trends Cardiovasc Med. 2000;10:238-245

123. Di Lisa F, Canton M, Menabo R, Kaludercic N and Bernardi P. Mitochondria and cardioprotection. Heart Fail Rev. 2007;12:249-260

124. Kim HR, Roe JS, Lee JE, Cho EJ and Youn HD. P53 regulates glucose metabolism by mir-34a. Biochem Biophys Res Commun. 2013;437:225-231

125. Zhu H, Shyh-Chang N, Segre AV, Shinoda G, Shah SP, Einhorn WS, Takeuchi A, Engreitz JM, Hagan JP, Kharas MG, Urbach A, Thornton JE, Triboulet R, Gregory RI, Consortium D, Investigators M, Altshuler D and Daley GQ. The lin28/let-7 axis regulates glucose metabolism. Cell. 2011;147:8194

126. Frost RJ and Olson EN. Control of glucose homeostasis and insulin sensitivity by the let-7 family of micrornas. Proc Natl Acad Sci U S A. 2011;108:21075-21080

127. Li J, Ren Y, Shi E, Tan Z, Xiong J, Yan L and Jiang X. Inhibition of the let-7 family micrornas induces cardioprotection against ischemia-reperfusion injury in diabetic rats. Ann Thorac Surg. 2016;102: 829-835 
128. Viswanathan SR, Daley GQ and Gregory RI. Selective blockade of microrna processing by lin28. Science. 2008;320:97-100

129. Rybak A, Fuchs H, Smirnova L, Brandt C, Pohl EE, Nitsch R and Wulczyn FG. A feedback loop comprising lin-28 and let-7 controls pre-let-7 maturation during neural stem-cell commitment. Nat Cell Biol. 2008;10:987-993

130. Zhang M, Sun D, Li S, Pan X, Zhang X, Zhu D, Li C, Zhang R, Gao E and Wang H. Lin28a protects against cardiac ischaemia/reperfusion injury in diabetic mice through the insulin-pi3k-mtor pathway. J Cell Mol Med. 2015;19:1174-1182

131. Grueter CE, van Rooij E, Johnson BA, DeLeon SM, Sutherland LB, Qi X, Gautron L, Elmquist JK, Bassel-Duby R and Olson EN. A cardiac microrna governs systemic energy homeostasis by regulation of med13. Cell. 2012;149:671-683

132. Yang WM, Jeong HJ, Park SY and Lee W. Saturated fatty acid-induced mir-195 impairs insulin signaling and glycogen metabolism in hepg2 cells. FEBS letters. 2014;588:3939-3946

133. Trajkovski M, Hausser J, Soutschek J, Bhat B, Akin A, Zavolan M, Heim MH and Stoffel M. Micrornas 103 and 107 regulate insulin sensitivity. Nature. 2011;474:649-653

134. Jordan SD, Kruger M, Willmes DM, Redemann N, Wunderlich FT, Bronneke HS, Merkwirth C, Kashkar H, Olkkonen VM, Bottger T, Braun T, Seibler J and Bruning JC. Obesity-induced overexpression of mirna-143 inhibits insulin-stimulated akt activation and impairs glucose metabolism. Nat Cell Biol. 2011;13:434-446

135. Horie T, Ono K, Nishi H, Iwanaga Y, Nagao K, Kinoshita M, Kuwabara Y, Takanabe R, Hasegawa K, Kita T and Kimura T. Microrna-133 regulates the expression of glut4 by targeting Klf15 and is involved in metabolic control in cardiac myocytes. Biochem Biophys Res Commun. 2009;389: $315-320$

136. Chen YH, Heneidi S, Lee JM, Layman LC, Stepp DW, Gamboa GM, Chen BS, Chazenbalk G and Azziz R. Mirna-93 inhibits glut4 and is overexpressed in adipose tissue of polycystic ovary syndrome patients and women with insulin resistance. Diabetes. 2013;62:2278-2286

137. Lu H, Buchan RJ and Cook SA. Microrna-223 regulates glut4 expression and cardiomyocyte glucose metabolism. Cardiovasc Res. 2010;86:410-420

138. Hu F and Liu F. Mitochondrial stress: A bridge between mitochondrial dysfunction and metabolic diseases? Cellular signalling. 2011;23:1528-1533

139. Paradies G, Petrosillo G, Pistolese M, Di Venosa N, Federici A and Ruggiero FM. Decrease in mitochondrial complex i activity in ischemic/reperfused rat heart: Involvement of reactive oxygen species and cardiolipin. Circ Res. 2004;94:53-59

140. Boengler K, Hilfiker-Kleiner D, Heusch $G$ and Schulz R. Inhibition of permeability transition pore opening by mitochondrial stat3 and its role in myocardial ischemia/reperfusion. Basic Res Cardiol. 2010;105:771-785

141. Hoshino A, Mita Y, Okawa Y, Ariyoshi M, Iwai-Kanai E, Ueyama T, Ikeda K, Ogata T and Matoba S. Cytosolic p53 inhibits parkin-mediated mitophagy and promotes mitochondrial dysfunction in the mouse heart. Nat Commun. 2013;4:2308 
142. Handschin C and Spiegelman BM. Peroxisome proliferator-activated receptor gamma coactivator 1 coactivators, energy homeostasis, and metabolism. Endocr Rev. 2006;27:728-735

143. Wenz T. Mitochondria and pgc-1alpha in aging and age-associated diseases. J Aging Res. 2011; 2011:810619

144. Aoi W, Naito Y, Mizushima K, Takanami Y, Kawai Y, Ichikawa H and Yoshikawa T. The microrna mir-696 regulates pgc-1\{alpha\} in mouse skeletal muscle in response to physical activity. Am J Physiol Endocrinol Metab. 2010;298:E799-806

145. Nishi H, Ono K, Iwanaga Y, Horie T, Nagao K, Takemura G, Kinoshita M, Kuwabara Y, Mori RT, Hasegawa K, Kita T and Kimura T. Microrna-15b modulates cellular atp levels and degenerates mitochondria via arl2 in neonatal rat cardiac myocytes. J Biol Chem. 2010;285:4920-4930

146. Sun LL, Jiang BG, Li WT, Zou JJ, Shi YQ and Liu ZM. Microrna-15a positively regulates insulin synthesis by inhibiting uncoupling protein-2 expression. Diabetes Res Clin Pract. 2011;91:94-100

147. Das S, Bedja D, Campbell N, Dunkerly B, Chenna V, Maitra A and Steenbergen C. Mir-181c regulates the mitochondrial genome, bioenergetics, and propensity for heart failure in vivo. PloS one. 2014;9:e96820

148. Chu B, Wu T, Miao L, Mei Y and Wu M. Mir-181a regulates lipid metabolism via idh1. Scientific reports. 2015;5:8801

149. Aschrafi A, Schwechter AD, Mameza MG, Natera-Naranjo O, Gioio AE and Kaplan BB. Microrna-338 regulates local cytochrome c oxidase iv mrna levels and oxidative phosphorylation in the axons of sympathetic neurons. J Neurosci. 2008;28:12581-12590

150. Wang K, Long B, Jiao JQ, Wang JX, Liu JP, Li Q and Li PF. Mir-484 regulates mitochondrial network through targeting fis1. Nat Commun. 2012;3:781

151. Hekimi S, Lapointe J and Wen Y. Taking a "good" look at free radicals in the aging process. Trends Cell Biol. 2011;21:569-576

152. Magenta A, Greco S, Capogrossi MC, Gaetano C and Martelli F. Nitric oxide, oxidative stress, and p66shc interplay in diabetic endothelial dysfunction. BioMed research international. 2014;2014: 193095

153. Haendeler J, Hoffmann J, Diehl JF, Vasa M, Spyridopoulos I, Zeiher AM and Dimmeler S. Antioxidants inhibit nuclear export of telomerase reverse transcriptase and delay replicative senescence of endothelial cells. Circ Res. 2004;94:768-775

154. Tsutsui M, Shimokawa H, Otsuji Y, Ueta Y, Sasaguri Y and Yanagihara N. Nitric oxide synthases and cardiovascular diseases: Insights from genetically modified mice. Circ J. 2009;73:986-993

155. Faraonio R, Salerno P, Passaro F, Sedia C, laccio A, Bellelli R, Nappi TC, Comegna M, Romano S, Salvatore G, Santoro M and Cimino F. A set of mirnas participates in the cellular senescence program in human diploid fibroblasts. Cell death and differentiation. 2012;19:713-721

156. Chan SY, Zhang YY, Hemann C, Mahoney CE, Zweier JL and Loscalzo J. Microrna-210 controls mitochondrial metabolism during hypoxia by repressing the iron-sulfur cluster assembly proteins iscu1/2. Cell Metab. 2009;10:273-284

157. Puissegur MP, Mazure NM, Bertero T, Pradelli L, Grosso S, Robbe-Sermesant K, Maurin T, Lebrigand K, Cardinaud B, Hofman V, Fourre S, Magnone V, Ricci JE, Pouyssegur J, Gounon P, Hofman 
P, Barbry P and Mari B. Mir-210 is overexpressed in late stages of lung cancer and mediates mitochondrial alterations associated with modulation of hif- 1 activity. Cell death and differentiation. 2011;18:465-478

158. Kyrychenko S, Kyrychenko V, Badr MA, Ikeda Y, Sadoshima J and Shirokova N. Pivotal role of mir-448 in the development of ros-induced cardiomyopathy. Cardiovasc Res. 2015;108:324-334

159. Tsutsui H, Kinugawa S and Matsushima S. Oxidative stress and heart failure. Am J Physiol Heart Circ Physiol. 2011;301:H2181-2190

160. Nojiri H, Shimizu T, Funakoshi M, Yamaguchi O, Zhou H, Kawakami S, Ohta Y, Sami M, Tachibana T, Ishikawa H, Kurosawa H, Kahn RC, Otsu K and Shirasawa T. Oxidative stress causes heart failure with impaired mitochondrial respiration. J Biol Chem. 2006;281:33789-33801

161. Bai XY, Ma Y, Ding R, Fu B, Shi S and Chen XM. Mir-335 and mir-34a promote renal senescence by suppressing mitochondrial antioxidative enzymes. Journal of the American Society of Nephrology: JASN. 2011;22:1252-1261

162. Fleissner F, Jazbutyte V, Fiedler J, Gupta SK, Yin X, Xu Q, Galuppo P, Kneitz S, Mayr M, Ertl G, Bauersachs $J$ and Thum T. Short communication: Asymmetric dimethylarginine impairs angiogenic progenitor cell function in patients with coronary artery disease through a microrna-21dependent mechanism. Circ Res. 2010;107:138-143

163. Vasa-Nicotera M, Chen H, Tucci P, Yang AL, Saintigny G, Menghini R, Mahe C, Agostini M, Knight RA, Melino G and Federici M. Mir-146a is modulated in human endothelial cell with aging. Atherosclerosis. 2011;217:326-330

164. Wang L, Yuan Y, Li J, Ren H, Cai Q, Chen X, Liang H, Shan H, Fu ZD, Gao X, Lv Y, Yang B and Zhang Y. Microrna-1 aggravates cardiac oxidative stress by post-transcriptional modification of the antioxidant network. Cell Stress Chaperones. 2015;20:411-420

165. Yu M, Liu Y, Zhang B, Shi Y, Cui L and Zhao X. Inhibiting microrna-144 abates oxidative stress and reduces apoptosis in hearts of streptozotocin-induced diabetic mice. Cardiovasc Pathol. 2015; 24:375-381

166. Poulsen HE, Specht E, Broedbaek K, Henriksen T, Ellervik C, Mandrup-Poulsen T, Tonnesen M, Nielsen PE, Andersen HU and Weimann A. Rna modifications by oxidation: A novel disease mechanism? Free Radic Biol Med. 2012;52:1353-1361

167. Wang JX, Gao J, Ding SL, Wang K, Jiao JQ, Wang Y, Sun T, Zhou LY, Long B, Zhang XJ, Li Q, Liu JP, Feng C, Liu J, Gong Y, Zhou Z and Li PF. Oxidative modification of mir-184 enables it to target bcl-xl and bcl-w. Mol Cell. 2015;59:50-61

168. Linnane AW, Marzuki S, Ozawa T and Tanaka M. Mitochondrial DNA mutations as an important contributor to ageing and degenerative diseases. Lancet. 1989;1:642-645

169. Khrapko K, Bodyak N, Thilly WG, van Orsouw NJ, Zhang X, Coller HA, Perls TT, Upton M, Vijg J and Wei JY. Cell-by-cell scanning of whole mitochondrial genomes in aged human heart reveals a significant fraction of myocytes with clonally expanded deletions. Nucleic Acids Res. 1999;27: 2434-2441

170. Rezzani R, Stacchiotti A and Rodella LF. Morphological and biochemical studies on aging and autophagy. Ageing Res Rev. 2012;11:10-31 
171. Terzioglu M and Larsson NG. Mitochondrial dysfunction in mammalian ageing. Novartis Found Symp. 2007;287:197-208; discussion 208-113

172. Wang K and Klionsky DJ. Mitochondria removal by autophagy. Autophagy. 2011;7:297-300

173. Dutta D, Calvani R, Bernabei R, Leeuwenburgh C and Marzetti E. Contribution of impaired mitochondrial autophagy to cardiac aging: Mechanisms and therapeutic opportunities. Circ Res. 2012;110:1125-1138

174. Rubinsztein DC, Marino G and Kroemer G. Autophagy and aging. Cell. 2011;146:682-695

175. Inuzuka Y, Okuda J, Kawashima T, Kato T, Niizuma S, Tamaki Y, Iwanaga Y, Yoshida Y, Kosugi R, Watanabe-Maeda K, Machida Y, Tsuji S, Aburatani H, Izumi T, Kita T and Shioi T. Suppression of phosphoinositide 3-kinase prevents cardiac aging in mice. Circulation. 2009;120:1695-1703

176. Terman A, Kurz T, Navratil M, Arriaga EA and Brunk UT. Mitochondrial turnover and aging of longlived postmitotic cells: The mitochondrial-lysosomal axis theory of aging. Antioxidants \& redox signaling. 2010;12:503-535

177. Gibbings D, Mostowy S, Jay F, Schwab Y, Cossart P and Voinnet O. Selective autophagy degrades dicer and ago2 and regulates mirna activity. Nat Cell Biol. 2012;14:1314-1321

178. Sakurai K, Amarzguioui M, Kim DH, Alluin J, Heale B, Song MS, Gatignol A, Behlke MA and Rossi JJ. A role for human dicer in pre-risc loading of sirnas. Nucleic Acids Res. 2011;39:1510-1525

179. Wan G, Xie W, Liu Z, Xu W, Lao Y, Huang N, Cui K, Liao M, He J, Jiang Y, Yang BB, Xu H, Xu N and Zhang Y. Hypoxia-induced mir155 is a potent autophagy inducer by targeting multiple players in the mtor pathway. Autophagy. 2014;10:70-79

180. Cao DJ, Wang ZV, Battiprolu PK, Jiang N, Morales CR, Kong Y, Rothermel BA, Gillette TG and Hill JA. Histone deacetylase (hdac) inhibitors attenuate cardiac hypertrophy by suppressing autophagy. Proc Natl Acad Sci U S A. 2011;108:4123-4128

181. Nakai A, Yamaguchi O, Takeda T, Higuchi Y, Hikoso S, Taniike M, Omiya S, Mizote I, Matsumura Y, Asahi M, Nishida K, Hori M, Mizushima N and Otsu K. The role of autophagy in cardiomyocytes in the basal state and in response to hemodynamic stress. Nat Med. 2007;13:619-624

182. Zhu H, Wu H, Liu X, Li B, Chen Y, Ren X, Liu CG and Yang JM. Regulation of autophagy by a beclin 1-targeted microrna, mir-30a, in cancer cells. Autophagy. 2009;5:816-823

183. Zou Z, Wu L, Ding H, Wang Y, Zhang Y, Chen X, Chen X, Zhang CY, Zhang Q and Zen K. Microrna30a sensitizes tumor cells to cis-platinum via suppressing beclin 1-mediated autophagy. J Biol Chem. 2012;287:4148-4156

184. Pan W, Zhong Y, Cheng C, Liu B, Wang L, Li A, Xiong L and Liu S. Mir-30-regulated autophagy mediates angiotensin ii-induced myocardial hypertrophy. PloS one. 2013;8:e53950

185. Duisters RF, Tijsen AJ, Schroen B, Leenders JJ, Lentink V, van der Made I, Herias V, van Leeuwen RE, Schellings MW, Barenbrug P, Maessen JG, Heymans S, Pinto YM and Creemers EE. Mir-133 and mir-30 regulate connective tissue growth factor: Implications for a role of micrornas in myocardial matrix remodeling. Circ Res. 2009;104:170-178, 176p following 178

186. Wu H, Wang F, Hu S, Yin C, Li X, Zhao S, Wang J and Yan X. Mir-20a and mir-106b negatively regulate autophagy induced by leucine deprivation via suppression of ulk1 expression in c2c12 myoblasts. Cellular signalling. 2012;24:2179-2186 
187. Frankel LB, Wen J, Lees M, Hoyer-Hansen M, Farkas T, Krogh A, Jaattela M and Lund AH. Microrna-101 is a potent inhibitor of autophagy. EMBO J. 2011;30:4628-4641

188. Wu D, Jiang H, Chen S and Zhang H. Inhibition of microrna-101 attenuates hypoxia/reoxygenationinduced apoptosis through induction of autophagy in h9c2 cardiomyocytes. Mol Med Rep. 2015;11:3988-3994

189. Li Z, Song Y, Liu L, Hou N, An X, Zhan D, Li Y, Zhou L, Li P, Yu L, Xia J, Zhang Y, Wang J and Yang X. Mir-199a impairs autophagy and induces cardiac hypertrophy through mtor activation. Cell death and differentiation. 2015

190. Wang C, Wang S, Zhao P, Wang X, Wang J, Wang Y, Song L, Zou Y and Hui R. Mir-221 promotes cardiac hypertrophy in vitro through the modulation of p27 expression. J Cell Biochem. 2012; 113:2040-2046

191. Su M, Wang J, Wang C, Wang X, Dong W, Qiu W, Wang Y, Zhao X, Zou Y, Song L, Zhang L and Hui R. Microrna-221 inhibits autophagy and promotes heart failure by modulating the p27/cdk2/mtor axis. Cell death and differentiation. 2015;22:986-999

192. Su M, Chen Z, Wang C, Song L, Zou Y, Zhang L, Hui R and Wang J. Cardiac-specific overexpression of mir-222 induces heart failure and inhibits autophagy in mice. Cell Physiol Biochem. 2016;39: 1503-1511

193. Huang Y, Guerrero-Preston R and Ratovitski EA. Phospho-deltanp63alpha-dependent regulation of autophagic signaling through transcription and micro-rna modulation. Cell cycle. 2012;11: 1247-1259

194. Bergmann O, Bhardwaj RD, Bernard S, Zdunek S, Barnabe-Heider F, Walsh S, Zupicich J, Alkass K, Buchholz BA, Druid H, Jovinge S and Frisen J. Evidence for cardiomyocyte renewal in humans. Science. 2009;324:98-102

195. Whelan RS, Kaplinskiy V and Kitsis RN. Cell death in the pathogenesis of heart disease: Mechanisms and significance. Annu Rev Physiol. 2010;72:19-44

196. Kajstura J, Cheng W, Sarangarajan R, Li P, Li B, Nitahara JA, Chapnick S, Reiss K, Olivetti G and Anversa P. Necrotic and apoptotic myocyte cell death in the aging heart of fischer 344 rats. Am J Physiol. 1996;271:H1215-1228

197. Kung G, Konstantinidis K and Kitsis RN. Programmed necrosis, not apoptosis, in the heart. Circ Res. 2011;108:1017-1036

198. Kroemer G, Galluzzi L, Vandenabeele P, Abrams J, Alnemri ES, Baehrecke EH, Blagosklonny MV, El-Deiry WS, Golstein P, Green DR, Hengartner M, Knight RA, Kumar S, Lipton SA, Malorni W, Nunez G, Peter ME, Tschopp J, Yuan J, Piacentini M, Zhivotovsky B, Melino G and Nomenclature Committee on Cell D. Classification of cell death: Recommendations of the nomenclature committee on cell death 2009. Cell death and differentiation. 2009;16:3-11

199. Chiong M, Wang ZV, Pedrozo Z, Cao DJ, Troncoso R, Ibacache M, Criollo A, Nemchenko A, Hill JA and Lavandero S. Cardiomyocyte death: Mechanisms and translational implications. Cell Death Dis. 2011;2:e244

200. Guerra S, Leri A, Wang X, Finato N, Di Loreto C, Beltrami CA, Kajstura J and Anversa P. Myocyte death in the failing human heart is gender dependent. Circ Res. 1999;85:856-866 
201. Liu J, van Mil A, Vrijsen K, Zhao J, Gao L, Metz CH, Goumans MJ, Doevendans PA and Sluijter JP. Microrna-155 prevents necrotic cell death in human cardiomyocyte progenitor cells via targeting rip1. J Cell Mol Med. 2011;15:1474-1482

202. Crow MT, Mani K, Nam YJ and Kitsis RN. The mitochondrial death pathway and cardiac myocyte apoptosis. Circ Res. 2004;95:957-970

203. Gustafsson AB and Gottlieb RA. Heart mitochondria: Gates of life and death. Cardiovasc Res. 2008;77:334-343

204. Hengartner MO. The biochemistry of apoptosis. Nature. 2000;407:770-776

205. Matsumoto S, Sakata Y, Suna S, Nakatani D, Usami M, Hara M, Kitamura T, Hamasaki T, Nanto S, Kawahara $Y$ and Komuro I. Circulating p53-responsive micrornas are predictive indicators of heart failure after acute myocardial infarction. Circ Res. 2013;113:322-326

206. Desai VG, J CK, Vijay V, Moland CL, Herman EH, Lee T, Han T, Lewis SM, Davis KJ, Muskhelishvili L, Kerr S and Fuscoe JC. Early biomarkers of doxorubicin-induced heart injury in a mouse model. Toxicol Appl Pharmacol. 2014;281:221-229

207. Boon RA, lekushi K, Lechner S, Seeger T, Fischer A, Heydt S, Kaluza D, Treguer K, Carmona G, Bonauer A, Horrevoets AJ, Didier N, Girmatsion Z, Biliczki P, Ehrlich JR, Katus HA, Muller OJ, Potente M, Zeiher AM, Hermeking H and Dimmeler S. Microrna-34a regulates cardiac ageing and function. Nature. 2013;495:107-110

208. Yang Y, Cheng HW, Qiu Y, Dupee D, Noonan M, Lin YD, Fisch S, Unno K, Sereti KI and Liao R. Microrna-34a plays a key role in cardiac repair and regeneration following myocardial infarction. Circ Res. 2015;117:450-459

209. Bonauer A, Carmona G, Iwasaki M, Mione M, Koyanagi M, Fischer A, Burchfield J, Fox H, Doebele C, Ohtani K, Chavakis E, Potente M, Tjwa M, Urbich C, Zeiher AM and Dimmeler S. Microrna-92a controls angiogenesis and functional recovery of ischemic tissues in mice. Science. 2009;324: $1710-1713$

210. Liu H, Li G, Zhao W and Hu Y. Inhibition of mir-92a may protect endothelial cells after acute myocardial infarction in rats: Role of klf2/4. Medical science monitor: international medical journal of experimental and clinical research. 2016;22:2451-2462

211. Jiang C, Ji N, Luo G, Ni S, Zong J, Chen Z, Bao D, Gong X and Fu T. The effects and mechanism of mir-92a and mir-126 on myocardial apoptosis in mouse ischemia-reperfusion model. Cell Biochem Biophys. 2014;70:1901-1906

212. Zhang L, Zhou M, Qin G, Weintraub NL and Tang Y. Mir-92a regulates viability and angiogenesis of endothelial cells under oxidative stress. Biochem Biophys Res Commun. 2014;446:952-958

213. Tijsen AJ, van der Made I, van den Hoogenhof MM, Wijnen WJ, van Deel ED, de Groot NE, Alekseev S, Fluiter K, Schroen B, Goumans MJ, van der Velden J, Duncker DJ, Pinto YM and Creemers EE. The microrna-15 family inhibits the tgfbeta-pathway in the heart. Cardiovasc Res. 2014;104:61-71

214. Porrello ER, Mahmoud Al, Simpson E, Johnson BA, Grinsfelder D, Canseco D, Mammen PP, Rothermel BA, Olson EN and Sadek HA. Regulation of neonatal and adult mammalian heart regeneration by the mir-15 family. Proc Natl Acad Sci U S A. 2013;110:187-192 
215. Thum T, Galuppo P, Wolf C, Fiedler J, Kneitz S, van Laake LW, Doevendans PA, Mummery CL, Borlak J, Haverich A, Gross C, Engelhardt S, Ertl G and Bauersachs J. Micrornas in the human heart: A clue to fetal gene reprogramming in heart failure. Circulation. 2007;116:258-267

216. Hullinger TG, Montgomery RL, Seto AG, Dickinson BA, Semus HM, Lynch JM, Dalby CM, Robinson K, Stack C, Latimer PA, Hare JM, Olson EN and van Rooij E. Inhibition of mir-15 protects against cardiac ischemic injury. Circ Res. 2012;110:71-81

217. Li X, Zeng Z, Li Q, Xu Q, Xie J, Hao H, Luo G, Liao W, Bin J, Huang X and Liao Y. Inhibition of microrna-497 ameliorates anoxia/reoxygenation injury in cardiomyocytes by suppressing cell apoptosis and enhancing autophagy. Oncotarget. 2015;6:18829-18844

218. Zhu H, Yang Y, Wang Y, Li J, Schiller PW and Peng T. Microrna-195 promotes palmitate-induced apoptosis in cardiomyocytes by down-regulating sirt1. Cardiovasc Res. 2011;92:75-84

219. Ye Y, Hu Z, Lin Y, Zhang C and Perez-Polo JR. Downregulation of microrna-29 by antisense inhibitors and a ppar-gamma agonist protects against myocardial ischaemia-reperfusion injury. Cardiovasc Res. 2010;87:535-544

220. Li J, Li Y, Jiao J, Wang J, Li Y, Qin D and Li P. Mitofusin 1 is negatively regulated by microrna 140 in cardiomyocyte apoptosis. Mol Cell Biol. 2014;34:1788-1799

221. Wang H, Bei Y, Huang P, Zhou Q, Shi J, Sun Q, Zhong J, Li X, Kong X and Xiao J. Inhibition of mir155 protects against Ips-induced cardiac dysfunction and apoptosis in mice. Mol Ther Nucleic Acids. 2016;5:e374

222. Zhu WS, Guo W, Zhu JN, Tang CM, Fu YH, Lin QX, Tan N and Shan ZX. Hsp90aa1: A novel target gene of mir-1 in cardiac ischemia/reperfusion injury. Scientific reports. 2016;6:24498

223. Chen A, Li G, Chen L, Guo J and Liu Y. Downregulation of microrna-100 protects h202-induced apoptosis in neonatal cardiomyocytes. International journal of clinical and experimental pathology. 2015;8:5491-5496

224. Hong S, Lee J, Seo HH, Lee CY, Yoo KJ, Kim SM, Lee S, Hwang KC and Choi E. Na(+)-ca(2+) exchanger targeting mir-132 prevents apoptosis of cardiomyocytes under hypoxic condition by suppressing ca(2+) overload. Biochem Biophys Res Commun. 2015;460:931-937

225. Yan HL, Xue G, Mei Q, Wang YZ, Ding FX, Liu MF, Lu MH, Tang Y, Yu HY and Sun SH. Repression of the mir-17-92 cluster by 553 has an important function in hypoxia-induced apoptosis. EMBO J. 2009;28:2719-2732

226. Song S, Seo HH, Lee SY, Lee CY, Lee J, Yoo KJ, Yoon C, Choi E, Hwang KC and Lee S. Microrna17-mediated down-regulation of apoptotic protease activating factor 1 attenuates apoptosome formation and subsequent apoptosis of cardiomyocytes. Biochem Biophys Res Commun. 2015; 465:299-304

227. Xu J, Tang Y, Bei Y, Ding S, Che L, Yao J, Wang H, Lv D and Xiao J. Mir-19b attenuates h2o2-induced apoptosis in rat h9c2 cardiomyocytes via targeting pten. Oncotarget. 2016;7:10870-10878

228. Cheng Y and Zhang C. Microrna-21 in cardiovascular disease. J Cardiovasc Trans/ Res. 2010;3: 251-255 
229. Dong S, Cheng Y, Yang J, Li J, Liu X, Wang X, Wang D, Krall TJ, Delphin ES and Zhang C. Microrna expression signature and the role of microrna-21 in the early phase of acute myocardial infarction. J Biol Chem. 2009;284:29514-29525

230. Yang F, Liu W, Yan X, Zhou H, Zhang H, Liu J, Yu M, Zhu X and Ma K. Effects of mir-21 on cardiac microvascular endothelial cells after acute myocardial infarction in rats: Role of phosphatase and tensin homolog (pten)/vascular endothelial growth factor (vegf) signal pathway. Medical science monitor : international medical journal of experimental and clinical research. 2016;22: 3562-3575

231. Meng F, Henson R, Wehbe-Janek H, Ghoshal K, Jacob ST and Patel T. Microrna-21 regulates expression of the pten tumor suppressor gene in human hepatocellular cancer. Gastroenterology. 2007;133:647-658

232. Yang Q, Yang K and Li A. Microrna-21 protects against ischemia-reperfusion and hypoxia-reperfusion-induced cardiocyte apoptosis via the phosphatase and tensin homolog/akt-dependent mechanism. Mol Med Rep. 2014;9:2213-2220

233. Cheng Y, Liu X, Zhang S, Lin Y, Yang J and Zhang C. Microrna-21 protects against the h(2)o(2)induced injury on cardiac myocytes via its target gene pdcd4. J Mol Cell Cardiol. 2009;47:5-14

234. Asangani IA, Rasheed SA, Nikolova DA, Leupold JH, Colburn NH, Post S and Allgayer H. Microrna-21 (mir-21) post-transcriptionally downregulates tumor suppressor pdcd4 and stimulates invasion, intravasation and metastasis in colorectal cancer. Oncogene. 2008;27:2128-2136

235. Zhu S, Si ML, Wu H and Mo YY. Microrna-21 targets the tumor suppressor gene tropomyosin 1 (tpm1). J Biol Chem. 2007;282:14328-14336

236. Huang W, Tian SS, Hang PZ, Sun C, Guo J and Du ZM. Combination of microrna-21 and microrna$146 \mathrm{a}$ attenuates cardiac dysfunction and apoptosis during acute myocardial infarction in mice. Mol Ther Nucleic Acids. 2016;5:e296

237. Qian L, Van Laake LW, Huang Y, Liu S, Wendland MF and Srivastava D. Mir-24 inhibits apoptosis and represses bim in mouse cardiomyocytes. The Journal of experimental medicine. 2011;208: 549-560

238. Yang X, Qin Y, Shao S, Yu Y, Zhang C, Dong H, Lv G and Dong S. Microrna-214 inhibits left ventricular remodeling in an acute myocardial infarction rat model by suppressing cellular apoptosis via the phosphatase and tensin homolog (pten). Int Heart J. 2016;57:247-250

239. Ke ZP, Xu P, Shi Y and Gao AM. Microrna-93 inhibits ischemia-reperfusion induced cardiomyocyte apoptosis by targeting pten. Oncotarget. 2016;7:28796-28805

240. Fiedler J, Jazbutyte V, Kirchmaier BC, Gupta SK, Lorenzen J, Hartmann D, Galuppo P, Kneitz S, Pena JT, Sohn-Lee C, Loyer X, Soutschek J, Brand T, Tuschl T, Heineke J, Martin U, Schulte-Merker S, Ertl G, Engelhardt S, Bauersachs J and Thum T. Microrna-24 regulates vascularity after myocardial infarction. Circulation. 2011;124:720-730

241. Xu C, Hu Y, Hou L, Ju J, Li X, Du N, Guan X, Liu Z, Zhang T, Qin W, Shen N, Bilal MU, Lu Y, Zhang Y and Shan H. Beta-blocker carvedilol protects cardiomyocytes against oxidative stress-induced apoptosis by up-regulating mir-133 expression. J Mol Cell Cardiol. 2014;75:111-121 
242. He B, Xiao J, Ren AJ, Zhang YF, Zhang H, Chen M, Xie B, Gao XG and Wang YW. Role of mir-1 and mir-133a in myocardial ischemic postconditioning. J Biomed Sci. 2011;18:22

243. Roca-Alonso L, Castellano L, Mills A, Dabrowska AF, Sikkel MB, Pellegrino L, Jacob J, Frampton AE, Krell J, Coombes RC, Harding SE, Lyon AR and Stebbing J. Myocardial mir-30 downregulation triggered by doxorubicin drives alterations in beta-adrenergic signaling and enhances apoptosis. Cell Death Dis. 2015;6:e1754

244. Li J, Donath S, Li Y, Qin D, Prabhakar BS and Li P. Mir-30 regulates mitochondrial fission through targeting p53 and the dynamin-related protein-1 pathway. PLoS genetics. 2010;6:e1000795

245. Rane S, He M, Sayed D, Vashistha H, Malhotra A, Sadoshima J, Vatner DE, Vatner SF and Abdellatif M. Downregulation of mir-199a derepresses hypoxia-inducible factor-1alpha and sirtuin 1 and recapitulates hypoxia preconditioning in cardiac myocytes. Circ Res. 2009;104:879-886

246. Yang J, Chen L, Ding J, Zhang J, Fan Z, Yang C, Yu Q and Yang J. Cardioprotective effect of mirna-22 on hypoxia/reoxygenation induced cardiomyocyte injury in neonatal rats. Gene. 2016;579:17-22

247. Li G, Wang G, Ma L, Guo J, Song J, Ma L and Zhao X. Mir-22 regulates starvation-induced autophagy and apoptosis in cardiomyocytes by targeting p38alpha. Biochem Biophys Res Commun. 2016; 478:1165-1172

248. Ruan W, Xu JM, Li SB, Yuan LQ and Dai RP. Effects of down-regulation of microrna-23a on tnfalpha-induced endothelial cell apoptosis through caspase-dependent pathways. Cardiovasc Res. 2012;93:623-632

249. Mao J, Lv Z and Zhuang Y. Microrna-23a is involved in tumor necrosis factor-alpha induced apoptosis in mesenchymal stem cells and myocardial infarction. Exp Mol Pathol. 2014;97:23-30

250. Ma H, Wang X, Ha T, Gao M, Liu L, Wang R, Yu K, Kalbfleisch JH, Kao RL, Williams DL and Li C. Microrna-125b prevents cardiac dysfunction in polymicrobial sepsis by targeting traf6 mediated nfkappab activation and p53 mediated apoptotic signaling. J Infect Dis. 2016

251. Tang Y, Wang Y, Park KM, Hu Q, Teoh JP, Broskova Z, Ranganathan P, Jayakumar C, Li J, Su H, Tang Y, Ramesh G and Kim IM. Microrna-150 protects the mouse heart from ischaemic injury by regulating cell death. Cardiovasc Res. 2015;106:387-397

252. Song G, Zhang Y and Wang L. Microrna-206 targets notch3, activates apoptosis, and inhibits tumor cell migration and focus formation. J Biol Chem. 2009;284:31921-31927

253. Paulus WJ and Tschope C. A novel paradigm for heart failure with preserved ejection fraction: Comorbidities drive myocardial dysfunction and remodeling through coronary microvascular endothelial inflammation. J Am Coll Cardiol. 2013;62:263-271

254. Collier P, Watson CJ, Voon V, Phelan D, Jan A, Mak G, Martos R, Baugh JA, Ledwidge MT and McDonald KM. Can emerging biomarkers of myocardial remodelling identify asymptomatic hypertensive patients at risk for diastolic dysfunction and diastolic heart failure? European journal of heart failure. 2011;13:1087-1095

255. Lam CS, Lyass A, Kraigher-Krainer E, Massaro JM, Lee DS, Ho JE, Levy D, Redfield MM, Pieske BM, Benjamin EJ and Vasan RS. Cardiac dysfunction and noncardiac dysfunction as precursors of heart failure with reduced and preserved ejection fraction in the community. Circulation. 2011; 124:24-30 
256. Lakatta EG. So! What's aging? Is cardiovascular aging a disease? J Mol Cell Cardiol. 2015;83:1-13

257. Lakatta EG, Wang M and Najjar SS. Arterial aging and subclinical arterial disease are fundamentally intertwined at macroscopic and molecular levels. Med Clin North Am. 2009;93:583-604, Table of Contents

258. Campisi J, Andersen JK, Kapahi P and Melov S. Cellular senescence: A link between cancer and age-related degenerative disease? Semin Cancer Biol. 2011;21:354-359

259. Freund A, Patil CK and Campisi J. P38mapk is a novel DNA damage response-independent regulator of the senescence-associated secretory phenotype. EMBO J. 2011;30:1536-1548

260. Brandes RP, Fleming I and Busse R. Endothelial aging. Cardiovasc Res. 2005;66:286-294

261. Hajra L, Evans Al, Chen M, Hyduk SJ, Collins T and Cybulsky MI. The nf-kappa b signal transduction pathway in aortic endothelial cells is primed for activation in regions predisposed to atherosclerotic lesion formation. Proc Natl Acad Sci U S A. 2000;97:9052-9057

262. Jongstra-Bilen J, Haidari M, Zhu SN, Chen M, Guha D and Cybulsky MI. Low-grade chronic inflammation in regions of the normal mouse arterial intima predisposed to atherosclerosis. The Journal of experimental medicine. 2006;203:2073-2083

263. Warboys CM, de Luca A, Amini N, Luong L, Duckles H, Hsiao S, White A, Biswas S, Khamis R, Chong CK, Cheung WM, Sherwin SJ, Bennett MR, Gil J, Mason JC, Haskard DO and Evans PC. Disturbed flow promotes endothelial senescence via a p53-dependent pathway. Arterioscler Thromb Vasc Biol. 2014;34:985-995

264. Harris TA, Yamakuchi M, Ferlito M, Mendell JT and Lowenstein CJ. Microrna-126 regulates endothelial expression of vascular cell adhesion molecule 1. Proc Natl Acad Sci U S A. 2008;105: 1516-1521

265. Menghini R, Casagrande V, Cardellini M, Martelli E, Terrinoni A, Amati F, Vasa-Nicotera M, Ippoliti A, Novelli G, Melino G, Lauro R and Federici M. Microrna 217 modulates endothelial cell senescence via silent information regulator 1. Circulation. 2009;120:1524-1532

266. Suarez Y, Fernandez-Hernando C, Pober JS and Sessa WC. Dicer dependent micrornas regulate gene expression and functions in human endothelial cells. Circ Res. 2007;100:1164-1173

267. Kuehbacher A, Urbich C, Zeiher AM and Dimmeler S. Role of dicer and drosha for endothelial microrna expression and angiogenesis. Circ Res. 2007;101:59-68

268. Qin X, Wang X, Wang Y, Tang Z, Cui Q, Xi J, Li YS, Chien S and Wang N. Microrna-19a mediates the suppressive effect of laminar flow on cyclin d1 expression in human umbilical vein endothelial cells. Proc Natl Acad Sci U S A. 2010;107:3240-3244

269. Hergenreider E, Heydt S, Treguer K, Boettger T, Horrevoets AJ, Zeiher AM, Scheffer MP, Frangakis AS, Yin X, Mayr M, Braun T, Urbich C, Boon RA and Dimmeler S. Atheroprotective communication between endothelial cells and smooth muscle cells through mirnas. Nat Cell Biol. 2012;14:249256

270. Li K, Ching D, Luk FS and Raffai RL. Apolipoprotein e enhances microrna-146a in monocytes and macrophages to suppress nuclear factor-kappab-driven inflammation and atherosclerosis. Circ Res. 2015;117:e1-e11 
271. Cheng HS, Sivachandran N, Lau A, Boudreau E, Zhao JL, Baltimore D, Delgado-Olguin P, Cybulsky $\mathrm{MI}$ and Fish JE. Microrna-146 represses endothelial activation by inhibiting pro-inflammatory pathways. EMBO Mol Med. 2013;5:1017-1034

272. Ma S, Tian XY, Zhang Y, Mu C, Shen H, Bismuth J, Pownall HJ, Huang Y and Wong WT. E-selectintargeting delivery of micrornas by microparticles ameliorates endothelial inflammation and atherosclerosis. Scientific reports. 2016;6:22910

273. Zernecke A, Bidzhekov K, Noels H, Shagdarsuren E, Gan L, Denecke B, Hristov M, Koppel T, Jahantigh MN, Lutgens E, Wang S, Olson EN, Schober A and Weber C. Delivery of microrna-126 by apoptotic bodies induces cxcl12-dependent vascular protection. Science signaling. 2009;2:ra81

274. Hu J, Zeng L, Huang J, Wang G and Lu H. Mir-126 promotes angiogenesis and attenuates inflammation after contusion spinal cord injury in rats. Brain Res. 2015;1608:191-202

275. Olivieri F, Spazzafumo L, Santini G, Lazzarini R, Albertini MC, Rippo MR, Galeazzi R, Abbatecola AM, Marcheselli F, Monti D, Ostan R, Cevenini E, Antonicelli R, Franceschi C and Procopio AD. Age-related differences in the expression of circulating micrornas: Mir-21 as a new circulating marker of inflammaging. Mech Ageing Dev. 2012;133:675-685

276. Schetter AJ, Nguyen GH, Bowman ED, Mathe EA, Yuen ST, Hawkes JE, Croce CM, Leung SY and Harris CC. Association of inflammation-related and microrna gene expression with cancerspecific mortality of colon adenocarcinoma. Clin Cancer Res. 2009;15:5878-5887

277. Zhou J, Wang KC, Wu W, Subramaniam S, Shyy JY, Chiu JJ, Li JY and Chien S. Microrna-21 targets peroxisome proliferators-activated receptor-alpha in an autoregulatory loop to modulate flowinduced endothelial inflammation. Proc Natl Acad Sci U S A. 2011;108:10355-10360

278. Akhtar S, Hartmann P, Karshovska E, Rinderknecht FA, Subramanian P, Gremse F, Grommes J, Jacobs M, Kiessling F, Weber C, Steffens S and Schober A. Endothelial hypoxia-inducible factorlalpha promotes atherosclerosis and monocyte recruitment by upregulating microrna-19a. Hypertension. 2015;66:1220-1226

279. Wang KC, Garmire LX, Young A, Nguyen P, Trinh A, Subramaniam S, Wang N, Shyy JY, Li YS and Chien S. Role of microrna-23b in flow-regulation of rb phosphorylation and endothelial cell growth. Proc Natl Acad Sci U S A. 2010;107:3234-3239

280. Wang KC, Nguyen P, Weiss A, Yeh YT, Chien HS, Lee A, Teng D, Subramaniam S, Li YS and Chien S. Microrna-23b regulates cyclin-dependent kinase-activating kinase complex through cyclin $\mathrm{h}$ repression to modulate endothelial transcription and growth under flow. Arterioscler Thromb Vasc Biol. 2014;34:1437-1445

281. Son DJ, Kumar S, Takabe W, Kim CW, Ni CW, Alberts-Grill N, Jang IH, Kim S, Kim W, Won Kang S, Baker AH, Woong Seo J, Ferrara KW and Jo H. The atypical mechanosensitive microrna-712 derived from pre-ribosomal rna induces endothelial inflammation and atherosclerosis. Nat Commun. 2013;4:3000

282. Sun X, Icli B, Wara AK, Belkin N, He S, Kobzik L, Hunninghake GM, Vera MP, Registry M, Blackwell TS, Baron RM and Feinberg MW. Microrna-181b regulates nf-kappab-mediated vascular inflammation. J Clin Invest. 2012;122:1973-1990 
283. Sun X, He S, Wara AK, Icli B, Shvartz E, Tesmenitsky Y, Belkin N, Li D, Blackwell TS, Sukhova GK, Croce $K$ and Feinberg MW. Systemic delivery of microrna-181b inhibits nuclear factor-kappab activation, vascular inflammation, and atherosclerosis in apolipoprotein e-deficient mice. Circ Res. 2014;114:32-40

284. Loyer X, Potteaux S, Vion AC, Guerin CL, Boulkroun S, Rautou PE, Ramkhelawon B, Esposito B, Dalloz M, Paul JL, Julia P, Maccario J, Boulanger CM, Mallat Z and Tedgui A. Inhibition of microrna-92a prevents endothelial dysfunction and atherosclerosis in mice. Circ Res. 2014;114: 434-443

285. Liao YC, Wang YS, Guo YC, Lin WL, Chang MH and Juo SH. Let-7g improves multiple endothelial functions through targeting transforming growth factor-beta and sirt-1 signaling. J Am Coll Cardiol. 2014;63:1685-1694

286. Wang X, Wang HX, Li YL, Zhang CC, Zhou CY, Wang L, Xia YL, Du J and Li HH. Microrna let-7i negatively regulates cardiac inflammation and fibrosis. Hypertension. 2015;66:776-785

287. Hartmann P, Zhou Z, Natarelli L, Wei Y, Nazari-Jahantigh M, Zhu M, Grommes J, Steffens S, Weber $\mathrm{C}$ and Schober A. Endothelial dicer promotes atherosclerosis and vascular inflammation by mirna-103-mediated suppression of klf4. Nat Commun. 2016;7:10521

288. Hartmann P, Zhou Z, Natarelli L, Wei Y, Nazari-Jahantigh M, Zhu M, Grommes J, Steffens S, Weber $C$ and Schober A. Corrigendum: Endothelial dicer promotes atherosclerosis and vascular inflammation by mirna-103-mediated suppression of klf4. Nat Commun. 2016;7:11907

289. Kanters E, Pasparakis M, Gijbels MJ, Vergouwe MN, Partouns-Hendriks I, Fijneman RJ, Clausen BE, Forster I, Kockx MM, Rajewsky K, Kraal G, Hofker MH and de Winther MP. Inhibition of nfkappab activation in macrophages increases atherosclerosis in Idl receptor-deficient mice. J Clin Invest. 2003;112:1176-1185

290. Pinto AR, Godwin JW, Chandran A, Hersey L, llinykh A, Debuque R, Wang L and Rosenthal NA. Age-related changes in tissue macrophages precede cardiac functional impairment. Aging (Albany NY). 2014;6:399-413

291. Bujak M, Kweon HJ, Chatila K, Li N, Taffet G and Frangogiannis NG. Aging-related defects are associated with adverse cardiac remodeling in a mouse model of reperfused myocardial infarction. J Am Coll Cardiol. 2008;51:1384-1392

292. Fordham JB, Naqvi AR and Nares S. Regulation of mir-24, mir-30b, and mir-142-3p during macrophage and dendritic cell differentiation potentiates innate immunity. Journal of leukocyte biology. 2015;98:195-207

293. Lin HS, Gong JN, Su R, Chen MT, Song L, Shen C, Wang F, Ma YN, Zhao HL, Yu J, Li WW, Huang LX, XU XH and Zhang JW. Mir-199a-5p inhibits monocyte/macrophage differentiation by targeting the activin a type $1 \mathrm{~b}$ receptor gene and finally reducing c/ebpalpha expression. Journal of leukocyte biology. 2014;96:1023-1035

294. Naqvi AR, Fordham JB and Nares S. Mir-24, mir-30b, and mir-142-3p regulate phagocytosis in myeloid inflammatory cells. J Immunol. 2015;194:1916-1927

295. Bettencourt P, Marion S, Pires D, Santos LF, Lastrucci C, Carmo N, Blake J, Benes V, Griffiths G, Neyrolles $\mathrm{O}$, Lugo-Villarino $\mathrm{G}$ and Anes $\mathrm{E}$. Actin-binding protein regulation by micrornas as a 
novel microbial strategy to modulate phagocytosis by host cells: The case of n-wasp and mir142-3p. Front Cell Infect Microbiol. 2013;3:19

296. Das A, Sinha M, Datta S, Abas M, Chaffee S, Sen CK and Roy S. Monocyte and macrophage plasticity in tissue repair and regeneration. Am J Pathol. 2015;185:2596-2606

297. Sica A, Erreni M, Allavena P and Porta C. Macrophage polarization in pathology. Cell Mol Life Sci. 2015;72:4111-4126

298. Lichtnekert J, Kawakami T, Parks WC and Duffield JS. Changes in macrophage phenotype as the immune response evolves. Curr Opin Pharmacol. 2013;13:555-564

299. Graff JW, Dickson AM, Clay G, McCaffrey AP and Wilson ME. Identifying functional micrornas in macrophages with polarized phenotypes. J Biol Chem. 2012;287:21816-21825

300. O'Connell RM, Taganov KD, Boldin MP, Cheng G and Baltimore D. Microrna-155 is induced during the macrophage inflammatory response. Proc Natl Acad Sci U S A. 2007;104:1604-1609

301. Nazari-Jahantigh M, Wei Y, Noels H, Akhtar S, Zhou Z, Koenen RR, Heyll K, Gremse F, Kiessling F, Grommes J, Weber $\mathrm{C}$ and Schober A. Microrna-155 promotes atherosclerosis by repressing bcl6 in macrophages. J Clin Invest. 2012;122:4190-4202

302. Sredni ST, Gadd S, Jafari N and Huang CC. A parallel study of mrna and microrna profiling of peripheral blood in young adult women. Front Genet. 2011;2:49

303. Frasca D, Diaz A, Romero M, Ferracci F and Blomberg BB. Micrornas mir-155 and mir-16 decrease aid and e47 in b cells from elderly individuals. J Immunol. 2015;195:2134-2140

304. Frasca D, Diaz A, Romero M and Blomberg BB. Human peripheral late/exhausted memory b cells express a senescent-associated secretory phenotype and preferentially utilize metabolic signaling pathways. Exp Gerontol. 2016;87:113-120

305. Corsten MF, Papageorgiou A, Verhesen W, Carai P, Lindow M, Obad S, Summer G, Coort SL, Hazebroek M, van Leeuwen R, Gijbels MJ, Wijnands E, Biessen EA, De Winther MP, Stassen FR, Carmeliet P, Kauppinen S, Schroen B and Heymans S. Microrna profiling identifies microrna-155 as an adverse mediator of cardiac injury and dysfunction during acute viral myocarditis. Circ Res. 2012;111:415-425

306. Heymans S, Corsten MF, Verhesen W, Carai P, van Leeuwen RE, Custers K, Peters T, Hazebroek M, Stoger L, Wijnands E, Janssen BJ, Creemers EE, Pinto YM, Grimm D, Schurmann N, Vigorito E, Thum T, Stassen F, Yin X, Mayr M, de Windt LJ, Lutgens E, Wouters K, de Winther MP, Zacchigna S, Giacca M, van Bilsen M, Papageorgiou AP and Schroen B. Macrophage microrna-155 promotes cardiac hypertrophy and failure. Circulation. 2013;128:1420-1432

307. Donners MM, Wolfs IM, Stoger LJ, van der Vorst EP, Pottgens CC, Heymans S, Schroen B, Gijbels MJ and de Winther MP. Hematopoietic mir155 deficiency enhances atherosclerosis and decreases plaque stability in hyperlipidemic mice. PloS one. 2012;7:e35877

308. Du F, Yu F, Wang Y, Hui Y, Carnevale K, Fu M, Lu H and Fan D. Microrna-155 deficiency results in decreased macrophage inflammation and attenuated atherogenesis in apolipoprotein e-deficient mice. Arterioscler Thromb Vasc Biol. 2014;34:759-767 
309. Wei Y, Zhu M, Corbalan-Campos J, Heyll K, Weber C and Schober A. Regulation of csf1r and bcl6 in macrophages mediates the stage-specific effects of microrna-155 on atherosclerosis. Arterioscler Thromb Vasc Biol. 2015;35:796-803

310. Liu YL, Wu W, Xue Y, Gao M, Yan Y, Kong Q, Pang Y and Yang F. Microrna-21 and -146b are involved in the pathogenesis of murine viral myocarditis by regulating th-17 differentiation. Arch Virol. 2013;158:1953-1963

311. Zhang X, Azhar G and Wei JY. The expression of microrna and microrna clusters in the aging heart. PloS one. 2012;7:e34688

312. Schroen B and Heymans S. Small but smart--micrornas in the centre of inflammatory processes during cardiovascular diseases, the metabolic syndrome, and ageing. Cardiovasc Res. 2012;93: 605-613

313. Zhu D, Pan C, Li L, Bian Z, Lv Z, Shi L, Zhang J, Li D, Gu H, Zhang CY, Liu Y and Zen K. Microrna17/20a/106a modulate macrophage inflammatory responses through targeting signal-regulatory protein alpha. The Journal of allergy and clinical immunology. 2013;132:426-436 e428

314. Njock MS, Cheng HS, Dang LT, Nazari-Jahantigh M, Lau AC, Boudreau E, Roufaiel M, Cybulsky MI, Schober A and Fish JE. Endothelial cells suppress monocyte activation through secretion of extracellular vesicles containing antiinflammatory micrornas. Blood. 2015;125:3202-3212

315. DeQuach JA, Mezzano V, Miglani A, Lange S, Keller GM, Sheikh F and Christman KL. Simple and high yielding method for preparing tissue specific extracellular matrix coatings for cell culture. PloS one. 2010;5:e13039

316. Gupta A, Kaur CD, Jangdey M and Saraf S. Matrix metalloproteinase enzymes and their naturally derived inhibitors: Novel targets in photocarcinoma therapy. Ageing Res Rev. 2014;13:65-74

317. Borlaug BA and Paulus WJ. Heart failure with preserved ejection fraction: Pathophysiology, diagnosis, and treatment. Eur Heart J. 2011;32:670-679

318. Barasch E, Gottdiener JS, Aurigemma G, Kitzman DW, Han J, Kop WJ and Tracy RP. The relationship between serum markers of collagen turnover and cardiovascular outcome in the elderly: The cardiovascular health study. Circulation. Heart failure. 2011;4:733-739

319. Lu D, Aroonsakool N, Yokoyama U, Patel HH and Insel PA. Increase in cellular cyclic amp concentrations reverses the profibrogenic phenotype of cardiac myofibroblasts: A novel therapeutic approach for cardiac fibrosis. Mol Pharmacol. 2013;84:787-793

320. Gaspard GJ, MacLean J, Rioux D and Pasumarthi KB. A novel beta-adrenergic response element regulates both basal and agonist-induced expression of cyclin-dependent kinase 1 gene in cardiac fibroblasts. Am J Physiol Cell Physiol. 2014;306:C540-550

321. Tomoda Y, Kikumoto K, Isumi Y, Katafuchi T, Tanaka A, Kangawa K, Dohi K and Minamino N. Cardiac fibroblasts are major production and target cells of adrenomedullin in the heart in vitro. Cardiovasc Res. 2001;49:721-730

322. Cieslik KA, Taffet GE, Carlson S, Hermosillo J, Trial J and Entman ML. Immune-inflammatory dysregulation modulates the incidence of progressive fibrosis and diastolic stiffness in the aging heart. J Mol Cell Cardiol. 2011;50:248-256 
323. Ghosh AK, Bradham WS, Gleaves LA, De Taeye B, Murphy SB, Covington JW and Vaughan DE. Genetic deficiency of plasminogen activator inhibitor-1 promotes cardiac fibrosis in aged mice: Involvement of constitutive transforming growth factor-beta signaling and endothelial-tomesenchymal transition. Circulation. 2010;122:1200-1209

324. Herum KM, Lunde IG, Skrbic B, Florholmen G, Behmen D, Sjaastad I, Carlson CR, Gomez MF and Christensen G. Syndecan-4 signaling via nfat regulates extracellular matrix production and cardiac myofibroblast differentiation in response to mechanical stress. J Mol Cell Cardiol. 2013; 54:73-81

325. Westermann D, Lindner D, Kasner M, Zietsch C, Savvatis K, Escher F, von Schlippenbach J, Skurk C, Steendijk P, Riad A, Poller W, Schultheiss HP and Tschope C. Cardiac inflammation contributes to changes in the extracellular matrix in patients with heart failure and normal ejection fraction. Circulation. Heart failure. 2011;4:44-52

326. Van Linthout S, Miteva K and Tschope C. Crosstalk between fibroblasts and inflammatory cells. Cardiovasc Res. 2014;102:258-269

327. Ghosh SS, Salloum FN, Abbate A, Krieg R, Sica DA, Gehr TW and Kukreja RC. Curcumin prevents cardiac remodeling secondary to chronic renal failure through deactivation of hypertrophic signaling in rats. Am J Physiol Heart Circ Physiol. 2010;299:H975-984

328. Vasquez C, Benamer N and Morley GE. The cardiac fibroblast: Functional and electrophysiological considerations in healthy and diseased hearts. J Cardiovasc Pharmacol. 2011;57:380-388

329. Chen MM, Lam A, Abraham JA, Schreiner GF and Joly AH. Ctgf expression is induced by tgf- beta in cardiac fibroblasts and cardiac myocytes: A potential role in heart fibrosis. J Mol Cell Cardiol. 2000;32:1805-1819

330. Davis BN, Hilyard AC, Lagna G and Hata A. Smad proteins control drosha-mediated microrna maturation. Nature. 2008;454:56-61

331. Kumarswamy R, Volkmann I, Jazbutyte V, Dangwal S, Park DH and Thum T. Transforming growth factor-beta-induced endothelial-to-mesenchymal transition is partly mediated by microrna-21. Arterioscler Thromb Vasc Biol. 2012;32:361-369

332. Volkmann I, Kumarswamy R, Pfaff N, Fiedler J, Dangwal S, Holzmann A, Batkai S, Geffers R, Lother A, Hein L and Thum T. Microrna-mediated epigenetic silencing of sirtuin1 contributes to impaired angiogenic responses. Circ Res. 2013;113:997-1003

333. Kumarswamy R, Volkmann I, Beermann J, Napp LC, Jabs O, Bhayadia R, Melk A, Ucar A, Chowdhury K, Lorenzen JM, Gupta SK, Batkai S and Thum T. Vascular importance of the mir-212/132 cluster. Eur Heart J. 2014;35:3224-3231

334. van Almen GC, Verhesen W, van Leeuwen RE, van de Vrie M, Eurlings C, Schellings MW, Swinnen M, Cleutjens JP, van Zandvoort MA, Heymans S and Schroen B. Microrna-18 and microrna-19 regulate ctgf and tsp-1 expression in age-related heart failure. Aging Cell. 2011;10:769-779

335. Zou M, Wang F, Gao R, Wu J, Ou Y, Chen X, Wang T, Zhou X, Zhu W, Li P, Qi LW, Jiang T, Wang W, Li C, Chen J, He Q and Chen Y. Autophagy inhibition of hsa-mir-19a-3p/19b-3p by targeting tgf-beta rii during tgf-beta1-induced fibrogenesis in human cardiac fibroblasts. Scientific reports. 2016;6: 24747 
336. Hu Y, Matkovich SJ, Hecker PA, Zhang Y, Edwards JR and Dorn GW, 2nd. Epitranscriptional orchestration of genetic reprogramming is an emergent property of stress-regulated cardiac micrornas. Proc Natl Acad Sci U S A. 2012;109:19864-19869

337. Jazbutyte V, Fiedler J, Kneitz S, Galuppo P, Just A, Holzmann A, Bauersachs J and Thum T. Microrna-22 increases senescence and activates cardiac fibroblasts in the aging heart. Age (Dordr). 2013;35:747-762

338. Huang ZP, Chen J, Seok HY, Zhang Z, Kataoka M, Hu X and Wang DZ. Microrna-22 regulates cardiac hypertrophy and remodeling in response to stress. Circ Res. 2013;112:1234-1243

339. Gurha P, Abreu-Goodger C, Wang T, Ramirez MO, Drumond AL, van Dongen S, Chen Y, Bartonicek N, Enright AJ, Lee B, Kelm RJ, Jr., Reddy AK, Taffet GE, Bradley A, Wehrens XH, Entman ML and Rodriguez A. Targeted deletion of microrna-22 promotes stress-induced cardiac dilation and contractile dysfunction. Circulation. 2012;125:2751-2761

340. Huang Y, Qi Y, Du JQ and Zhang DF. Microrna-34a regulates cardiac fibrosis after myocardial infarction by targeting smad4. Expert Opin Ther Targets. 2014;18:1355-1365

341. Bernardo BC, Gao XM, Winbanks CE, Boey EJ, Tham YK, Kiriazis H, Gregorevic P, Obad S, Kauppinen S, Du XJ, Lin RC and McMullen JR. Therapeutic inhibition of the mir-34 family attenuates pathological cardiac remodeling and improves heart function. Proc Natl Acad Sci U S A. 2012;109: $17615-17620$

342. Emanueli $C$ and Thum T. Mirnage-34 induces cardiac damage. Cell Res. 2013;23:866-867

343. Loffredo FS, Pancoast JR and Lee RT. Keep pnuts in your heart. Circ Res. 2013;113:97-99

344. Villar AV, Garcia R, Merino D, Llano M, Cobo M, Montalvo C, Martin-Duran R, Hurle MA and Nistal JF. Myocardial and circulating levels of microrna-21 reflect left ventricular fibrosis in aortic stenosis patients. Int J Cardiol. 2013;167:2875-2881

345. Thum T, Gross C, Fiedler J, Fischer T, Kissler S, Bussen M, Galuppo P, Just S, Rottbauer W, Frantz S, Castoldi M, Soutschek J, Koteliansky V, Rosenwald A, Basson MA, Licht JD, Pena JT, Rouhanifard SH, Muckenthaler MU, Tuschl T, Martin GR, Bauersachs J and Engelhardt S. Microrna-21 contributes to myocardial disease by stimulating map kinase signalling in fibroblasts. Nature. 2008;456: 980-984

346. Roy S, Khanna S, Hussain SR, Biswas S, Azad A, Rink C, Gnyawali S, Shilo S, Nuovo GJ and Sen CK. Microrna expression in response to murine myocardial infarction: Mir-21 regulates fibroblast metalloprotease-2 via phosphatase and tensin homologue. Cardiovasc Res. 2009;82:21-29

347. Lorenzen JM, Schauerte C, Hubner A, Kolling M, Martino F, Scherf K, Batkai S, Zimmer K, Foinquinos A, Kaucsar T, Fiedler J, Kumarswamy R, Bang C, Hartmann D, Gupta SK, Kielstein J, Jungmann A, Katus HA, Weidemann F, Muller OJ, Haller H and Thum T. Osteopontin is indispensible for ap1-mediated angiotensin ii-related mir-21 transcription during cardiac fibrosis. Eur Heart J. 2015;36:2184-2196

348. Liang H, Zhang C, Ban T, Liu Y, Mei L, Piao X, Zhao D, Lu Y, Chu W and Yang B. A novel reciprocal loop between microrna-21 and tgfbetariii is involved in cardiac fibrosis. Int J Biochem Cell Biol. 2012;44:2152-2160 
349. Kriegel AJ, Liu Y, Fang Y, Ding X and Liang M. The mir-29 family: Genomics, cell biology, and relevance to renal and cardiovascular injury. Physiol Genomics. 2012;44:237-244

350. Roncarati R, Viviani Anselmi C, Losi MA, Papa L, Cavarretta E, Da Costa Martins P, Contaldi C, Saccani Jotti G, Franzone A, Galastri L, Latronico MV, Imbriaco M, Esposito G, De Windt L, Betocchi S and Condorelli G. Circulating mir-29a, among other up-regulated micrornas, is the only biomarker for both hypertrophy and fibrosis in patients with hypertrophic cardiomyopathy. J Am Coll Cardiol. 2014;63:920-927

351. Dawson K, Wakili R, Ordog B, Clauss S, Chen Y, Iwasaki Y, Voigt N, Qi XY, Sinner MF, Dobrev D, Kaab S and Nattel S. Microrna29: A mechanistic contributor and potential biomarker in atrial fibrillation. Circulation. 2013;127:1466-1475, 1475e1461-1428

352. Tao H, Chen ZW, Yang JJ and Shi KH. Microrna-29a suppresses cardiac fibroblasts proliferation via targeting vegf-a/mapk signal pathway. Int J Biol Macromol. 2016;88:414-423

353. Abonnenc M, Nabeebaccus AA, Mayr U, Barallobre-Barreiro J, Dong X, Cuello F, Sur S, Drozdov I, Langley SR, Lu R, Stathopoulou K, Didangelos A, Yin X, Zimmermann WH, Shah AM, Zampetaki A and Mayr M. Extracellular matrix secretion by cardiac fibroblasts: Role of microrna-29b and microrna-30c. Circ Res. 2013;113:1138-1147

354. Zhang Y, Huang XR, Wei LH, Chung AC, Yu CM and Lan HY. Mir-29b as a therapeutic agent for angiotensin ii-induced cardiac fibrosis by targeting tgf-beta/smad3 signaling. Mol Ther. 2014;22: 974-985

355. Zhu JN, Chen R, Fu YH, Lin QX, Huang S, Guo LL, Zhang MZ, Deng CY, Zou X, Zhong SL, Yang M, Zhuang J, Yu XY and Shan ZX. Smad3 inactivation and mir-29b upregulation mediate the effect of carvedilol on attenuating the acute myocardium infarction-induced myocardial fibrosis in rat. PloS one. 2013;8:e75557

356. Castoldi G, Di Gioia CR, Bombardi C, Catalucci D, Corradi B, Gualazzi MG, Leopizzi M, Mancini M, Zerbini G, Condorelli G and Stella A. Mir-133a regulates collagen 1a1: Potential role of mir-133a in myocardial fibrosis in angiotensin ii-dependent hypertension. Journal of cellular physiology. 2012;227:850-856

357. Chen S, Puthanveetil P, Feng B, Matkovich SJ, Dorn GW, 2nd and Chakrabarti S. Cardiac mir-133a overexpression prevents early cardiac fibrosis in diabetes. J Cell Mol Med. 2014;18:415-421

358. Wang J, Huang W, Xu R, Nie Y, Cao X, Meng J, Xu X, Hu S and Zheng Z. Microrna-24 regulates cardiac fibrosis after myocardial infarction. J Cell Mol Med. 2012;16:2150-2160

359. Beaumont J, Lopez B, Hermida N, Schroen B, San Jose G, Heymans S, Valencia F, Gomez-Doblas JJ, De Teresa E, Diez J and Gonzalez A. Microrna-122 down-regulation may play a role in severe myocardial fibrosis in human aortic stenosis through tgf-beta1 up-regulation. Clinical science. 2014;126:497-506

360. Pan Z, Sun X, Shan H, Wang N, Wang J, Ren J, Feng S, Xie L, Lu C, Yuan Y, Zhang Y, Wang Y, Lu $Y$ and Yang B. Microrna-101 inhibited postinfarct cardiac fibrosis and improved left ventricular compliance via the fbj osteosarcoma oncogene/transforming growth factor-beta1 pathway. Circulation. 2012;126:840-850 
361. Zhao X, Wang K, Liao Y, Zeng Q, Li Y, Hu F, Liu Y, Meng K, Qian C, Zhang Q, Guan H, Feng K, Zhou Y, Du Y and Chen Z. Microrna-101a inhibits cardiac fibrosis induced by hypoxia via targeting tgfbetari on cardiac fibroblasts. Cell Physiol Biochem. 2015;35:213-226

362. Fan H, Ma L, Fan B, Wu J, Yang Z and Wang L. Role of pdgfr-beta/pi3k/akt signaling pathway in pdgf-bb induced myocardial fibrosis in rats. Am J Trans/ Res. 2014;6:714-723

363. Li R, Xiao J, Qing X, Xing J, Xia Y, Qi J, Liu X, Zhang S, Sheng X, Zhang X and Ji X. Sp1 mediates a therapeutic role of mir-7a/b in angiotensin ii-induced cardiac fibrosis via mechanism involving the tgf-beta and mapks pathways in cardiac fibroblasts. PloS one. 2015;10:e0125513

364. Deng P, Chen L, Liu Z, Ye P, Wang S, Wu J, Yao Y, Sun Y, Huang X, Ren L, Zhang A, Wang K, Wu C, Yue Z, Xu X and Chen M. Microrna-150 inhibits the activation of cardiac fibroblasts by regulating c-myb. Cell Physiol Biochem. 2016;38:2103-2122

365. Nagpal V, Rai R, Place AT, Murphy SB, Verma SK, Ghosh AK and Vaughan DE. Mir-125b is critical for fibroblast-to-myofibroblast transition and cardiac fibrosis. Circulation. 2016;133:291-301

366. Anversa P, Rota M, Urbanek K, Hosoda T, Sonnenblick EH, Leri A, Kajstura J and Bolli R. Myocardial aging--a stem cell problem. Basic Res Cardiol. 2005;100:482-493 




\section{CHAPTER 3}

\section{MicroRNAs Act as Pleiotropic Regulators of Cellular Processes Underlying Heart Failure:}

\section{A High-Throughput Phenotypical Screen in Three Primary Cardiac Cell Types}

\section{In preparation}

Robin Verjans ${ }^{1,2}$, Wouter J.A. Derks ${ }^{1,29}$, Kerstin Korn ${ }^{1}$, Birte Sönnichsen ${ }^{1}$, Rick E.W. van Leeuwen ${ }^{2}$, Blanche Schroen ${ }^{2}$, Marc van Bilsen $^{2,38}$, Stephane Heymans ${ }^{2}$

Cenix BioScience GmbH, 01307 Dresden, Saxony, Germany.

${ }^{2}$ Department of Cardiology, Cardiovascular Research Institute Maastricht (CARIM),

Maastricht University, 6200 MD Maastricht, Limburg, the Netherlands.

${ }^{3}$ Department of Physiology, Cardiovascular Research Institute Maastricht (CARIM),

Maastricht University, 6200 MD Maastricht, Limburg, the Netherlands

${ }^{4}$ Center for Molecular and Cardiovascular Biology, Department of Cardiovascular Sciences, 3001 Leuven, Vlaams-Brabant, Belgium.

${ }^{5}$ Netherlands Heart Institute, 3511 EP Utrecht, Utrecht, the Netherlands. - These authors contributed equally to this work. - These authors also contributed equally to this work.

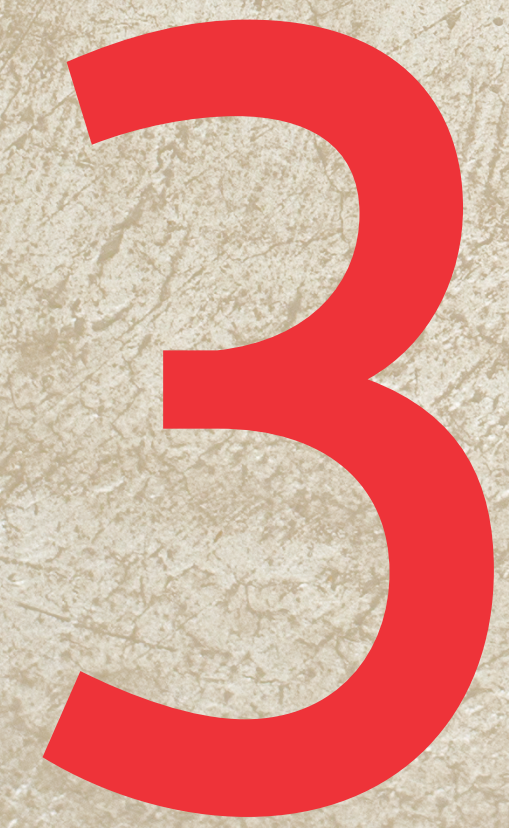




\section{CHAPTER 4}

\section{The micoRNA-221/222 Family Counteracts Myocardial Fibrosis in Pressure Overload-Induced Heart Failure}

\section{Adapted from Hypertension}

Robin Verjans ${ }^{1}$, Tim Peters ${ }^{1}$, Javier Beaumont ${ }^{2}$, Rick van Leeuwen ${ }^{1}$, Mitchell Bijnen ${ }^{1}$, Michiel Henkens ${ }^{1}$, Javier Diez $z^{2,3}$, Leon J. de Windt ${ }^{1}$, Marc van Bilsen ${ }^{1}$, Stephane Heymans ${ }^{1,4,5}$, Arantxa González ${ }^{2}$, Blanche Schroen ${ }^{1}$

${ }^{1}$ Department of Cardiology, Cardiovascular Research Institute Maastricht (CARIM), Maastricht University, 6200 MD Maastricht, Limburg, the Netherlands.

${ }^{2}$ Program of Cardiovascular Diseases, Centre for Applied Medical Research, University of Navarra, Pamplona, Spain; Instituto de Investigación Sanitaria de Navarra (IdiSNA), Pamplona, Spain

Department of Cardiology and Cardiac Surgery, University of Navarra Clinic, Pamplona, Spain.

${ }^{4}$ Netherlands Heart Institute, 3511 EP Utrecht, Utrecht, the Netherlands.

${ }^{5}$ Center for Molecular and Cardiovascular Biology, Department of Cardiovascular

Sciences, 3001 Leuven, Vlaams-Brabant, Belgium.

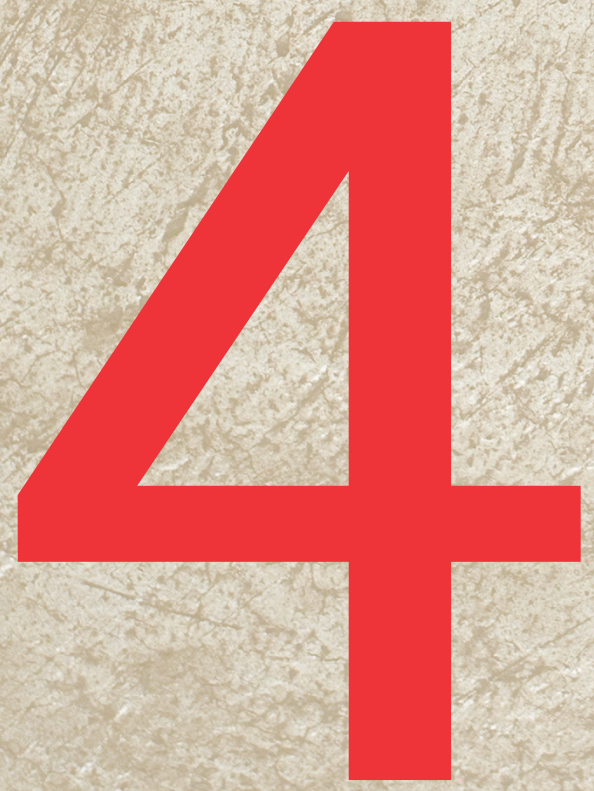




\section{Abstract}

Pressure overload-induced pathologic remodeling of the heart involves myocardial interstitial fibrosis. In response to various stresses, cardiac fibroblasts become activated and undergo transformation to myofibroblasts. These myofibroblasts can form excessive amounts of fibrosis, increasing myocardial stiffness and mediating diastolic dysfunction. A better understanding of the molecular mechanisms by which cardiac pressure overload, most often resulting from hypertension or aortic valve stenosis, induces cardiac remodeling will have important implications for future treatment strategies.

The microRNA-221/222 family, consisting of miR-221-3p and miR-222-3p, is differentially regulated in mouse and human cardiac pathology and inversely associated with kidney and liver fibrosis. Here we investigated the role of this microRNA family during pressure overload-induced cardiac remodeling and heart failure. In myocardial biopsies of patients with severe fibrosis and idiopathic dilated cardiomyopathy or aortic stenosis, we found significantly lower microRNA-221/222 levels as compared to matched patients without fibrosis. In addition, microRNA-221/222 levels in aortic stenosis patients correlated negatively with cardiac stiffness.

Inhibition of both miRNAs during angiotensin II-mediated pressure overload in mice led to increased fibrosis and aggravated left ventricular dilation and dysfunction. In isolated rat cardiac fibroblasts, inhibition of microRNA-221/222 de-repressed the activation of TGF $\beta$-mediated pro-fibrotic SMAD2 signaling and downstream gene expression, while overexpression of both miRNAs blunted TGF $\beta$-induced pro-fibrotic signaling. We found evidence that the microRNA-221/222 family may target several genes, next to validated target ETS Proto-Oncogene 1 (ETS-1), involved in TGF $\beta$ signaling, including c-Jun N-terminal kinase 1 (JNK1), TGF $\beta$-receptor-1 (TGF $\beta R 1$ ), and -2 (TGFßR2). Our findings identify downregulation of the microRNA-221/222 family to enable fibrotic signaling in the pressure-overloaded heart.

\section{Keywords:}

Aortic Valve Stenosis / Fibrosis / Heart Failure / miR-221 / miR-222 / Pressure Overload 


\section{Introduction}

Hypertension and aortic valve stenosis induce pressure overload of the heart which goes along with left ventricular hypertrophic and fibrotic remodeling, culminating in heart failure (HF). In 2014, the global prevalence of elevated blood pressure was around 20-25\% [1], meaning that every $4^{\text {th }}$ person on earth is predisposed to HF. Myocardial fibrosis determines patient outcome even under optimal medical treatment by contributing to cardiac dysfunction, arrhythmias and possibly ischemia [2], and therefore is a particularly interesting therapeutic target.

MicroRNAs (miRNAs) are a class of small ( 22 nucleotide long) non protein-coding RNAs that regulate expression of target genes via binding to (partially) complementary regions in their messenger RNAs thereby repressing translation. Importantly, a single microRNA can regulate an entire signaling cascade by repressing translation of several genes involved in that pathway [3]. As such, miRNAs have been implicated in the regulation of the major fibrotic signaling pathways, including transforming growth factor beta (TGF $\beta$ )-SMAD2/3, ERK1/2-MAP kinase and platelet derived growth factor (PDGF) signaling [4]. Indeed, the potential of miRNAs to modulate myocardial fibrosis has been shown exemplarily for miR21 [5] and miR-122 [6] by the stimulation of fibroblast ERK-MAP kinase signaling and by directly targeting of TGF $\beta$, respectively. However, our mechanistic understanding of the role of miRNAs in pressure overload-induced cardiac fibrosis and $\mathrm{HF}$ is still incomplete.

The miRNAs 221-3p and 222-3p (miR-221/222) are both encoded in the same genomic region on the human $X$ chromosome and show a profound sequence similarity. Consequently, both miRNAs have a large overlap in their target genes and are considered a microRNA family. Both miRNAs are differentially regulated in human cardiomyopathies [7-9] and in mouse models of cardiac diseases [10-12] and we recently showed a role for these miRNAs in viral replication and the cardiac immune response during viral myocarditis [13]. So far, there are no reports on a physiological role of the miR-221/222 family in the development of pressure overload-induced cardiac dysfunction. Although some studies investigated the role of miR-221 or miR-222 in the heart, these made use of generated cardiomyocyte-specific overexpressing transgenic mice, not taking into account endogenous miRNA levels and cell source(s) [14-16]. In organs other than the heart, both miR-221 and miR-222 have been linked to fibrosis formation. In particular, miR-221 levels are increased in diabetic nephropathy [17] and is shown to regulate renal fibroblast activation and fibrosis by targeting ETS-1 [18]. Similarly, the miR-221/222 family is upregulated in the liver in a fibrosis progression [19], protecting the liver from excessive fibrosis formation, at least party, via targeting of ETS-1 [20-22].

The aim of this study was therefore to investigate the physiological role of the microRNA-221/222 family during pressure overload-induced cardiac remodeling. We determined miR-221/222 levels in endomyocardial biopsies of patients with idiopathic dilated cardiomyopathy (DCM) and aortic stenosis (AOS) with either severe of non-severe fibrosis. In addition, we examined the role of these miRNAs in murine pressure overload-induced cardiac fibrosis and failure. Finally, we studied the role of miR-221/222 in pro-fibrotic signaling and myofibroblast differentiation of isolated rat cardiac fibroblasts. 


\section{Results}

Decreased miR-221/222 expression is associated with severe cardiac interstitial fibrosis in patients with dilated cardiomyopathy or aortic stenosis

In myocardial biopsies from DCM patients with either non-severe (DCM-NSF, $n=41$ ) or severe interstitial fibrosis (DCM-SF, $n=38$ ) (Table 1 ), cardiac miR-221-3p and miR-222-3p levels were determined. Clinical parameters in both groups were similar, including distri-

Table 1 DCM Patient characteristics

\begin{tabular}{|c|c|c|c|}
\hline & DCM-NSF $(n=41)$ & DCM-SF $(n=38)$ & $p$ value \\
\hline \multicolumn{4}{|l|}{ Demographics } \\
\hline Male (\%) & $21(51,2 \%)$ & $21(55,3 \%)$ & 0.719 \\
\hline Age at onset, yrs & $54.4 \pm 1.7$ & $51.8 \pm 2.2$ & 0.338 \\
\hline Heart rate, beats/min & $73.4 \pm 2.4$ & $72.0 \pm 2.3$ & 0.659 \\
\hline SBP, mm Hg & $133.4 \pm 2.7$ & $126.9 \pm 4.1$ & 0.182 \\
\hline DBP, mm Hg & $80.8 \pm 1.6$ & $77.6 \pm 2.6$ & 0.297 \\
\hline Body height, cm & $172.6 \pm 1.6$ & $173.8 \pm 1.8$ & 0.606 \\
\hline Body weight, kg & $80.3 \pm 2.6$ & $80.9 \pm 3.1$ & 0.876 \\
\hline \multicolumn{4}{|l|}{ Symptoms } \\
\hline NYHA class I & $10(24,4 \%)$ & $8(21,1 \%)$ & 0,724 \\
\hline NYHA class II & $19(46,3 \%)$ & $17(44,7 \%)$ & 0,886 \\
\hline NYHA class III & $11(26,8 \%)$ & $9(23,7 \%)$ & 0,748 \\
\hline NYHA class IV & $1(2,4 \%)$ & $4(10,5 \%)$ & 0,190 \\
\hline \multicolumn{4}{|l|}{ Echocardiography } \\
\hline LVEF, \% & $29.8 \pm 1.8$ & $25.83 \pm 1.8$ & 0.131 \\
\hline LVEDD, mm & $62.0 \pm 1.3$ & $64.69 \pm 1.5$ & 0.168 \\
\hline LVMI & $112.6 \pm 5.0$ & $120.5 \pm 5.0$ & 0.272 \\
\hline \multicolumn{4}{|l|}{ Comorbidities } \\
\hline Hyperlipidemia & $6(14,6 \%)$ & $2(5,3 \%)$ & 0.266 \\
\hline Diabetes mellitus & $7(17,1 \%)$ & $2(5,3 \%)$ & 0.157 \\
\hline \multicolumn{4}{|l|}{ Cardiac incident } \\
\hline CRTD & $7(17,1 \%)$ & $6(15,8 \%)$ & 0,878 \\
\hline CRT & $3(7,3 \%)$ & $1(2,6 \%)$ & 0,616 \\
\hline Pacemaker & $2(4,9 \%)$ & $0(0,0 \%)$ & 0.494 \\
\hline HTx & $0(0,0 \%)$ & $1(2,6 \%)$ & 0,481 \\
\hline Death & $5(12,2 \%)$ & $3(7,9 \%)$ & 0,713 \\
\hline
\end{tabular}

Values are mean $\pm \mathrm{SEM}$, or $\mathrm{n}(\%) \mathrm{BSA}=$ body surface area; $\mathrm{CRT}=$ cardiac resynchronization therapy; $\mathrm{CRTD}=$ cardiac resynchronization therapy defibrilator; $\mathrm{DBP}=$ diastolic blood pressure; $\mathrm{DCM}=$ dilated cardiomyopathy; $\mathrm{HTx}=$ heart transplantation; LVEDD=left ventricular end-diastolic diameter; LVEF=left ventricular ejection fraction; LVMI; left ventricular mass index; NSF=non-severe fibrosis; NYHA=New York Heart Association; SBP=systolic blood pressure; $\mathrm{SF}=$ severe fibrosis. 
bution of NYHA classification, left ventricular ejection fraction (LVEF), left ventricular mass index (LVMI), and occurrence of cardiac incidents. Figure 1A shows that DCM-SF patients had significantly lower myocardial levels of both miR-221 and miR-222 in comparison with the DCM-NSF group. These results indicate that decreased myocardial expression of miR$221 / 222$ is associated with increased fibrosis formation in patients diagnosed with DCM.

Aortic stenosis (AOS) increases the afterload on the left ventricle and induces cardiac remodeling including increased deposition of interstitial fibrosis. Myocardial expression levels of both miR-221-3p and miR-222-3p were significantly decreased in AOS-SF patients as compared to AOS-NSF (Figure 1B). In addition, both miRNA levels correlated negatively with CVF (Figure 1C) and positively with early filling deceleration time (Figure 1D), indicating more fibrosis and slower left ventricular filling in patients with low microRNA levels. In line with this, left ventricular stiffness (KLV) correlated negatively with the expression

A
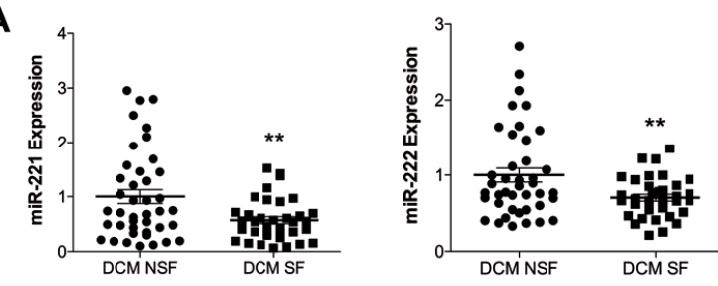

B
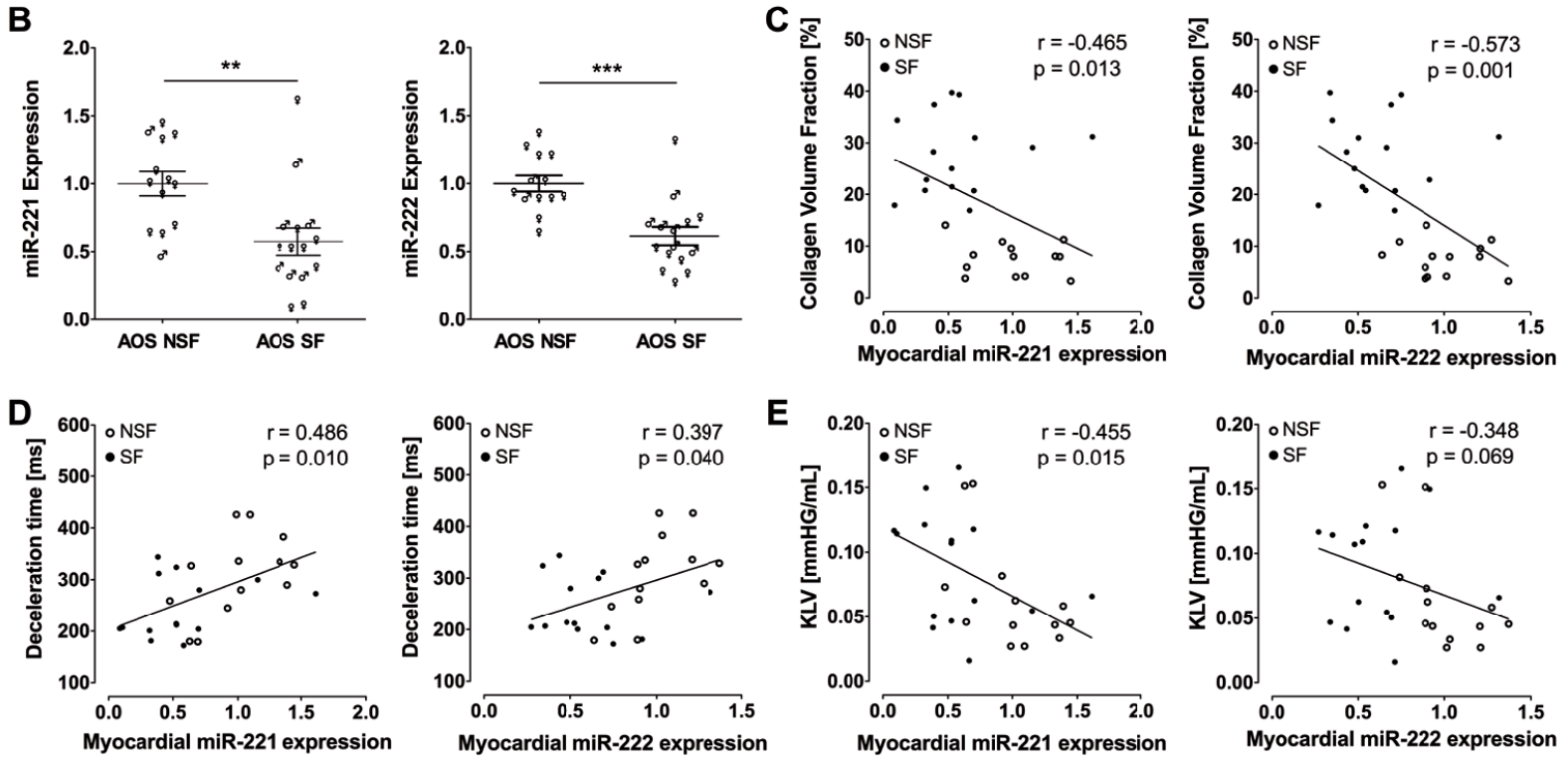

Figure 1: Myocardial miR-221 and -222 levels are decreased in patients with dilated cardiomyopathy or aortic stenosis with severe fibrosis. Myocardial biopsies form dilated cardiomyopathy (DCM) patients showed either non-severe (NSF, $n=41$ ) or severe fibrosis ( $S F, n=38$ ). Expression of both miR-221 and miR-222 is significantly lower in the myocardium of DCM patients with SF versus NSF (A). In left ventricular biopsies of aortic stenosis patients, expression of both miRNAs is significantly lower in patients with SF (filled circles, $n=15$ ) versus NSF (empty circles, $n=13, B$ ) and correlates negatively with collagen volume fraction (C). A positive correlation of miR-221/222 expression with deceleration time of the early mitral filling wave (D) and a negative correlation with left ventricular chamber stiffness constant KLV (E) indicate the negative association of miR-221/222 levels with left ventricular stiffness. ${ }^{\star \star} p<0.01 ;{ }^{* \star \star} p<0.001$ 
of both miRNAs (Figure 1E) although this did not reach statistical significance for miR$222(p=0.069)$. On the other hand, cardiomyocyte size did not correlate with expression of either miR-221 or miR-222 (Suppl. Figure S1A) indicating that miR-221/222 levels may be involved in the fibrotic but not hypertrophic response to cardiac pressure overload. Taken together, decreased myocardial miR-221/222 levels are significantly associated with increased myocardial interstitial fibrosis and stiffness during human pressure overload. Additionally, we found circulating levels of miR-221, but not miR-222, to negatively correlate with cardiac CVF, identifying miR-221 as a potential biomarker of myocardial fibrosis (Supplemental Figure 1B).

\section{In vivo inhibition of miR-221/222 aggravates Angiotensin II-induced cardiac dysfunction and fibrosis}

To investigate if the miR-221/222 family plays a causative role in pressure overload-induced left ventricular fibrotic remodeling, we subjected mice to 4 weeks of angiotensin II (AngII)
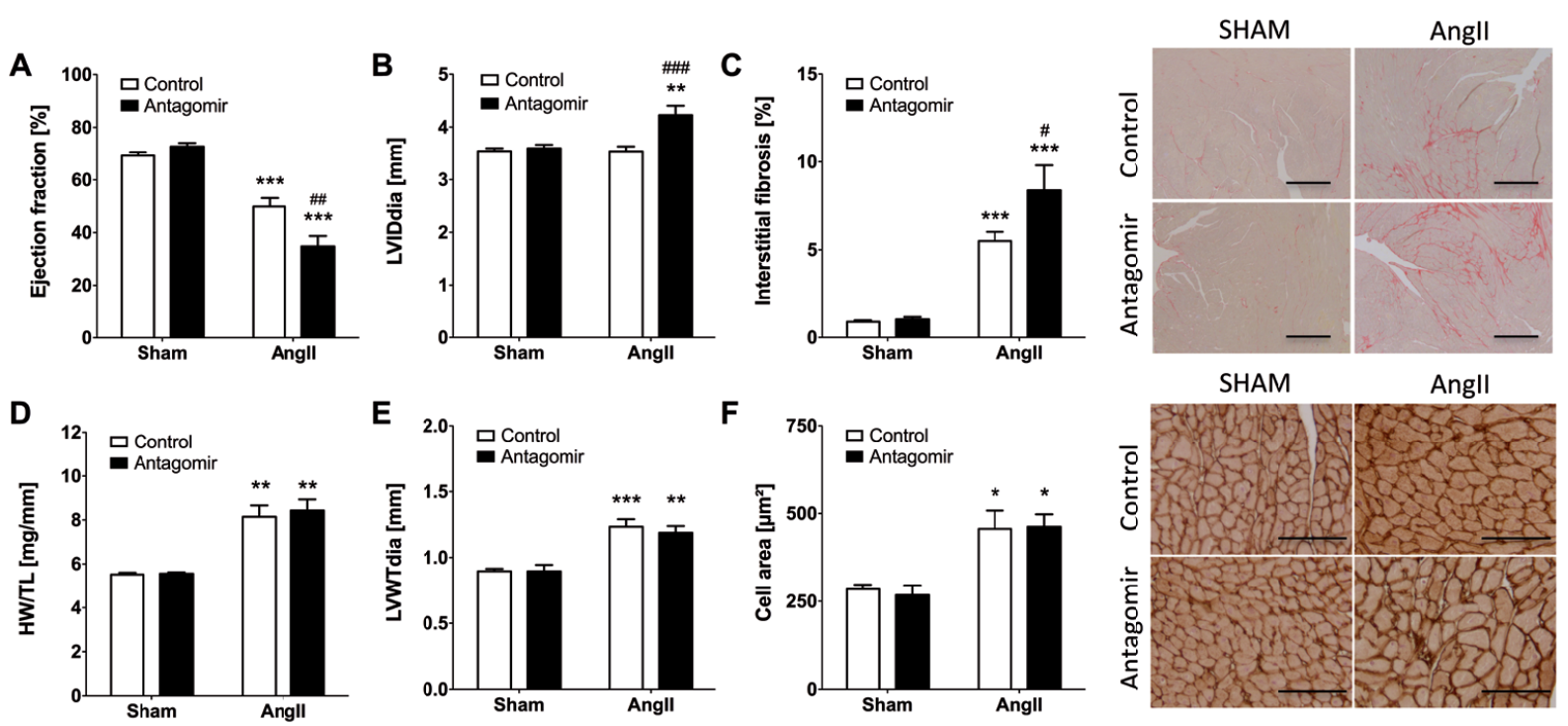

Figure 2: Inhibition of miR-221/222 during angiotensin II-induced pressure overload exaggerates cardiac dysfunction by contributing to cardiac fibrosis but not hypertrophy. Cardiac function as indicated by echocardiographically established left ventricular ejection fraction decreases after 4 weeks of angiotensin II-induced pressure overload, and further deteriorates when miR-221/222 are inhibited (A). In line, cardiac dimensions as indicated by diastolic left ventricular inner diameter (LVIDdia) are significantly increased upon pressure overload in combination with miR-221/222 inhibition (B). This adverse remodeling goes along with increased cardiac interstitial fibrosis deposition upon pressure overload in mice receiving miR-221/222 antagomirs as compared to negative control oligonucleotides (C). Representative images of Sirius red-stained left ventricular sections (D; scale bar: $100 \mu \mathrm{m})$. Cardiac mass corrected for tibia length (E), diastolic left ventricular wall thickness (LVWTdia) measured by echocardiography (F) and cardiomyocyte cross-sectional area (G) as measures of cardiac hypertrophy increase significantly in mice subjected to angiotensin II without being affected by inhibition of miR-221/222. Representative images of laminin staining of left ventricular sections ( $\mathrm{H}$; scale bar: $100 \mu \mathrm{m})$. Angll, angiotensin II; $n=5-8$ for sham groups; $n=6-11$ for Angll groups; ${ }^{\star} p<0.05,{ }^{* \star} p<0.01,{ }^{\star \star \star} p<0.001$ Angll versus Sham; ${ }^{+} p<0.05,{ }^{++} p<0.01,{ }^{+++} p<0.001$ Antagomir versus Control. 
infusion while inhibiting miR-221/222 using antagomirs, resulting in about 50\% cardiac knockdown of both miRNAs (Suppl. Figure S2A). During Angll-induced pressure overload, inhibition of miR-221/222 significantly aggravated left ventricular dilation and dysfunction as compared to mice receiving scrambled control oligonucleotides, indicating increased susceptibility to pressure overload-induced HF upon miR-221/222 inhibition (Figure 2AB). In addition, while Angll induced the deposition of cardiac interstitial fibrosis in both antagomir- and control oligonucleotide-treated mice, knockdown of miR-221/222 further increased Angll-induced cardiac fibrotic remodeling (Figure 2C-D). The Angll-induced increase in systolic blood pressure was similar in antagomir- and control oligonucleotidetreated mice (Suppl. Figure S2C) and also perivascular fibrosis remained unchanged (Suppl. Figure S2B), indicating that aggravated left ventricular dysfunction after inhibition of miR-221/222 was not due to differences in pressure overload. In line, cardiac hypertrophy was comparable in antagomir- and control oligonucleotide-treated mice as indicated by similar AngII-effects on heart weight (Figure 2E), left ventricular wall thickness (Figure 2F) and cardiomyocyte cross-sectional area (Figure $2 \mathrm{G}-\mathrm{H}$ ). In conclusion, these data implicate the miR-221/222 family in pressure overload-induced myocardial fibrosis and dysfunction, whereas endogenous miR-221/222 have no role in cardiac hypertrophy.

\section{The miR-221/222 family regulates pro-fibrotic signaling in neonatal cardiac fibroblasts}

During cardiac pressure overload, an intracardiac renin-angiotensin system is activated that increases local AngII signaling and contributes to the development of cardiac hypertrophy and fibrosis [23]. In the myocardium, Angll promotes activation of resident fibroblasts via induction of TGF $\beta$ signaling [24]. To investigate if and how miR-221/222 modulate the fibrotic response of cardiac fibroblasts to TGF $\beta$, we examined the role of the miRNA family in nRCFs. We found that miR-221/222 is able to control fibroblast proliferation. Forced expression of miR-221/222 decreased BrdU incorporation in nRCFs while miRNA inhibition had opposite effects (Figure 3A-B). The expression of miR-221/222 in nRCFs was downregulated by TGF $\beta$ (Figure 3C), in line with the decreased miR-221/222 levels we found in human DCM-SF and AOS-SF. Rescue of this response by the artificial overexpression of both miRNAs using miRNA mimics reduced TGF $\beta$-induced fibroblast activation. This was evidenced by miR-221/222-dependent repression of TGF $\beta$-induced upregulation of the pro-fibrotic genes Connective tissue growth factor (Ctgf), fibronectin (Fn 1) and alpha smooth muscle actin (aSMA) (Figure 3D-F), indicative of impaired trans-differentiation of fibroblasts into collagen producing myofibroblasts [25]. Western blot analysis confirmed that miR-221/222 modulate TGF $\beta$-induced pro-fibrotic SMAD-signaling and downstream CTGF expression in nRCFs.

Inhibition of the microRNA family by use of miRNA inhibitors prior to TGF $\beta$ stimulation further increased the phosphorylation of SMAD2 and the subsequent induction of CTGF gene expression (Figure 4A-C), which is in line with the observed increased myocardial fibrosis in Angll-treated mice after inhibition of miR-221/222. In contrast, simultaneous 
A

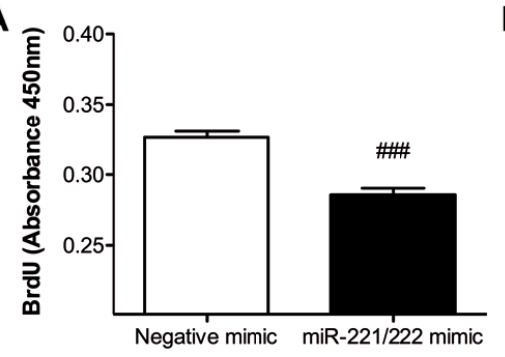

D

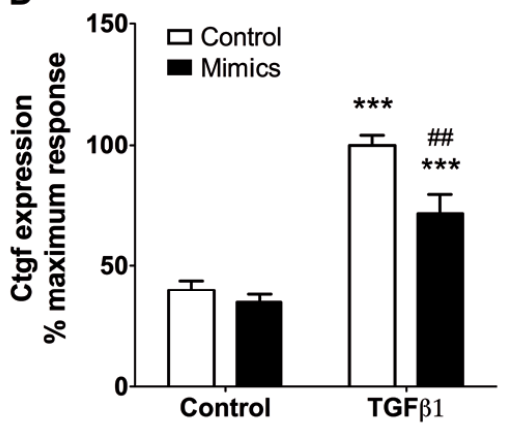

B

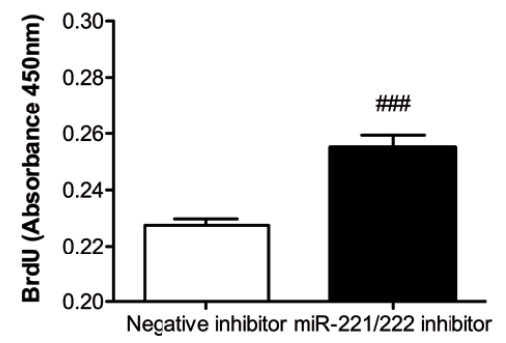

E

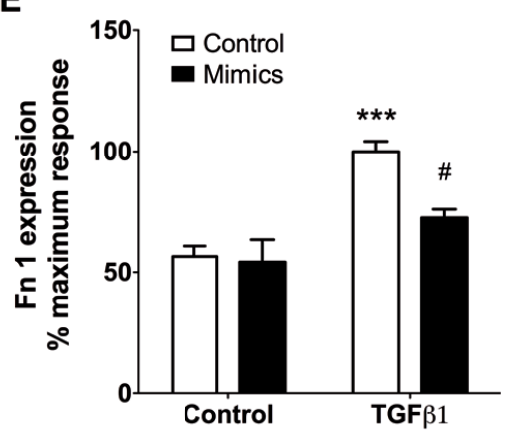

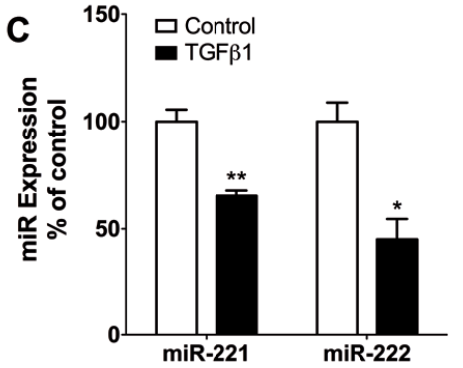

$\mathbf{F}$

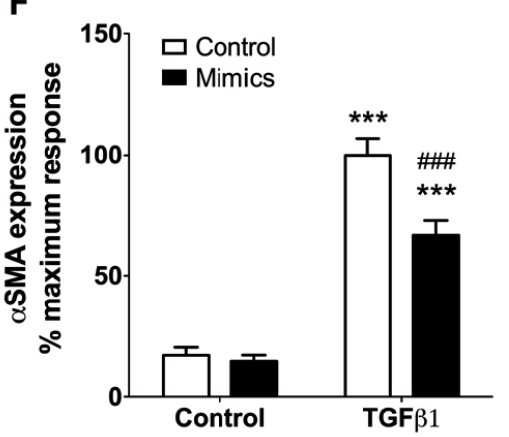

Figure 3: Expression of miR-221/222 in cardiac fibroblasts is regulated by TGF $\beta$ and miR221/222 controls proliferation and blunts fibroblast activation after TGF $\beta$ stimulation. MiR221/222 controls fibroblast proliferation, evidenced by decreased BrdU incorporation upon miRNA overexpression (A) while miRNA inhibition leads to increased BrdU incorporation (B). MiR-221/222 are downregulated in neonatal rat cardiac fibroblasts (nRCF) after stimulation with TGF $\beta$ (C). RT-PCR shows that trans-differentiation of fibroblasts to myofibroblasts upon TGF $\beta$ stimulation is blunted by overexpression of miR-221/222 as evidenced by reduced induction of $\mathrm{Ctgf}(\mathrm{D})$, fibronectin $(\mathrm{Fn} 1, \mathrm{E})$ and alpha smooth muscle actin (aSMA, F) mRNA expression. A-B $n=18-24 /$ group; $E-F n=3-6 ;{ }^{*} p<0.05,{ }^{\star \star} p<0.01,{ }^{\star \star \star} p<0.001$ : TGF $\beta$ versus Buffer; ${ }^{+} p<0.05$, ${ }^{++} \mathrm{p}<0.01$ : miR-inhibitors or -mimics versus respective control oligonucleotides.

overexpression of both miRNAs reduced the induction of CTGF upon TGF $\beta$ stimulation, with repressive though non-significant effects on SMAD2 phosphorylation (Figure 4D-F), confirming that the increased presence of the microRNA-221/222 family can restrict pro-fibrotic signaling in stimulated cardiac fibroblasts. These results indicate that downregulation of miR-221/222 upon cardiac stress allows for fibroblast activation and trans-differentiation, characterised by induction of pro-fibrotic gene expression and fibroblast proliferation, and contributes to cardiac remodelling. These data identify this microRNA family as a potential therapeutic candidate in cardiac fibrosis and consequent dysfunction.

\section{The miR-221/222 family may directly target ETS-1, JNK1, TGF $\beta R 1$, and TGF $\beta R 2$}

The miR-221/222 family is shown to influence the fibrotic response, at least partly, through targeting of the transcription factor ETS Proto-Oncogene 1 (ETS-1) $[13,18,26]$. To determine the full underlying mechanism how miR-221/222 exerts its fibrosis-regulatory function, we identified 3 additional predicted target genes involved in TGF $\beta$-signalling: c-Jun N-terminal kinase 1 (JNK1), TGFß-receptor-1 (TGFßR1), and -2 (TGFßR2) (Figure 5A). Silencing of the miR-221/222 family in pressure overloaded-hearts increased the transcript expression 

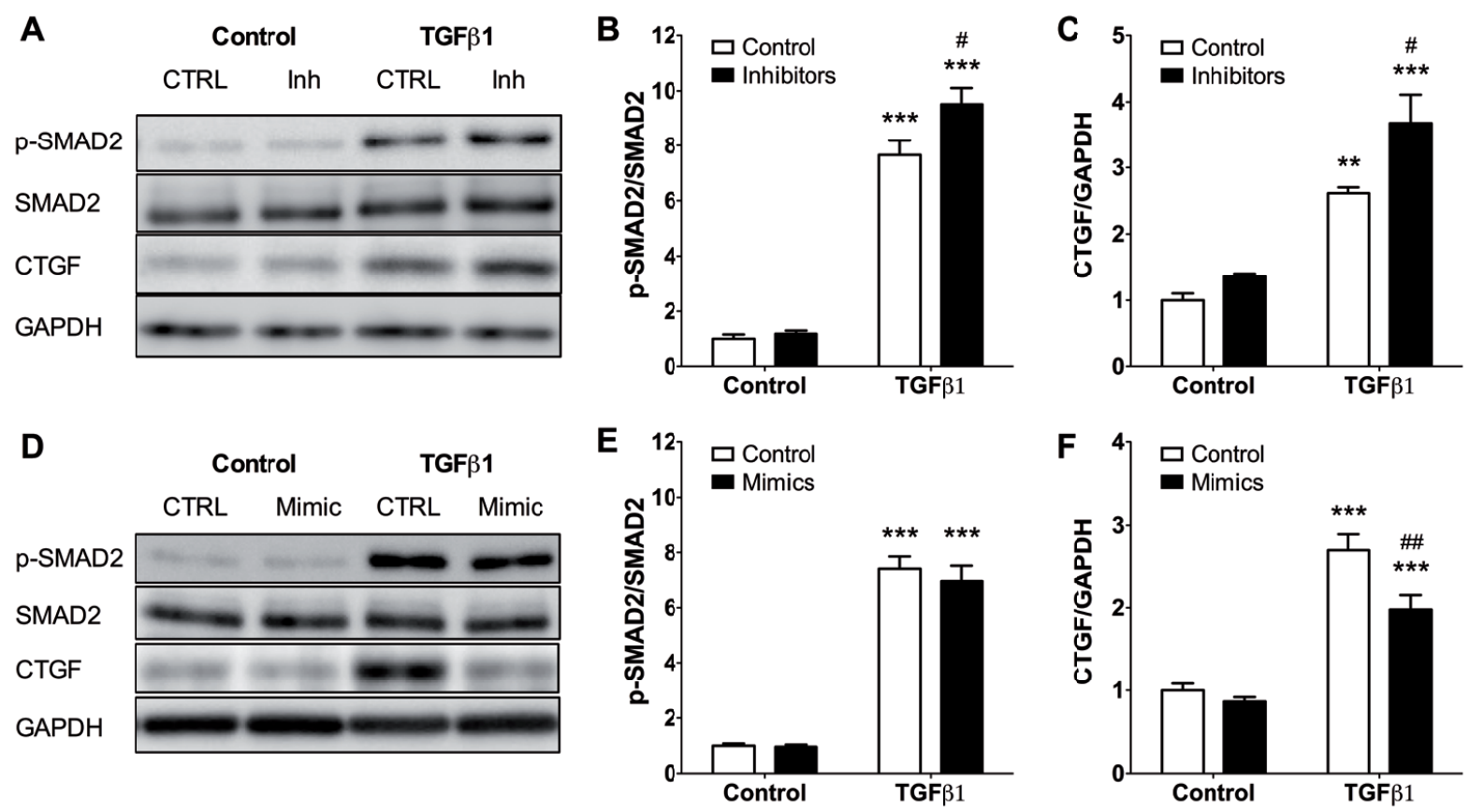

Figure 4: Protein levels of CTGF in TGF $\beta$ stimulated cardiac fibroblasts depend on miR-221/222 levels. Representative western blots of neonatal rat cardiac fibroblast stimulated with TGF $\beta$ after inhibition of miR-221/222 (A). Inhibition of both miRNAs increases TGF $\beta$-induced SMAD2 phosphorylation (B) and CTGF induction (C). Representative western blots of neonatal rat cardiac fibroblast stimulated with TGF $\beta$ after overexpression of miR-221/222 (D). TGF $\beta$-induced SMAD2 phosphorylation is non-significantly reduced by miR-221/222 mimics (E), with significant downstream effects on CTGF expression (F). $n=3-6 /$ group; ${ }^{\star} p<0.05$, ${ }^{* *} p<0.01$, ${ }^{\star * *} p<0.001$ : TGF $\beta$ versus Control; ${ }^{+} p<0.05,{ }^{++} p<0.01$ : miR-inhibitors or -mimics versus respective control oligonucleotides.

A
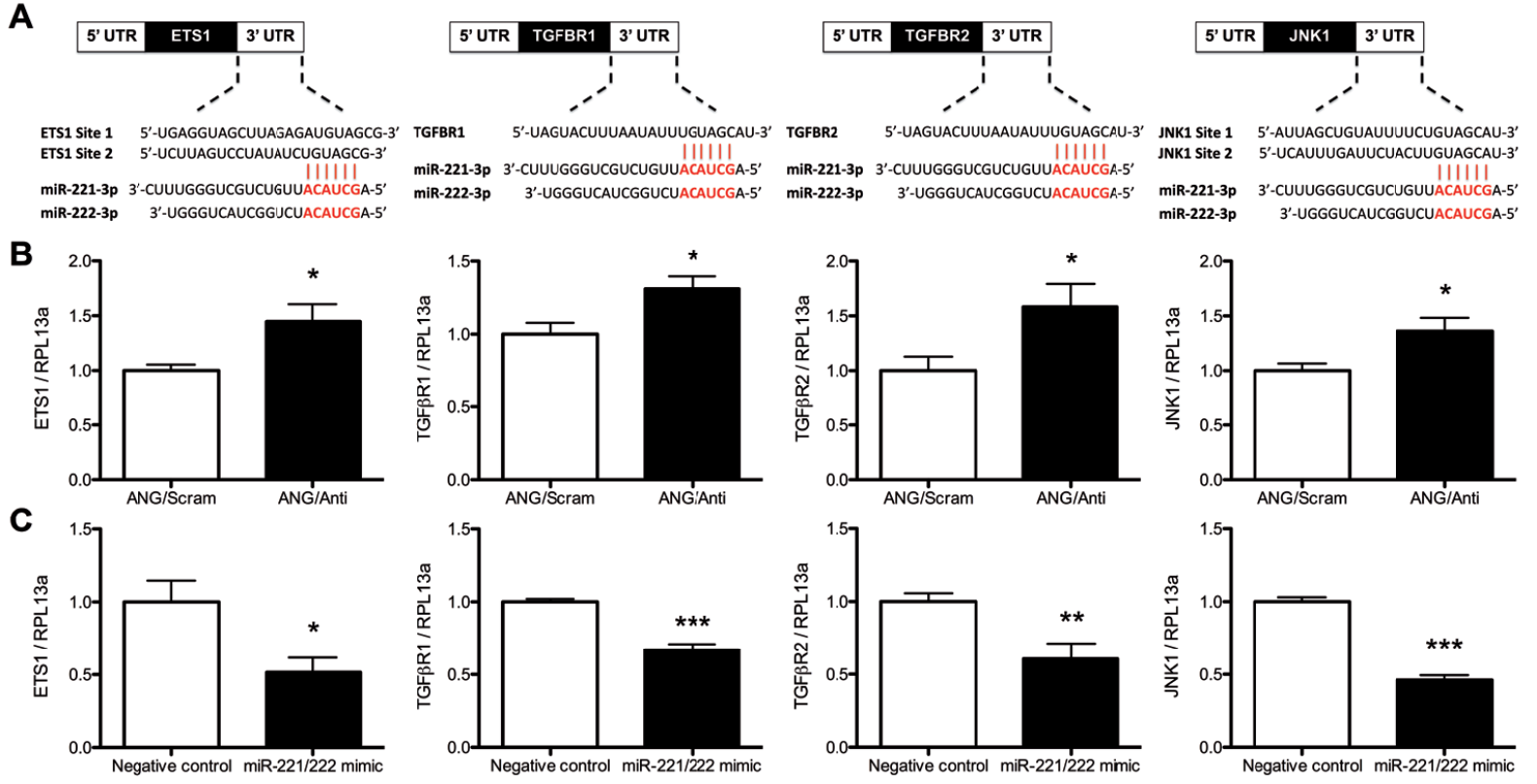

Figure 5: The miR-221/222 family targets ETS-1, JNK1, TGF $\beta R 1$, and TGF $\beta R 2$. The miR-221/222 family is predicted to target ETS-1, JNK1, TGF $\beta R 1$, and TGF $\beta R 2$ (A). Silencing of of miR-221/222 during angiotensin II-induced pressure overload increased murine cardiac transcript expression of ETS-1, JNK1, TGF $\beta R 1$, and TGF $\beta R 2$ (B). Overexpression of miR-221/222 in nRCFs decreases transcript expression levels of predicted target genes with a crucial role in TGF $\beta$-signalling, including ETS-1, JNK1, TGF $\beta R 1$, and TGF $\beta R 2$ (C). For nRCFs: $n=6$ / group; ${ }^{* *} p<0.01,{ }^{* \star *} p<0.001$ : miR-mimics versus control oligonucleotides. For murine hearts: Angll, angioten$\sin I$ I; $n=5-8$ for sham groups; $n=6-9$ for Angll groups; ${ }^{\star} p<0.05,{ }^{\star \star} p<0.01,{ }^{\star \star \star} p<0.001$ Antagomir versus Control. 
of ETS-1, JNK1, TGF $\beta R 1$, and TGF $\beta R 2$ (Figure 5B), while transcript levels of these 4 genes decreased upon overexpression of miR-221/222 in cultured cardiac fibroblasts (Figure 5C). Taken together, these results indicate that miR-221/222 may regulate the fibrotic response through targeting of ETS-1, JNK1, TGF $\beta$ R1, and TGF $\beta R 2$.

\section{Conclusion \& Discussion}

Pathological stressors such as hypertension and aortic stenosis cause myocardial interstitial fibrosis, disrupting electrical and mechanical properties and predisposing to the development of HF [2]. In the last years, factors involved in myocardial fibrosis including miRNAs have been identified [2], but our mechanistic insight into the molecular processes underlying fibrosis is still limited. Downregulation of miR-122 in human aortic stenosis was found to de-repress its target TGF $\beta$ and may play a role in severe cardiac fibrosis [6]. In addition, miR-21, which is consistently up-regulated in HF, was found to promote cardiac fibroblast survival and growth factor secretion by targeting the ERK/MAPK and PTEN/ SMAD7 signaling pathways $[5,27]$. In the present study, we identify two novel miRNAs, the microRNA-221/222 family, which downregulation upon pressure overload contributes to myocardial fibrosis and consequent HF by allowing fibroblast activation and differentiation. Dilated cardiomyopathy patients with severe fibrosis formation displayed lower myocardial levels of miR-221/222. Similarly, in patients with severe aortic valve stenosis, lower levels of miR-221/222 correlated significantly with more severe myocardial fibrosis and left ventricular stiffness. In line with these findings, inhibition of miR-221/222 in a mouse model of angiotensin II-induced pressure overload lead to increased myocardial interstitial fibrosis, left ventricular dilation and cardiac dysfunction.

Angiotensin II can exert its pro-fibrotic effects via induction of TGF $\beta$ in cardiac fibroblasts [24]. TGF $\beta$ expression is increased in the myocardium of both patients and experimental models with pressure overload and HF. It is one of the most potent inducers of extracellular matrix proteins, and its role in the pathogenesis of fibrosis is well established [28]. In cardiac fibroblasts, TGF $\beta$ induced the downregulation of miR-221/222, pointing to TGF $\beta$ as a potential regulator of these miRNAs and identifying a feedback mechanism to potentiate TGF $\beta$ signaling. TGF $\beta / S$ MAD signaling directly induces expression of CTGF, a secreted growth hormone that augments induction of extracellular matrix synthesis [29]. Persistent fibrosis appears to be initially induced by TGF $\beta$ signaling whereas CTGF acts as maintenance factor for fibrotic remodelling [30]. Importantly, TGF $\beta$ does not directly induce collagen synthesis in cardiac fibroblasts, but rather induces fibroblast activation which is accompanied by increased proliferation and trans-differentiation into collagen synthetizing myofibroblasts [25]. Here, we found that this proliferation is under the control of miR-221/222, evidenced by decreased BrdU incorporation upon miRNA overexpression while silencing of the miRNA-family increased BrdU incorporation in cardiac fibroblasts. Fibroblast trans-differentiation is augmented by CTGF signaling [31] and goes along with 
upregulation of the myofibroblast markers aSMA [32, 33] and fibronectin [34, 35]. Indeed, we found that overexpression of miR-221/222 significantly blunted the induction of these myofibroblast markers after stimulation with TGF $\beta$, indicating that downregulation of these miRNAs upon pressure overload contributes to myofibroblast differentiation and collagen production. On the protein level, we confirmed that overexpression of miR221/222 impedes the TGF $\beta$-induced expression of CTGF, whereas inhibition of both miRNAs significantly augmented SMAD2 phosphorylation and subsequent CTGF induction. These results provide evidence that the microRNA-221/222 family inhibits fibroblast to myofibroblast trans-differentiation after TGF $\beta$ stimulation. Downregulation of these miRNAs in cardiac fibroblasts upon pressure overload will therefore facilitate interstitial fibrosis deposition, as is indeed suggested by the negative correlation between miR-221/222 levels and interstitial fibrosis in aortic stenosis patients. Interestingly, we found a non-significant increase of miR-221/222 levels by Angll in whole heart extracts, apparently contradicting their down-regulation in fibroblasts. However, Angll has been shown to increase expression of both miRNAs in vascular smooth muscle cells [36] and miR-222 was found to be increased in cardiomyocytes of mice after wheel running, whereas its expression was slightly reduced in non-cardiomyocytes [14]. This indicates that Angll may induce expression of miR-221/222 in VSMCs and cardiomyocytes, while subsequent activation of TGF $\beta$ signaling leads to repression of the miR-221/222 family in fibroblasts.

Recently, miR-222 has been suggested to drive liver fibrosis by exerting pro-proliferative effects on stellate cells $[20,37]$, apparently contradicting our findings. However, both studies relate to biliary atresia, in which occlusion of the bile duct leads to cholestasis with secondary fibrosis of the liver [38] It is therefore conceivable, that the high miR-222 levels found in these studies do not directly correlate with pro-fibrotic signaling, but rather relate to increased stellate cell proliferation with secondary effects on the degree of cholestasis and fibrosis.

We found evidence that the microRNA-221/222 family may target several genes involved in TGF $\beta$ signaling, including ETS-1, JNK1, TGF $\beta R 1$, and TGF $\beta R 2$. The transcription factor ETS-1 synergizes with TGF $\beta$ to induce CTGF expression [39] and was found to mediate the pro-fibrotic effects of angiotensin II on renal fibroblast [40]. ETS-1 expression is repressed by both miR-221 and miR-222 [13, 18, 26]. In particular, overexpression of miR-221 in normal rat kidney fibroblasts (NRK-49F cells) is able to prevent the angiotensin II-induced expression of fibronectin and alpha smooth muscle actin (aSMA) through targeting of ETS-1 [18]. Various reports have shown that the stress-activated protein kinase JNK1 is required for the development of fibrosis in multiple organs, including the liver [41, 42], lung [43, 44], kidney [45], and heart [46]. In particular, JNK1 is necessary for expression of profibrotic genes through stimulation of fibroblast activation, proliferation and transdifferentiation into myofibroblasts [45, 47-49]. JNK1-deficient mice are protected against the development of hepatic [41, 49] and pulmonary fibrosis [44]. Furthermore, enhanced expression of JNK1 is associated with an accelerated progression of diabetic myocardial interstitial fibrosis [46]. Similarly, both TGF $\beta R 1$ and TGF $\beta R 2$ play a crucial role in heart failure development since 
TGF $\beta$ signals through binding a heterotetrameric receptor complex of these 2 receptors [50]. Upon TGF $\beta$ binding, TGF $\beta R 2$ phosphorylates and thereby activates TGF $\beta R 1$ serine/ theronine kinases that in their turn activate SMAD2/3 transcription factors. In addition to this canonical TGF $\beta$ pathway, TGF $\beta$ R2-mediated activation of TGF $\beta$-activated kinase 1 (TAK1) results in downstream stimulation of JNK1 and $p 38$ [51, 52]. Thus, TGF $\beta R 1$ and -R2 mediate activation of both the canonical and non-canonical TGF $\beta$ signaling pathways, playing a key role in the cardiac fibrotic response. Therapeutical inhibition of TGF $\beta R 1$ after TAC prevented cardiac fibrosis and attenuated cardiac dysfunction [53]. Similarly, blocking of TGF $\beta$ via soluble TGF $\beta 22$ treatment upon myocardial infarction prevented cardiac dilatation and dysfunction through diminishing cardiomyocyte hypertrophy and interstitial fibrosis [54]. Taken together, these results suggest that restoration of miR-221/222-induced inhibition of TGF $\beta$ signalling upon cardiac stress, through their targeting of ETS-1, JNK1, TGF $\beta R 1$, and TGF $\beta R 2$, may provide a suitable therapy to prevent excessive fibrosis formation and heart failure development.

Recently, two groups have investigated the cardiac effects of miR-221 and miR-222 in cardiomyocyte restricted overexpression models. Generated transgenic mice overexpressing miR-221 or miR-222 in the cardiomyocytes develop HF spontaneously, accompanied by impaired autophagy, cardiomyocyte dysfunction and death, and increased fibrosis [15, 16]. On the contrary, mice with inducible cardiomyocyte-specific miR-222 expression were protected against adverse cardiac remodeling and dysfunction after ischemia/reperfusion injury, as evidenced by reduced cardiomyocyte death and reduced myocardial fibrosis [14]. In these models of cardiomyocyte-restricted miR-221/222 overexpression, myocardial fibrosis most probably occurs secondary to an influence of these miRNAs on cardiomyocyte function and survival. In contrast to these models, we manipulated miR-221/222 in the adult whole heart including cardiac fibroblasts and found a direct effect on the pro-fibrotic phenotype of these cells.

Altogether, we show that lower levels of microRNA-221 and -222 correlate with higher levels of fibrosis and left ventricular stiffness in patients with $\mathrm{HF}$, and provide evidence that decreased levels of miR-221/222 contribute to pressure overload-induced myocardial fibrosis and dysfunction in mice. Additionally, we found that in cardiac fibroblasts, TGF $\beta$ downregulates the expression of miR-221/222, alleviating their interference with its own pro-fibrotic signaling. Therefore, we propose that myocardial TGF $\beta$ signaling leads to downregulation of the miR-221/222 family to facilitate trans-differentiation of cardiac fibroblasts into collagen producing myofibroblasts, contributing to the development of myocardial fibrosis and $\mathrm{HF}$. 


\section{Materials \& Methods}

\section{Patient samples}

The study groups enrolled in this correlation analysis were explained in detail previously $[6,55]$. In brief, DCM patients with a left ventricular ejection fraction (LVEF) $<50 \%$ and indexed left ventricular end-diastolic diameter (LVEDDI)> $33 \mathrm{~mm} / \mathrm{m}^{2}$ (men) or $>32 \mathrm{~mm} / \mathrm{m}^{2}$ (women) in the absence of active viral myocarditis or a clinical history of myocardial infarction and/or atrial fibrillation were included $(n=79)$. Right ventricular septal biopsies of 41 DCM patients showed an interstitial collagen volume fraction (CVF) of below 5\%, called non-severe fibrosis (DCM-NSF), and 38 had an interstitial CVF of above 5\%, called severe fibrosis (DCM-SF) [55].

Similarly, endomyocardial biopsies of 28 patients with severe isolated aortic valve stenosis were collected and analysed for myocardial fibrosis and microRNA expression. M-mode and pulsed Doppler echocardiographic measurements were performed in all patients. Left ventricular chamber stiffness constant (KLV) was calculated as the ratio squared of the deceleration time of the early mitral filling wave according to the following equation [56]: KLV $=(0.07: D T)^{2}$.

The fraction of myocardium occupied by collagen or collagen volume fraction (CVF) was determined by quantitative morphometry with an automated image analysis system in sections stained with Picrosirius Red as previously described ${ }^{6}$. A cluster analysis was performed according to CVF values, and AS patients were divided in two groups: nonsevere fibrosis (AOS-NSF) group (CVF $\leq 15 \%, n=13$ ) and severe fibrosis (AOS-SF) group (CVF $>15 \%, \mathrm{n}=15)$. Cardiomyocyte area was analysed in Masson's trichrome stained sections. The cross-sectional area of approximately 100 cardiomyocytes (with the nucleus in central position) was measured in each sample using the AnalysIS 3.1 software (Soft Imaging System $\mathrm{GmbH}$ ).

Myocardial and serum RNA was isolated with TRIzol or TRIzol LS reagent (Invitrogen) according to manufacturer's recommendations. Synthetic C. elegans microRNA 39 (cel-miR-39) was spiked into serum after the addition of the Trizol LS reagent to the samples to be used as control. Reverse transcription (RT) of microRNAs was performed using specific primers for miR-221 and miR-222, cel-miR-39 and snU6 as an endogenous control for myocardium. The cDNA obtained was pre-amplified and amplified by PCR using the specific TaqMan microRNA assays (Life Technologies) for these microRNAs and for snU6 RNA. The fluorescent signal was detected with a 7900HT Fast Real-Time PCR System (Applied Biosystems) and analysed with the SDS 2.2.2 software. MicroRNA expression was normalised by snU6 RNA in the myocardium and by cel-miR-39 in serum and expressed as arbitrary units (A.U.).

\section{Animal models}

Eight week old C57Bl/6J mice (Charles River) received subcutaneous infusion of angioten$\sin$ II (Bachem, $2.5 \mathrm{mg} \cdot \mathrm{kg}^{-1} \cdot \mathrm{d}^{-1}$ ) by use of osmotic minipumps (Alzet) for four weeks. To 
inhibit miR-221 and miR-222 simultaneously, mice received intravenous injections of 40 $\mathrm{mg} / \mathrm{kg}$ of each antagomir (Fidelity Systems) at three consecutive days prior to minipump implantation, as well as at days 13 and 14 of Angll infusion. Injections of scrambled control oligonucleotides $(80 \mathrm{mg} / \mathrm{kg}$ ) served as control. After four weeks, echocardiography was performed on a Vevo2100 system (Visualsonics) to acquire M-mode images at the height of the papillary muscles. Afterwards, animals were sacrificed to harvest organs for histological and molecular biological analysis. Mice were housed under social conditions with ad libitum access to water and standard chow. All animal experiments were carried out in accordance with Dutch law and approved by the local ethics committee.

\section{Histology}

After sacrifice, organs were rinsed in PBS and fixed in 4\% neutral buffered formalin for 4 days before embedding in paraffin blocks. Sections were stained with Picrosirius Red to quantify fibrosis. Approximately 10 randomly chosen microphotographs across the left ventricle and septum were taken. Interstitial fibrosis was normalized to tissue area and perivascular fibrosis was normalized to the area of the respective vessel. Laminin staining was performed using rabbit anti-mouse laminin (Sigma, L9393) and Vectastain Elite ABC kit (Vector laboratories). Images were taken at the septum and left ventricular myocardium. Epicardial cells, as well as longitudinal cells and cells without visible nucleus were excluded from analysis. All images were taken and analysed in a blinded manner using a Leica DM2000 equipped with a Leica DFC450C camera and custom designed macros in ImageJ software.

\section{In vitro experiments}

Neonatal rat cardiac fibroblasts (nRCF) were isolated from 1-2 day old Wistar rat pups by digestion with Collagenase I (Gibco) and Pancreatin (Sigma) in spinner flasks. Adherent cells were collected and maintained in DMEM 22320 supplemented with 10\% heat inactivated fetal bovine serum (FBS) and penicillin/streptomycin. After 1-2 passages cells were seeded in 6-well plates. Sub-confluent cells were transfected with miRIDIAN miR-221 and miR-222 mimics (Dharmacon, $1 \mathrm{nM}$ each vs $2 \mathrm{nM}$ control) or Power Inhibitors (Exiqon, $20 \mathrm{nM}$ each vs $40 \mathrm{nM}$ control) in low serum medium (0.1\% FBS) using Lipofectamine2000 (Invitrogen). After 24 hours cells were stimulated with $10 \mathrm{ng} / \mathrm{mL}$ recombinant human TGF $\beta_{1}$ (Peprotech). After 15 minutes or 24 hours of stimulation cells were harvested in protein sample buffer (5mM TRIS buffer, $20 \%$ glycerol, 4\% SDS, 10\% $\beta$-mercaptoethanol) for western blot analysis or in lysis buffer for RNA isolation using mirVana miRNA isolation kit (Ambion).

\section{Western Blot}

Western blot of nRCF protein was performed using standard procedures. Primary antibodies used were as follows: rabbit anti-connective tissue growth factor (CTGF) (GeneTex \#GTX26992), rabbit anti-SMAD2/3 (CellSignaling \#8685P), and rabbit anti-pSMAD2/3 
(CellSignaling \#8828S). Mouse anti-Gapdh (Millipore MAB374) served as internal control. Secondary antibodies were HRP conjugated goat anti-rabbit (CellSignaling \#7074) or horse anti-mouse (CellSignaling \#7076). Enhanced chemiluminescence was measured in a custom made imaging system equipped with a cooled Artemis FS28 16-bit camera and analysed using ImageJ and Image Studio Lite software.

\section{RNA isolation and RT-qPCR}

RNA was isolated from animal tissue or cells using mirvana microRNA isolation kit (Ambion) according to manufacturer's instructions. Snap frozen heart tissue was homogenized in mirVana lysis buffer using ceramic beads (Lysing Matrix D, MP Biomedicals). RNA was reverse transcribed using miScript RT II kit (Qiagen) and RT-qPCR was performed using SYBR Green (Biorad). The expression of miR-221 and miR-222 was detected using microRNA LNA primer sets (Exiqon). Primer sequences to determine transcript levels are described in table 2.

\section{Table 2 RT-PCR primer sequences}

\begin{tabular}{lll}
\hline Gene & Forward sequence & Reverse sequence \\
\hline CTGF & CACAGAGTGGAGCGCCTGTTC & GATGCACTTTTTGCCCTTCTTAATG \\
Fn1 & AGTCCCGATGGTACCACTGGCC & CCTGCACGTCCAACGGCATG \\
aSMA & GTCCCAGACACCAGGGAGTGA & TCGGATACTTCAGGGTCAGGA \\
ETS-1 & GCTGTGGCAGTTTCTTCTGG & TTCCTCTTTCCCCATCTCCT \\
Rno-JNK1 & GCGTCATAAGAGGGCAGCCG & TGCTGTCTGTATCCGAGGCCA \\
Mmu-JNK1 & CCGAGGCCGGACGTTGC & CAAATATTCACCAAGGCCGGCAG \\
Rno-TGFBR1 & GCGGGGAGAAGAGTTGCCG & ACCATTGTCTTTGTTGTCTGCTGCT \\
Mmu-TGFBR1 & GGGCCGGGCCACAAACA & ACTGTAATGCCTTCGCCCCC \\
Rno-TGFBR2 & CCCCCGTTTGGTTCCAGAGTG & CACGATCTGGATGCCCTGGTG \\
Mmu-TGFBR2 & CAGGGGCCGGTCTATGACGA & ACATCACTGTTAACCGACTTGGGA \\
RPL13a & CAGAAAGTTTGCTTACCTGGGG & TTCTGCCTGTTTCCTTAGCCTC \\
U6 & CGCTTCGGCAGCACATATAC & TTCACGAATTTGCGTGTCAT \\
\hline
\end{tabular}

\section{Statistics}

Unless stated otherwise, data are presented as mean \pm SEM. Statistical analysis was performed with GraphPad Prism using Student's t-test or one-way ANOVA followed by Tukey post-hoc test to compare individual groups. Measurements on human dilated cardiomyopathy patients were analysed using Student's t-test. Measurements on human samples were analysed using Mann-Whitney test or Spearman's correlation. In all cases a p-value $<0.05$ was considered statistically significant. 


\section{References}

1. Organization WH. World health statistics 2015. Geneva: World Health Organization; 2015. 2015

2. Heymans S, Gonzalez A, Pizard A, Papageorgiou AP, Lopez-Andres N, Jaisser F, Thum T, Zannad F and Diez J. Searching for new mechanisms of myocardial fibrosis with diagnostic and/or therapeutic potential. European journal of heart failure. 2015;17:764-771

3. Small EM and Olson EN. Pervasive roles of micrornas in cardiovascular biology. Nature. 2011;469: 336-342

4. Kong P, Christia P and Frangogiannis NG. The pathogenesis of cardiac fibrosis. Cellular and molecular life sciences: CMLS. 2014;71:549-574

5. Thum T, Gross C, Fiedler J, Fischer T, Kissler S, Bussen M, Galuppo P, Just S, Rottbauer W, Frantz S, Castoldi M, Soutschek J, Koteliansky V, Rosenwald A, Basson MA, Licht JD, Pena JT, Rouhanifard SH, Muckenthaler MU, Tuschl T, Martin GR, Bauersachs J and Engelhardt S. Microrna-21 contributes to myocardial disease by stimulating map kinase signalling in fibroblasts. Nature. 2008;456: 980-984

6. Beaumont J, Lopez B, Hermida N, Schroen B, San Jose G, Heymans S, Valencia F, Gomez-Doblas JJ, De Teresa E, Diez J and Gonzalez A. Microrna-122 down-regulation may play a role in severe myocardial fibrosis in human aortic stenosis through tgf-beta1 up-regulation. Clinical science. 2014;126:497-506

7. Ikeda S, Kong SW, Lu J, Bisping E, Zhang H, Allen PD, Golub TR, Pieske B and Pu WT. Altered microrna expression in human heart disease. Physiol Genomics. 2007;31:367-373

8. Sucharov C, Bristow MR and Port JD. Mirna expression in the failing human heart: Functional correlates. J Mol Cell Cardiol. 2008;45:185-192

9. Wang C, Wang S, Zhao P, Wang X, Wang J, Wang Y, Song L, Zou Y and Hui R. Mir-221 promotes cardiac hypertrophy in vitro through the modulation of p27 expression. J Cell Biochem. 2012; 113:2040-2046

10. Sayed D, Hong C, Chen IY, Lypowy J and Abdellatif M. Micrornas play an essential role in the development of cardiac hypertrophy. Circ Res. 2007;100:416-424

11. Tatsuguchi M, Seok HY, Callis TE, Thomson JM, Chen JF, Newman M, Rojas M, Hammond SM and Wang DZ. Expression of micrornas is dynamically regulated during cardiomyocyte hypertrophy. J Mol Cell Cardiol. 2007;42:1137-1141

12. van Rooij E, Sutherland LB, Thatcher JE, DiMaio JM, Naseem RH, Marshall WS, Hill JA and Olson EN. Dysregulation of micrornas after myocardial infarction reveals a role of mir-29 in cardiac fibrosis. Proc Natl Acad Sci U S A. 2008;105:13027-13032

13. Corsten M, Heggermont W, Papageorgiou AP, Deckx S, Tijsma A, Verhesen W, van Leeuwen R, Carai P, Thibaut HJ, Custers K, Summer G, Hazebroek M, Verheyen F, Neyts J, Schroen B and Heymans S. The microrna-221/-222 cluster balances the antiviral and inflammatory response in viral myocarditis. Eur Heart J. 2015;36:2909-2919

14. Liu X, Xiao J, Zhu H, Wei X, Platt C, Damilano F, Xiao C, Bezzerides V, Bostrom P, Che L, Zhang C, Spiegelman BM and Rosenzweig A. Mir-222 is necessary for exercise-induced cardiac growth and protects against pathological cardiac remodeling. Cell Metab. 2015;21:584-595 
15. Su M, Wang J, Wang C, Wang X, Dong W, Qiu W, Wang Y, Zhao X, Zou Y, Song L, Zhang L and Hui R. Microrna-221 inhibits autophagy and promotes heart failure by modulating the p27/cdk2/mtor axis. Cell death and differentiation. 2015;22:986-999

16. Su M, Chen Z, Wang C, Song L, Zou Y, Zhang L, Hui R and Wang J. Cardiac-specific overexpression of mir-222 induces heart failure and inhibits autophagy in mice. Cell Physiol Biochem. 2016;39: 1503-1511

17. Fiorentino L, Cavalera M, Mavilio M, Conserva F, Menghini R, Gesualdo L and Federici M. Regulation of timp3 in diabetic nephropathy: A role for micrornas. Acta Diabetol. 2013;50:965-969

18. Di J, Jiang L, Zhou Y, Cao H, Fang L, Wen P, Li X, Dai C and Yang J. Ets-1 targeted by microrna-221 regulates angiotensin ii-induced renal fibroblast activation and fibrosis. Cell Physiol Biochem. 2014;34:1063-1074

19. Ogawa T, Enomoto M, Fujii H, Sekiya Y, Yoshizato K, Ikeda K and Kawada N. Microrna-221/222 upregulation indicates the activation of stellate cells and the progression of liver fibrosis. Gut. 2012;61:1600-1609

20. Shen WJ, Dong R, Chen G and Zheng S. Microrna-222 modulates liver fibrosis in a murine model of biliary atresia. Biochem Biophys Res Commun. 2014;446:155-159

21. Liu T, Wang P, Cong M, Zhang D, Liu L, Li H, Zhai Q, Li Z, Jia J and You H. Matrix metalloproteinase-1 induction by diethyldithiocarbamate is regulated via akt and erk/mir222/ets-1 pathways in hepatic stellate cells. Biosci Rep. 2016;36

22. Yu F, Zheng J, Mao Y, Dong P, Lu Z, Li G, Guo C, Liu Z and Fan X. Long non-coding rna growth arrest-specific transcript 5 (gas5) inhibits liver fibrogenesis through a mechanism of competing endogenous rna. J Biol Chem. 2015;290:28286-28298

23. Bader M. Role of the local renin-angiotensin system in cardiac damage: A minireview focussing on transgenic animal models. J Mol Cell Cardiol. 2002;34:1455-1462

24. Rosenkranz S. Tgf-beta1 and angiotensin networking in cardiac remodeling. Cardiovasc Res. 2004;63:423-432

25. Petrov W, Fagard RH and Lijnen PJ. Stimulation of collagen production by transforming growth factor-beta1 during differentiation of cardiac fibroblasts to myofibroblasts. Hypertension. 2002; 39:258-263

26. Zhu N, Zhang D, Chen S, Liu X, Lin L, Huang X, Guo Z, Liu J, Wang Y, Yuan W and Qin Y. Endothelial enriched micrornas regulate angiotensin ii-induced endothelial inflammation and migration. Atherosclerosis. 2011;215:286-293

27. Lorenzen JM, Schauerte C, Hubner A, Kolling M, Martino F, Scherf K, Batkai S, Zimmer K, Foinquinos A, Kaucsar T, Fiedler J, Kumarswamy R, Bang C, Hartmann D, Gupta SK, Kielstein J, Jungmann A, Katus HA, Weidemann F, Muller OJ, Haller H and Thum T. Osteopontin is indispensible for ap1-mediated angiotensin ii-related mir-21 transcription during cardiac fibrosis. Eur Heart J. 2015;36:2184-2196

28. Dobaczewski M, Chen W and Frangogiannis NG. Transforming growth factor (tgf)-beta signaling in cardiac remodeling. J Mol Cell Cardiol. 2011;51:600-606 
29. Moussad EE and Brigstock DR. Connective tissue growth factor: What's in a name? Mol Genet Metab. 2000;71:276-292

30. Mori T, Kawara S, Shinozaki M, Hayashi N, Kakinuma T, Igarashi A, Takigawa M, Nakanishi T and Takehara K. Role and interaction of connective tissue growth factor with transforming growth factor-beta in persistent fibrosis: A mouse fibrosis model. Journal of cellular physiology. 1999; 181:153-159

31. Yang M, Huang H, Li J, Li D and Wang H. Tyrosine phosphorylation of the Idl receptor-related protein (Irp) and activation of the erk pathway are required for connective tissue growth factor to potentiate myofibroblast differentiation. Faseb J. 2004;18:1920-1921

32. Desmouliere A, Geinoz A, Gabbiani F and Gabbiani G. Transforming growth factor-beta 1 induces alpha-smooth muscle actin expression in granulation tissue myofibroblasts and in quiescent and growing cultured fibroblasts. The Journal of cell biology. 1993;122:103-111

33. Ronnov-Jessen $L$ and Petersen OW. Induction of alpha-smooth muscle actin by transforming growth factor-beta 1 in quiescent human breast gland fibroblasts. Implications for myofibroblast generation in breast neoplasia. Lab Invest. 1993;68:696-707

34. Ignotz RA and Massague J. Transforming growth factor-beta stimulates the expression of fibronectin and collagen and their incorporation into the extracellular matrix. J Biol Chem. 1986;261: 4337-4345

35. Roberts AB, Sporn MB, Assoian RK, Smith JM, Roche NS, Wakefield LM, Heine UI, Liotta LA, Falanga V, Kehrl JH and et al. Transforming growth factor type beta: Rapid induction of fibrosis and angiogenesis in vivo and stimulation of collagen formation in vitro. Proc Natl Acad Sci U SA. 1986; 83:4167-4171

36. Leung A, Trac C, Jin W, Lanting L, Akbany A, Saetrom P, Schones DE and Natarajan R. Novel long noncoding rnas are regulated by angiotensin ii in vascular smooth muscle cells. Circ Res. 2013; 113:266-278

37. Dong R, Zheng Y, Chen G, Zhao R, Zhou Z and Zheng S. Mir-222 overexpression may contribute to liver fibrosis in biliary atresia by targeting ppp2r2a. J Pediatr Gastroenterol Nutr. 2015;60:84-90

38. Haafiz AB. Liver fibrosis in biliary atresia. Expert Rev Gastroenterol Hepatol. 2010;4:335-343

39. Geisinger MT, Astaiza R, Butler T, Popoff SN, Planey SL and Arnott JA. Ets-1 is essential for connective tissue growth factor (ctgf/ccn2) induction by tgf-beta1 in osteoblasts. PloS one. 2012;7: e35258

40. Feng W, Chumley P, Hua P, Rezonzew G, Jaimes D, Duckworth MW, Xing D and Jaimes EA. Role of the transcription factor erythroblastosis virus e26 oncogen homolog-1 (ets-1) as mediator of the renal proinflammatory and profibrotic effects of angiotensin ii. Hypertension. 2012;60:1226-1233

41. Kodama Y, Kisseleva T, Iwaisako K, Miura K, Taura K, De Minicis S, Osterreicher CH, Schnabl B, Seki $E$ and Brenner DA. C-jun n-terminal kinase-1 from hematopoietic cells mediates progression from hepatic steatosis to steatohepatitis and fibrosis in mice. Gastroenterology. 2009;137: $1467-1477$ e1465 
42. Kluwe J, Pradere JP, Gwak GY, Mencin A, De Minicis S, Osterreicher CH, Colmenero J, Bataller R and Schwabe RF. Modulation of hepatic fibrosis by c-jun-n-terminal kinase inhibition. Gastroenterology. 2010;138:347-359

43. van der Velden JL, Ye Y, Nolin JD, Hoffman SM, Chapman DG, Lahue KG, Abdalla S, Chen P, Liu Y, Bennett B, Khalil N, Sutherland D, Smith W, Horan G, Assaf M, Horowitz Z, Chopra R, Stevens RM, Palmisano M, Janssen-Heininger YM and Schafer PH. Jnk inhibition reduces lung remodeling and pulmonary fibrotic systemic markers. Clin Transl Med. 2016;5:36

44. Alcorn JF, van der Velden J, Brown AL, McElhinney B, Irvin CG and Janssen-Heininger YM. C-jun n-terminal kinase 1 is required for the development of pulmonary fibrosis. Am J Respir Cell Mol Biol. 2009;40:422-432

45. Ma FY, Flanc RS, Tesch GH, Han Y, Atkins RC, Bennett BL, Friedman GC, Fan JH and NikolicPaterson DJ. A pathogenic role for c-jun amino-terminal kinase signaling in renal fibrosis and tubular cell apoptosis. J Am Soc Nephrol. 2007;18:472-484

46. Liu X, Qi F and Wu W. Effect of intervention in the diacylglycerolprotein kinase c signaling pathway on jnk1 expression and its downstream signaling in diabetic cardiomyopathy. Mol Med Rep. 2014:9:979-984

47. Sabapathy K, Hochedlinger K, Nam SY, Bauer A, Karin M and Wagner EF. Distinct roles for jnk1 and jnk2 in regulating jnk activity and c-jun-dependent cell proliferation. Mol Cell. 2004;15:713725

48. Hong IH, Park SJ, Goo MJ, Lee HR, Park JK, Ki MR, Kim SH, Lee EM, Kim AY and Jeong KS. Jnk1 and jnk2 regulate alpha-sma in hepatic stellate cells during ccl4 -induced fibrosis in the rat liver. Pathol Int. 2013;63:483-491

49. Zhao G, Hatting M, Nevzorova YA, Peng J, Hu W, Boekschoten MV, Roskams T, Muller M, Gassler N, Liedtke C, Davis RJ, Cubero FJ and Trautwein C. Jnk1 in murine hepatic stellate cells is a crucial mediator of liver fibrogenesis. Gut. 2014;63:1159-1172

50. Creemers EE and Pinto YM. Molecular mechanisms that control interstitial fibrosis in the pressure-overloaded heart. Cardiovasc Res. 2011;89:265-272

51. Akiyama-Uchida Y, Ashizawa N, Ohtsuru A, Seto S, Tsukazaki T, Kikuchi H, Yamashita S and Yano K. Norepinephrine enhances fibrosis mediated by tgf-beta in cardiac fibroblasts. Hypertension. 2002;40:148-154

52. Davis J and Molkentin JD. Myofibroblasts: Trust your heart and let fate decide. J Mol Cell Cardiol. 2014; $70: 9-18$

53. Engebretsen KV, Skardal K, Bjornstad S, Marstein HS, Skrbic B, Sjaastad I, Christensen G, Bjornstad JL and Tonnessen T. Attenuated development of cardiac fibrosis in left ventricular pressure overload by sm16, an orally active inhibitor of alk5. J Mol Cell Cardiol. 2014;76:148-157

54. Ikeuchi M, Tsutsui H, Shiomi T, Matsusaka H, Matsushima S, Wen J, Kubota T and Takeshita A. Inhibition of tgf-beta signaling exacerbates early cardiac dysfunction but prevents late remodeling after infarction. Cardiovasc Res. 2004;64:526-535

55. Hazebroek MR, Moors S, Dennert R, van den Wijngaard A, Krapels I, Hoos M, Verdonschot J, Merken JJ, de Vries B, Wolffs PF, Crijns HJ, Brunner-La Rocca HP and Heymans S. Prognostic 
relevance of gene-environment interactions in patients with dilated cardiomyopathy: Applying the moge(s) classification. J Am Coll Cardiol. 2015;66:1313-1323

56. Little WC, Ohno M, Kitzman DW, Thomas JD and Cheng CP. Determination of left ventricular chamber stiffness from the time for deceleration of early left ventricular filling. Circulation. 1995; 92:1933-1939 


\section{Supplemental Figures \& Methods}

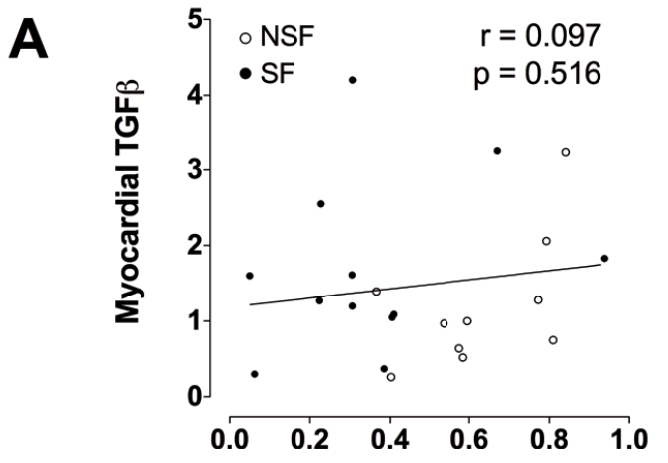

Myocardial miR-221 expression

B
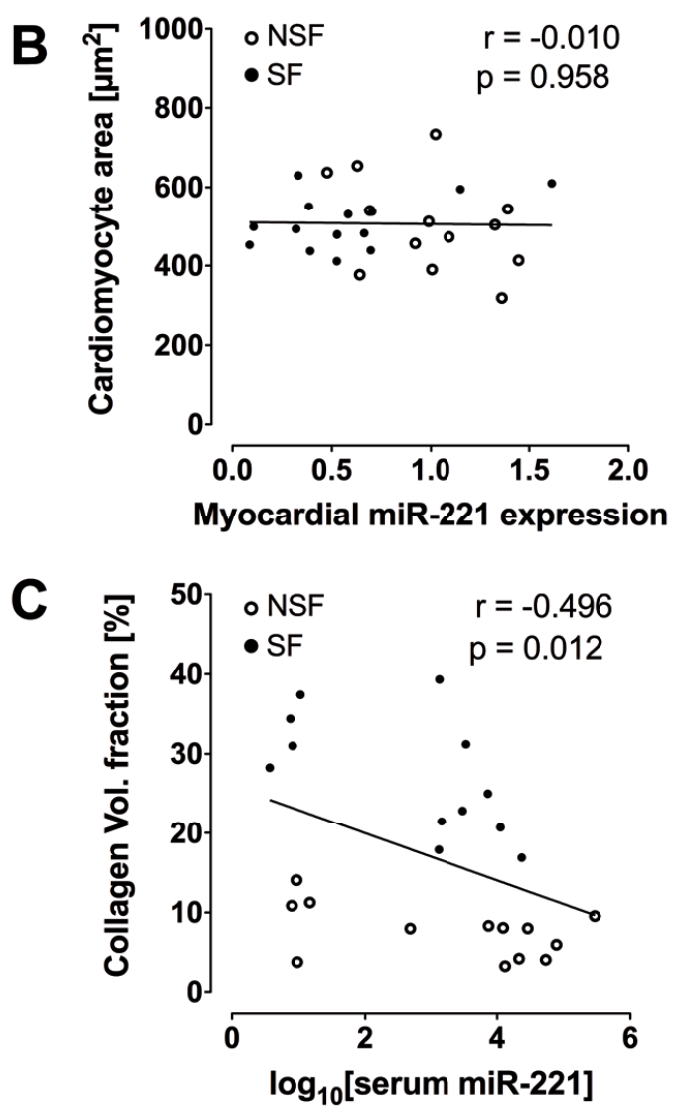
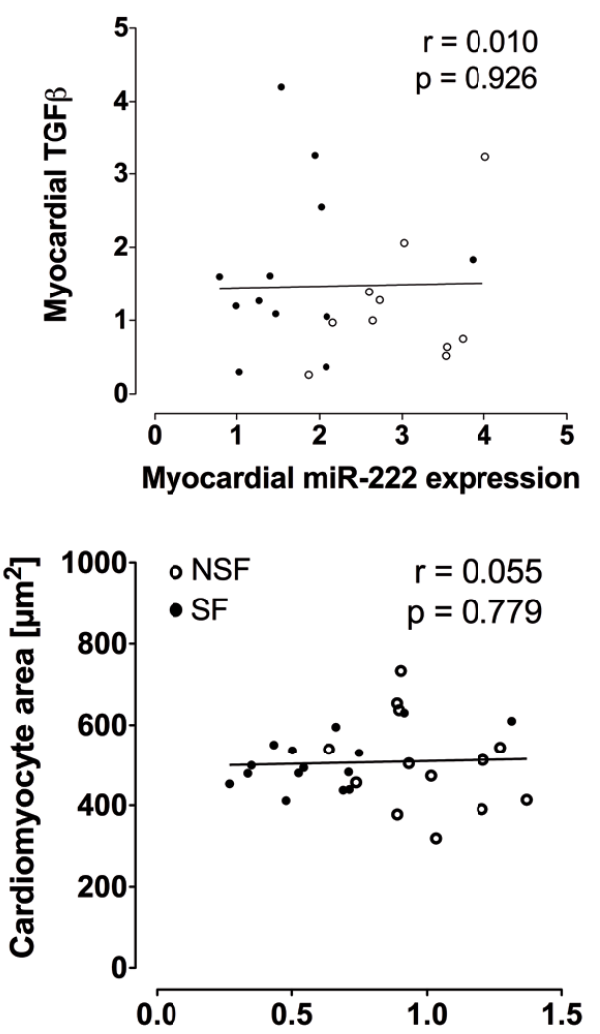

Myocardial miR-222 expression

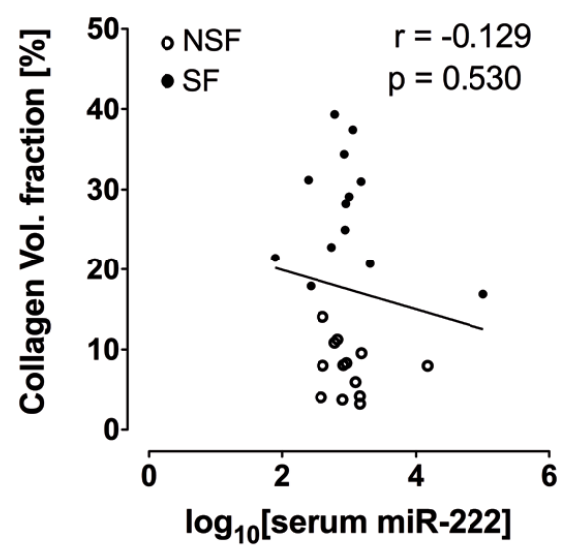

Supplemental Figure 1: Myocardial expression of miR-221 and miR-222 does not correlate with myocardial TGF $\beta$ levels (A) or cardiomyocyte size (B) in patients with aortic stenosis. Plasma levels of miR-221, but not miR222 significantly correlate with myocardial fibrosis (C). NSF: non-severe fibrosis (empty circles, $n=13$ ); SF: severe fibrosis (filled circles, $n=12-13$ ). 
A

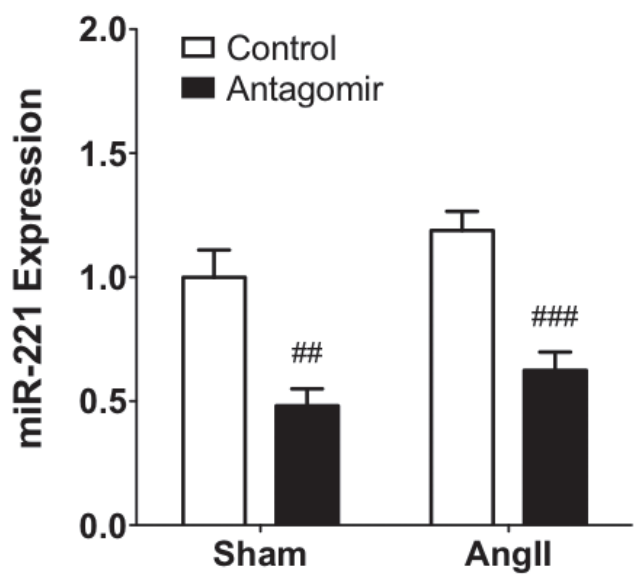

C

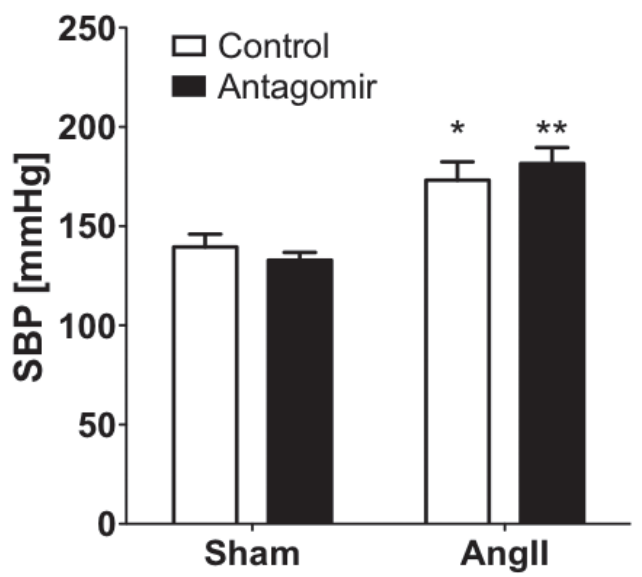

B
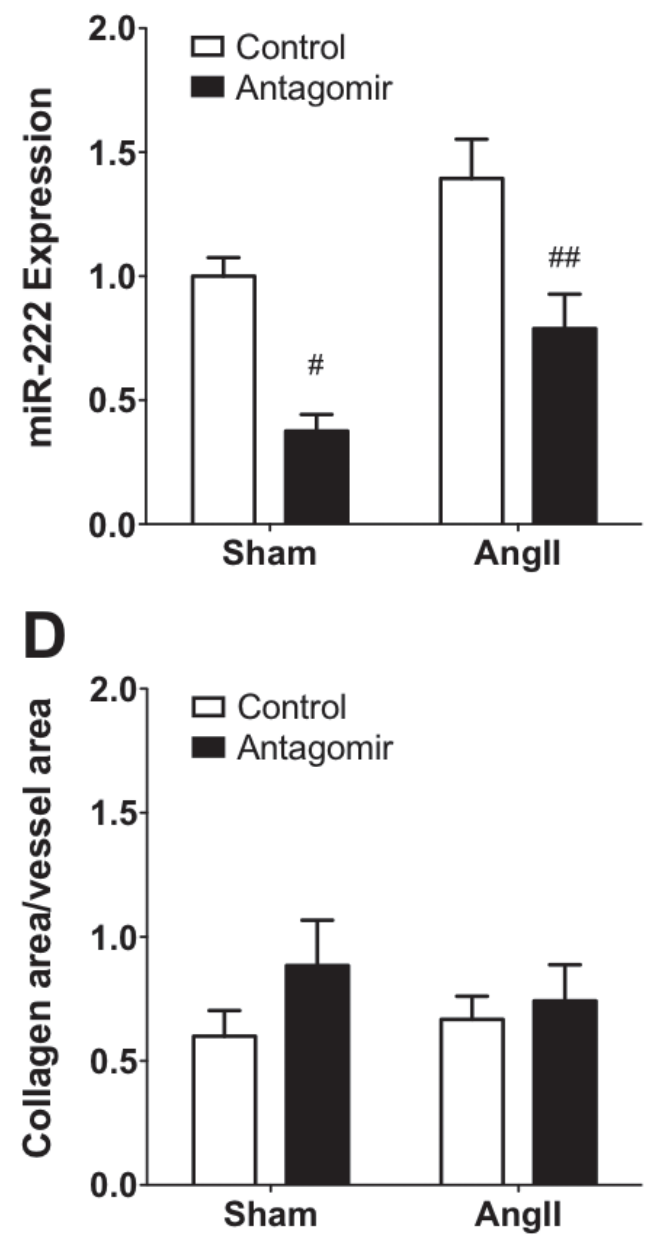

Supplemental Figure 2: Systemic administration of antagomirs resulted in a significant cardiac knockdown of miR-221 and miR-222 compared to injection of scrambled control oligonucleotides (A and B). Perivascular fibrosis was not affected by angiotensin II infusion or inhibition of miR-221/222 (C). The blood pressure increase by angiotensin II infusion was similar between mice receiving antagomirs or scrambled control oligonucleotides indicating that differences in fibrosis and LV function are not due to differences in the level of pressure overload (D). AngII, angiotensin II; $n=7-8$ for sham groups and $n=8-11$ for AngII groups; For SBP measurements $n=3-5$ / group; ${ }^{*} p<0.05,{ }^{* \star} p<0.01$, Angll versus Sham; ${ }^{+} p<0.05,{ }^{++} p<0.01,{ }^{+++} p<0.001$ Antagomir versus Control. 




\section{CHAPTER 5}

\section{MiR-151 Represses Cardiomyocyte Hypertrophy and Oxidative Metabolism by Targeting PGC-1a}

\section{In preparation}

Robin Verjans ${ }^{1}$, Blanche Schroen ${ }^{1}$, Marc van Bilsen

${ }^{1}$ Department of Cardiology, Cardiovascular Research Institute Maastricht (CARIM),

Maastricht University, 6200 MD Maastricht, Limburg, the Netherlands.

${ }^{2}$ Department of Physiology, Cardiovascular Research institute Maastricht (CARIM),

Maastricht University, 6200 MD Maastricht, Limburg, the Netherlands 


\section{CHAPTER 6}

\section{Cardiomyocyte Cell Cycle Activity is Under The Control of miR-125a}

\section{In preparation}

Robin Verjans ${ }^{1}$, Monika Rech ${ }^{1}$, Steffie Hermans-Beijusberger ${ }^{1}$, Paolo Carai ${ }^{1}$, Roel Spätjens ${ }^{1}$, Marc van Bilsen ${ }^{2}$, Blanche Schroen ${ }^{1}$

${ }^{1}$ Department of Cardiology, Cardiovascular Research institute Maastricht (CARIM),

Maastricht University, 6200 MD Maastricht, the Netherlands.

Department of Physiology, Cardiovascular Research Institute Maastricht (CARIM), Maastricht University, 6200 MD Maastricht, the Netherlands 


\section{CHAPTER 7}

\section{General Discussion}





\section{General discussion}

Heart failure is an age-related, multifaceted disease, driven by different cellular processes and involving various cell types. These include hypertrophic growth of cardiomyocytes, excessive extracellular matrix deposition by fibroblasts, and an exaggerated inflammatory response by immune cells. MiRNAs have a pivotal regulatory role in all those processes $[1,2]$. Therefore, the first aim of this thesis was to identify miRNAs that regulate cellular processes driving failure and aging of the myocardium. To address this aim, we reviewed the current literature describing the regulatory role of miRNAs in various processes mediating cardiac senescence and failure (Chapter 2). Furthermore, we selected 194 heart failure-associated miRNAs, which were probed for their effect on cardiomyocyte size, cardiac fibroblasts collagen content, and macrophage polarization in an extensive in vitro screen. As a result, we identified previously undescribed roles of miRNAs in hypertrophy, fibrosis, and inflammation, and attribute new cellular effects to various well-known miRNAs (Chapter 3).

The second aim was to interrogate the efficacy of miRNA-manipulation in retarding heart failure progression. To this aim, we selected specific miRNAs and studied their ability to influence cellular processes underlying cardiac disease progression. First, the role of the miR-221/222 family was investigated during pressure overload-induced cardiac remodelling. Antagomir-mediated inhibition of miR-221/222 expression enabled exaggerated cardiac fibrotic signalling and deteriorated cardiac function (Chapter 4). Second, miR-151a was shown to influence cardiomyocyte hypertrophy and, at the same time regulates mitochondrial oxidative capacity of cardiomyocytes, probably via regulation of PGC-1a levels (Chapter 5). Finally, cardiomyocyte cell cycle activity was found to be under the control of miR-125a, inducing, at least in vitro, non-pathological cell growth while increasing contractility. MiR-125a is able to induce CDKi expression in the murine heart and in neonatal cardiomyocytes, inducing cellular growth associated with G1-cell cycle arrest, and increased cardiac contractility and cardiomyocyte contraction frequency and amplitude (Chapter $\mathbf{6}$ ). The main conclusion from these studies is that miRNAs are important directors of molecular and multi-cellular processes underlying cardiac disease progression. Their regulatory function may be manipulated therapeutically in rodents and in the future in humans- to impact disease progression.

\subsection{The bigger picture: numerous miRNAs are involved in cardiac failure}

Despite the existing therapies, heart failure remains a major health problem with a high global prevalence and poor clinical outcome, especially threatening the lives of the elderly population [3-6]. MiRNA-targeted therapy may provide a novel approach to treat this agerelated disease. MiRNA-profiling studies show deregulated myocardial expression patterns during aging [7] and in different disease states, including heart failure (HF) [8], viral myocarditis [9], or myocardial infarction [10]. These studies associate various miRNAs with the 
cellular changes related to cardiac aging and disease progression. However, the question remains if identified deregulated miRNAs are part of a disease-mediating network, or that their differential expression merely represents a secondary effect. We therefore reviewed in chapter 2 the current knowledge concerning the molecular and cellular processes driving myocardial aging, and described the regulating role of known senescence-associated miRNAs in these processes. Altered miRNA expression profile seems not to be an "innocent bystander-effect". On the contrary, specific identified deregulated miRNAs influence healthy cardiac aging and disease.

The concept of the multi-cellular function of most of the HF-related miRNAs was confirmed in our screen of 194 miRNAs, differentially regulated in rodent and human inflammatory cardiac disease. Their effect on cardiomyocyte size, cardiac fibroblasts collagen content, and macrophage polarization was studied in vitro (Chapter 3). The simultaneous testing in different cell types broadened our understanding of the cellular involvement underlying the multifaceted pathogenesis of heart failure, identifying previously undescribed roles of miRNAs in hypertrophy, fibrosis, and inflammation, and attribute new cellular effects to various well-known miRNAs. Several high-throughput screens, aimed to identify on a large scale miRNAs as regulators of molecular processes crucially involved in cardiac (dys)function on a large scale, were performed by others. Cardiac processes which have been screened for the involvement of miRNAs include cardiomyocyte proliferation [11], intracellular calcium handling [12], and hypertrophic growth [13]. The uniqueness of our screen lies in its multi-cellular nature, whereas other screens only studied one specific cell type. Each screen has its own advantages and disadvantages. In general, high-throughput screening is accompanied with false-positive and false-negative rates. This necessitates further in-depth validation of the regulatory function of "top hit" miRNAs to support the process of selecting a miRNA that may impact cardiac disease outcome. Despite the shortcomings of high-throughput screening, large-scale assessment of miRNA function in one or more cellular processes forms a rich source of information and helps to identify promising miRNA candidates for therapeutic targeting.

\subsection{A closer look: specific miRNAs with specialised functions}

This thesis studied specific miRNAs as therapeutic candidate for their ability to regulate disease outcome in different animal models. In chapter 4, we silenced miR-221/222 via antagomir injections in a mouse model of Angll-induced pressure overload. MiR-221/222 inhibition results in an exaggerated cardiac fibrotic response along with a deterioration in cardiac function. This study indicates the pivotal role of the miR-221/222 family in controlling the fibrotic response during pressure-overload. However, the efficacy of miR-221/222 overexpression to prevent excessive fibrosis formation in the myocardium to attenuate detrimental cardiac remodelling still needs to be determined. In contrast, recent reports suggest that cardiomyocyte specific overexpression of either miR-221 or miR-222 impairs 
autophagy, leading to the spontaneous development of $\operatorname{HF}[14,15]$. However, the function of miR-221/222 in the cardiomyocyte was assessed using a transgenic overexpression model, reaching artificial expression levels that by far exceeded the pathophysiological levels observed in the heart in situ.

Other miRNA-based therapeutics have already made the transition from rodents to primate studies [16-18], confirming their specialised function and demonstration that modulation of their activity can impact disease progression in rodents and primates. This holds great promise regarding their translation into the clinic. Indeed, the first clinical trials modulating miRNA activity in humans have been performed. The safety and efficacy of anti-miR-122 treatment (Miravirsen) has been evaluated in 36 patients with chronic hepatitis C virus (HCV) genotype 1 infection [19]. The use of Miravirsen in patients with chronic HCV genotype 1 infection resulted in a dose-dependent reduction in HCV RNA levels that endured beyond the end of active therapy, while observing no dose-limiting adverse events and no escape mutations in the miR-122 binding site of the HCV genome [19]. In addition, both senescence-associated miR-16 and miR-34 (as discussed in chapter 2) are well known for their inhibitory effect on tumor growth and metastasis [20-23] and entered phase I clinical trials to investigate the safety, pharmacokinetics and pharmacodynamics of miRNA overexpression in cancer patients. The clinical trial for miR-16 has been completed, although no study results have been reported yet (Clinical trials.gov identifier NCT02369198). For miR-34, clinical testing in cancer patients was halted in September 2016, following multiple severe immune-related adverse events (Clinical trials.gov identifier NCT01829971). These clinical trials on the safety and efficacy of modulation of miRNAs indicate that we are on the edge of implementing miRNA-based therapeutics into the clinics.

\subsection{Beyond the horizon: possibilities \& limitations of future miRNA-based therapeutics}

Based on the impact of miRNA modulation on cardiac disease progression observed in rodent and primate studies and the initiated testing of miRNA-based therapeutics in clinical trials, we can conclude that miRNAs hold great promise as potential targets for therapy in the nearby future. However, clinical trials need to determine if miRNA-based therapeutics truly comprise the ability to prevent and/or cure cardiovascular disease in the human population. In order to progress the application of miRNA-based therapeutics in the clinics, improvement of current miRNA tools to impact miRNA function in vivo will be necessary.

Currently used techniques to inhibit specific miRNAs include the use of antagomirs, while miRNA overexpression is achieved via the use of miRNA mimics or adeno-associated virus (AAV)-mediated gene transfer. These miRNA mimics and antagomirs can be delivered systemically by intravenous, intraperitoneal, or subcutaneous injection with little or no 
toxicity $[24,25]$. However, since the vast majority of oligonucleotides is cleared through the liver and kidney [26], relatively high doses are needed to achieve therapeutic efficacy in the heart [27]. These high doses are paralleled by deregulation of the same miRNA in other unintended cell types, mainly being effective in circulating inflammatory cells and endothelial cells. Thus, using systemic administration of antagomirs or mimics limits the target options, necessitating the selection of a miRNA specifically expressed and/or functional in the cell type of interest to minimize off-target effects.

Local, instead of systemic, administration of miRNA-modulating agents would circumvent this problem. A single intra-cardiac injection of miRNA mimics has benefitted the heart after myocardial infarction, inducing a myocardial overexpression that lasted for at least 12 days [28]. Furthermore, AAV9-vectors have a tropism towards to heart and have been used to induce miRNA overexpression in the cardiomyocyte with minimal off target effects [29, 30]. However, the observed overexpression levels in the heart are rather mild, forming in some cases a suboptimal model to determine the phenotypical and functional consequences of miRNA modulation. Thus, current approaches to modulate miRNA expression force the researcher to choose between a potent but aspecific, or a mild but specific therapeutic strategy.

In spite of the current challenges, our knowledge about the role of miRNAs in cardiovascular disease accumulates rapidly and their translation into clinically applicable therapeutic tools will be established in the nearby future as specific delivery of miRNA-based therapeutics improves.

\subsection{Conclusions and Future Perspectives}

Heart failure is a major health problem. The lives of millions of people globally are threatened due to an increasing age of the general population and, more importantly, due to the lack of effective treatment. This thesis interrogated the role of miRNAs as regulators of cellular processes driving failure and aging of the myocardium, and elaborated on the efficacy of their manipulation in retarding heart failure progression. We identify multiple miRNAs that possess the ability to regulate cellular processes central to cardiac (dys)function, and provided proof of principle that their manipulation impacts cardiac disease progression. The obtained knowledge broadens our understanding of the mechanisms underlying the multifaceted pathogenesis of heart failure and the role of miRNAs therein.

While many different miRNAs are currently being studied to alter disease progression in rodent and primate studies, few promising miRNAs have already made the translation into clinical trials, indicating that we are on the edge of implementation of miRNA-based therapeutics. Development of improved therapeutic strategies to target miRNA activity will accelerate the utility of miRNA-based therapeutics in the clinics, holding great promise for the nearby future to treat cardiac disease and ensure healthy cardiac aging. 


\section{References}

1. Tijsen AJ, Pinto YM and Creemers EE. Non-cardiomyocyte micrornas in heart failure. CardiovasC Res. 2012;93:573-582

2. Kumarswamy R and Thum T. Non-coding rnas in cardiac remodeling and heart failure. Circ Res. 2013;113:676-689

3. Fang J, Mensah GA, Croft JB and Keenan NL. Heart failure-related hospitalization in the u.S., 1979 to 2004. J Am Coll Cardiol. 2008;52:428-434

4. Lakatta EG and Levy D. Arterial and cardiac aging: Major shareholders in cardiovascular disease enterprises: Part ii: The aging heart in health: Links to heart disease. Circulation. 2003;107:346354

5. Benjamin EJ, Blaha MJ, Chiuve SE, Cushman M, Das SR, Deo R, de Ferranti SD, Floyd J, Fornage M, Gillespie C, Isasi CR, Jimenez MC, Jordan LC, Judd SE, Lackland D, Lichtman JH, Lisabeth L, Liu S, Longenecker CT, Mackey RH, Matsushita K, Mozaffarian D, Mussolino ME, Nasir K, Neumar RW, Palaniappan L, Pandey DK, Thiagarajan RR, Reeves MJ, Ritchey M, Rodriguez CJ, Roth GA, Rosamond WD, Sasson C, Towfighi A, Tsao CW, Turner MB, Virani SS, Voeks JH, Willey JZ, Wilkins JT, Wu JH, Alger HM, Wong SS, Muntner P, American Heart Association Statistics C and Stroke Statistics S. Heart disease and stroke statistics-2017 update: A report from the american heart association. Circulation. 2017;135:e146-e603

6. Sliwa K, Wilkinson D, Hansen C, Ntyintyane L, Tibazarwa K, Becker A and Stewart S. Spectrum of heart disease and risk factors in a black urban population in south africa (the heart of soweto study): A cohort study. Lancet. 2008;371:915-922

7. Boon RA, lekushi K, Lechner S, Seeger T, Fischer A, Heydt S, Kaluza D, Treguer K, Carmona G, Bonauer A, Horrevoets AJ, Didier N, Girmatsion Z, Biliczki P, Ehrlich JR, Katus HA, Muller OJ, Potente M, Zeiher AM, Hermeking H and Dimmeler S. Microrna-34a regulates cardiac ageing and function. Nature. 2013;495:107-110

8. van Rooij E, Sutherland LB, Liu N, Williams AH, McAnally J, Gerard RD, Richardson JA and Olson EN. A signature pattern of stress-responsive micrornas that can evoke cardiac hypertrophy and heart failure. Proc Natl Acad Sci U S A. 2006;103:18255-18260

9. Corsten MF, Papageorgiou A, Verhesen W, Carai P, Lindow M, Obad S, Summer G, Coort SL, Hazebroek M, van Leeuwen R, Gijbels MJ, Wijnands E, Biessen EA, De Winther MP, Stassen FR, Carmeliet P, Kauppinen S, Schroen B and Heymans S. Microrna profiling identifies microrna-155 as an adverse mediator of cardiac injury and dysfunction during acute viral myocarditis. Circ Res. 2012;111:415-425

10. van Rooij E, Sutherland LB, Thatcher JE, DiMaio JM, Naseem RH, Marshall WS, Hill JA and Olson EN. Dysregulation of micrornas after myocardial infarction reveals a role of mir-29 in cardiac fibrosis. Proc Natl Acad Sci U S A. 2008;105:13027-13032

11. Eulalio A, Mano M, Dal Ferro M, Zentilin L, Sinagra G, Zacchigna S and Giacca M. Functional screening identifies mirnas inducing cardiac regeneration. Nature. 2012;492:376-381

12. Wahlquist C, Jeong D, Rojas-Munoz A, Kho C, Lee A, Mitsuyama S, van Mil A, Park WJ, Sluijter JP, Doevendans PA, Hajjar RJ and Mercola M. Inhibition of mir-25 improves cardiac contractility in the failing heart. Nature. 2014;508:531-535 
13. Jentzsch C, Leierseder S, Loyer X, Flohrschutz I, Sassi Y, Hartmann D, Thum T, Laggerbauer B and Engelhardt S. A phenotypic screen to identify hypertrophy-modulating micrornas in primary cardiomyocytes. J Mol Cell Cardiol. 2012;52:13-20

14. Su M, Chen Z, Wang C, Song L, Zou Y, Zhang L, Hui R and Wang J. Cardiac-specific overexpression of mir-222 induces heart failure and inhibits autophagy in mice. Cell Physiol Biochem. 2016;39: 1503-1511

15. Su M, Wang J, Wang C, Wang X, Dong W, Qiu W, Wang Y, Zhao X, Zou Y, Song L, Zhang L and Hui R. Microrna-221 inhibits autophagy and promotes heart failure by modulating the p27/cdk2/mtor axis. Cell death and differentiation. 2015;22:986-999

16. Lanford RE, Hildebrandt-Eriksen ES, Petri A, Persson R, Lindow M, Munk ME, Kauppinen S and Orum $H$. Therapeutic silencing of microrna-122 in primates with chronic hepatitis c virus infection. Science. 2010;327:198-201

17. Rayner KJ, Esau CC, Hussain FN, McDaniel AL, Marshall SM, van Gils JM, Ray TD, Sheedy FJ, Goedeke L, Liu X, Khatsenko OG, Kaimal V, Lees CJ, Fernandez-Hernando C, Fisher EA, Temel RE and Moore KJ. Inhibition of mir-33a/b in non-human primates raises plasma hdl and lowers vldl triglycerides. Nature. 2011;478:404-407

18. Elmen J, Lindow M, Schutz S, Lawrence M, Petri A, Obad S, Lindholm M, Hedtjarn M, Hansen HF, Berger U, Gullans S, Kearney P, Sarnow P, Straarup EM and Kauppinen S. Lna-mediated microrna silencing in non-human primates. Nature. 2008;452:896-899

19. Janssen HL, Reesink HW, Lawitz EJ, Zeuzem S, Rodriguez-Torres M, Patel K, van der Meer AJ, Patick AK, Chen A, Zhou Y, Persson R, King BD, Kauppinen S, Levin AA and Hodges MR. Treatment of hcv infection by targeting microrna. N Engl J Med. 2013;368:1685-1694

20. Rokavec M, Li H, Jiang L and Hermeking H. The p53/mir-34 axis in development and disease. J Mol Cell Biol. 2014;6:214-230

21. Agostini M and Knight RA. Mir-34: From bench to bedside. Oncotarget. 2014;5:872-881

22. Maroof H, Salajegheh A, Smith RA and Lam AK. Role of microrna-34 family in cancer with particular reference to cancer angiogenesis. Exp Mol Pathol. 2014;97:298-304

23. Reid G, Pel ME, Kirschner MB, Cheng YY, Mugridge N, Weiss J, Williams M, Wright C, Edelman JJ, Vallely MP, McCaughan BC, Klebe S, Brahmbhatt H, MacDiarmid JA and van Zandwijk N. Restoring expression of mir-16: A novel approach to therapy for malignant pleural mesothelioma. Ann Oncol. 2013;24:3128-3135

24. Stenvang J, Lindow M and Kauppinen S. Targeting of micrornas for therapeutics. Biochem Soc Trans. 2008;36:1197-1200

25. Stenvang J and Kauppinen S. Micrornas as targets for antisense-based therapeutics. Expert Opin Biol Ther. 2008;8:59-81

26. Obad S, dos Santos CO, Petri A, Heidenblad M, Broom O, Ruse C, Fu C, Lindow M, Stenvang J, Straarup EM, Hansen HF, Koch T, Pappin D, Hannon GJ and Kauppinen S. Silencing of microrna families by seed-targeting tiny Inas. Nat Genet. 2011;43:371-378

27. Ameres SL, Horwich MD, Hung JH, Xu J, Ghildiyal M, Weng Z and Zamore PD. Target rna-directed trimming and tailing of small silencing rnas. Science. 2010;328:1534-1539 
28. Lesizza P, Prosdocimo G, Martinelli V, Sinagra G, Zacchigna S and Giacca M. Single-dose intracardiac injection of pro-regenerative micrornas improves cardiac function after myocardial infarction. Circ Res. 2017;120:1298-1304

29. Pacak CA, Mah CS, Thattaliyath BD, Conlon TJ, Lewis MA, Cloutier DE, Zolotukhin I, Tarantal AF and Byrne BJ. Recombinant adeno-associated virus serotype 9 leads to preferential cardiac transduction in vivo. Circ Res. 2006;99:e3-9

30. Bish LT, Morine K, Sleeper MM, Sanmiguel J, Wu D, Gao G, Wilson JM and Sweeney HL. Adenoassociated virus (aav) serotype 9 provides global cardiac gene transfer superior to aav1, aav6, aav7, and aav8 in the mouse and rat. Hum Gene Ther. 2008;19:1359-1368 



\section{Summary / Samenvatting}





\section{Summary}

Heart failure (HF) currently forms a major global health problem and its prevalence is predicted to increase in the future, since effective treatment is still lacking. This highlights the urgent need to develop novel treatment strategies to save the lives of millions of people globally. Specific miRNAs are differentially expressed during cardiac pathophysiology and posses the ability to impact cardiac disease progression, highlighting their potential as therapeutic target. Therefore, the main aims of this thesis are: $\mathbf{1})$ to identify miRNAs that regulate cellular processes driving failure of the myocardium, and 2 ) to explore if the manipulation of some promising miRNA candidates (identified under aim 1) are able to retard heart failure progression.

To address the first aim, we review in chapter $\mathbf{2}$ the fundamental role of miRNAs in regulating molecular and cellular processes driving detrimental changes in the myocardium associated with senescence and heart failure. Chapter $\mathbf{3}$ describes an in vitro high-throughput screening approach to determine the regulatory function of miRNAs in cardiomyocyte hypertrophy, cardiac fibrosis, and inflammation in a large scale. As a result, we identified miRNAs as pleiotropic regulators, describing previously unknown roles of miRNAs in cardiomyocyte hypertrophy, fibrosis, and inflammation, and attribute new cellular functions to various well-known miRNAs.

Addressing the second aim, in chapter 4 through 6 we explored if the manipulation of selected promising miRNA candidates is able to retard heart failure progression. Chapter 4 addresses the pivotal role of the miR-221/222 family in the process of myocardial fibrosis formation as an underlying factor of HF progression. Cardiac miR-221/222 levels negatively correlate with myocardial fibrosis in different patient populations with heart failure. Inhibition of this miRNA family in mice subjected to pressure-overload increased cardiac fibrosis and aggravated left ventricular dilation and dysfunction. In isolated rat cardiac fibroblasts, inhibition of miR-221/222 de-repressed TGFß-signaling, while overexpression of both miRNAs blunted TGF $\beta$-induced pro-fibrotic signaling. MiR-221/222 is thus a key regulator of fibrotic signalling in the heart.

Chapter $\mathbf{5}$ focuses on the negative-regulatory function of miR-151 in cardiomyocyte hypertrophy and its ability to modulate mitochondrial oxidative capacity of cardiomyocytes, probably via regulation of PGC-1a. Although additional research needs to be conducted to validate and clarify the underlying mechanism, these findings mark miR-151 as an important regulator of the energetic profile of the heart.

Chapter 6 addresses the effect of miR-125a-identified as the strongest inducer of cell growth in neonatal cardiomyocytes (Chapter 3)- on cardiomyocyte cell cycle activity and the hypertrophic response. MiR-125a induces cardiomyocyte CDKi expression in vivo and in vitro, enhances cellular growth, and increases cardiac contractility and cardiomyocyte contraction frequency and amplitude. MiR-125a therefore is a modulator of cardiomyocyte differentiation and cell cycle activity. Whether miR-125a and its control of cell cycle reentry have a role in the failing heart will be subject of further investigations. 
Finally, in chapter $\mathbf{7}$ we recapitulate the findings of our studies and discuss this in a broader perspective. Furthermore, we address possibilities and limitations of miRNAbased therapeutic strategies and its potential utility in the clinic. 


\section{Samenvatting}

Hartfalen (HF) vormt momenteel een wereldwijd gezondheidsprobleem en de prevalentie hiervan is voorspeld in de toekomst toe te nemen aangezien effectieve behandeling nog steeds ontbreekt. Dit geeft de dringende behoefte aan om nieuwe behandelmethoden te ontwikkelen om zodoende de levens van miljoenen mensen wereldwijd te redden. Specifieke miRNAs komen differentieel tot expressie gedurende pathofysiologie van het hart en bezitten het vermogen om de progressie van hartziekten te beïnvloeden, wat hun potentie als therapeutisch doel duidt. Om die reden zijn de hoofddoelen van deze thesis: 1) het identificeren van miRNAs die in staat zijn om cellulaire processen die hartfalen bewerkstelligen, te reguleren, en 2 ) het bestuderen of het manipuleren van veelbelovende miRNA kandidaten (geïdentificeerd onder doel 1 ) in staat is om de progressie van hartfalen te remmen.

Om het eerste doel te realiseren, bespreken we in hoofdstuk $\mathbf{2}$ de fundamentele rol van miRNAs in het reguleren van moleculaire en cellulaire processen die nadelige veranderingen in het hart bewerkstelligen en geassocieerd worden met ouderdom en hartfalen.

Hoofdstuk 3 beschrijft een in vitro high-throughput screening methode voor het op grote schaal bepalen van de regulerende functie van miRNAs in hartspier hypertrofie, cardiale fibrose en inflammatie. Als resultaat hebben we miRNAs geïdentificeerd als pleiotrope regulatoren, beschreven we voorheen onbekende functies voor miRNAs in hypertrofie, fibrose en inflammatie, en schreven we nieuwe cellulaire effecten toe aan meerdere bekende miRNAs.

Bij het adresseren van de tweede doelstelling, hebben we in hoofdstuk 4 tot en met 6 onderzocht of de manipulatie van geselecteerde veelbelovende miRNA kandidaten in staat is om de progressie van hartfalen te remmen. Hoofdstuk $\mathbf{4}$ beschrijft de centrale rol van de miR-221/222 familie in het proces van fibrose vorming in het hart als een onderliggende factor voor de progressie van hartfalen. Cardiale miR-221/222 levels correleren negatief met fibrose in het myocard bij verschillende patiënt populaties met hartfalen. Het remmen van deze miRNA familie in muizen blootgesteld aan druk-overbelasting, vermeerdert cardiale fibrose en verergerdt linker ventrikel dilatatie en dysfunctie. In geïsoleerde rat cardiale fibroblasten, remming van miR-221/222 vermindert de onderdrukking van TGF $\beta$ signalering. MiR-221/222 is dus een belangrijke regulator van fibrose signalering in het hart.

Hoofdstuk 5 spitst zich toe op de regulerende functie van miR-151 in hartspier hypertrofie en zijn vermogen om de mitochondriale oxidatieve capaciteit van hartspieren te moduleren, waarschijnlijk via regulatie van PGC-1a. Hoewel additioneel onderzoek uitgevoerd moet worden om dit te valideren en het onderliggende mechanisme te verhelderen, markeren deze bevindingen miR-151 als een belangrijke regulator van het energie profiel van het hart.

Hoofdstuk 6 richt zich op het effect van miR-125a -geïdentificeerd als sterkste veroorzaker van celgroei in neonatale hartspieren (hoofdstuk 3)- op hartspier celcyclus activiteit en de hypertrofe response. MiR-125a induceert hartspier CDKi expressie in vivo en in vitro, 
versterkt celgroei, en vermeerdert contractiliteit van het hart en de contractie frequentie en amplitude van hartspieren. MiR-125a is daarom een bemiddelaar van cardiomyocyte differentiatie en celcyclus activiteit. Of miR-125a en zijn controle over celcyclus-herintrede een rol spelen in falen van het hart is onderwerp van toekomstig onderzoek.

Tenslotte, in hoofdstuk $\mathbf{7}$ vatten we de bevindingen van onze studies samen en stellen we dit ter discussie in een breder perspectief. Bovendien bespreken we de mogelijkheden en beperkingen van miRNA-gebaseerde therapeutische strategieën en de mogelijke toepasbaarheid hiervan in de kliniek. 




\section{Valorisation}





\section{Valorisation}

\section{Societal relevance}

Cardiovascular disease (CVD) is the leading global cause of death, accounting for more than 17.3 million deaths per year, representing 1 of every 3 deaths [1]. This life-threatening disease is accompanied with enormous annual costs, reaching \$863 billion in 2010 globally [2]. Almost half of the patients with newly diagnosed CVD have heart failure (HF). Importantly, $\mathrm{HF}$ is the only cardiovascular disease that has increased in prevalence over the last 20 years [3]. According to the American Heart Failure Association, the prevalence of HF will continue to increase with 46\% from 2012 to 2030, resulting in more than 8 million people with an age of 18 years or older with HF [4]. In the Netherlands, currently 142.000 patients suffer from HF, resulting in 940 million euros of annual costs for HF in 2011 in the Netherlands only [5]. In addition to the rising prevalence, the high five-year mortality of HF patients (52.6\%) did not decline since 2000, highlighting the ineffectiveness of current therapeutics and the urgent need to develop novel treatment strategies. Thus, improving $\mathrm{HF}$ therapy is necessary to prevent this disease to reach global epidemic proportions and to save the lives of millions of people around the world. However, to achieve this goal, we should expand the current knowledge concerning cellular processes driving HF development, and identify molecular key players to test as potential therapeutic targets.

In this thesis, we identified multiple specific microRNA (miRNA) candidates with a pivotal regulatory function in cellular processes driving HF development. Identification of these miRNAs and interrogation of the mechanism underlying their function increases the understanding of $\mathrm{HF}$ development. Increased understanding of the processes driving HF progression expands the body of knowledge, benefitting the scientific community. More importantly, identified miRNA candidates can be probed for their safety and efficacy to impact cellular processes underlying HF development and to retard disease progression. In this thesis we identified several promising miRNA candidates that in a next stage should be tested for their safety and ability to intervene with HF progression.

\section{Target groups}

The content of this thesis is relevant for the scientific community, for future drug development, and on the longer term for patients. Within the scientific community, increased understanding of the function of miRNAs during HF progression will benefit cardiac researchers. In addition to the cardiac research field, basic research studying other disease etiologies may be aided by the content of this thesis. The cellular processes studied within this thesis are not restricted to be involved in cardiac disease progression only. Therefore, miRNAs described in this thesis to regulate these processes are most likely also involved in other disease settings. For example, manipulation of the miR-221/222 family may also impact hepatic or pulmonary fibrosis formation. Furthermore, inducing cell cycle arrest through induction of miR-125a may potentially affect tumor growth. 
Almost half of the HF patients will die within 5-years after diagnosis. This marks the ineffectiveness of current therapeutic strategies to treat HF patients. Therefore, new drugs should be developed to save the lives of millions of people globally. Although the end result by means of a successful clinically utilised therapy lies beyond the horizon, we as basic scientists should strive for expansion of the scientific body of knowledge to increase the chances of developing life-saving therapeutic approaches. Although this thesis highlights multiple miRNAs crucially involved in processes underlying failure of the heart, different challenges need to be overcome before miRNA-based strategies can undergo widespread implementation, as discussed in the discussion section.

Described novel knowledge on how miRNAs control the development of heart failure is only of indirect value to the current patient population. Further rigorous investigation of these miRNA candidates is necessary to determine safety and efficacy in patients. However, the findings in this thesis will advance our understanding of the involvement of miRNAs in cardiac disease. Ultimately, patients will benefit from developed miRNA-based therapies, alleviating the heavy burden of HF on society.

\section{Innovation, products, and implementation}

Current ineffective therapeutic strategies to treat HF patients are not aimed at targeting miRNAs. This thesis proves an altered expression profile and functional involvement of specific miRNAs in the failing heart. These findings mark an innovative treatment approach in which therapies are designed to modulate miRNA function to impact HF progression. MiRNA identified by us using in vitro high-throughput screening, or specific miRNAs tested in animal models may form the basis for drug development. However, the process of developing a clinically applicable therapeutic strategy based on basic research is a long and costly process, making it difficult to predict the long-term value of this thesis.

Independent of the future development of miRNA-based therapeutic approaches, communication of the content of the described research is crucial for future implementation. Findings of this thesis are communicated through multiple international scientific conferences in which we were invited to present our work. Moreover, we have submitted and published our scientific results to international peer-reviewed journals, allowing the scientific community and general public to get access to it. 


\section{References}

1. Benjamin EJ, Blaha MJ, Chiuve SE, Cushman M, Das SR, Deo R, de Ferranti SD, Floyd J, Fornage M, Gillespie C, Isasi CR, Jimenez MC, Jordan LC, Judd SE, Lackland D, Lichtman JH, Lisabeth L, Liu S, Longenecker CT, Mackey RH, Matsushita K, Mozaffarian D, Mussolino ME, Nasir K, Neumar RW, Palaniappan L, Pandey DK, Thiagarajan RR, Reeves MJ, Ritchey M, Rodriguez CJ, Roth GA, Rosamond WD, Sasson C, Towfighi A, Tsao CW, Turner MB, Virani SS, Voeks JH, Willey JZ, Wilkins JT, Wu JH, Alger HM, Wong SS, Muntner P, American Heart Association Statistics C and Stroke Statistics S. Heart disease and stroke statistics-2017 update: A report from the american heart association. Circulation. 2017;135:e146-e603

2. Bloom DE, Ca ero, E.T., Jané-Llopis, E., Abrahams-Gessel, S., Bloom, L.R., Fathima, S., Feigl, A.B., Gaziano, T., Mowa, M., Pandya, A., Prettner, K., Rosenberg, L., Seligman, B., Stein, A.Z., \& Weinstein, C. . The global economic burden of noncommunicable diseases. Geneva: World Economic Forum. 2011

3. Braunwald E and Bristow MR. Congestive heart failure: Fifty years of progress. Circulation. 2000; 102:IV14-23

4. Heidenreich PA, Albert NM, Allen LA, Bluemke DA, Butler J, Fonarow GC, Ikonomidis JS, Khavjou O, Konstam MA, Maddox TM, Nichol G, Pham M, Pina IL, Trogdon JG, American Heart Association Advocacy Coordinating C, Council on Arteriosclerosis T, Vascular B, Council on Cardiovascular R, Intervention, Council on Clinical C, Council on E, Prevention and Stroke C. Forecasting the impact of heart failure in the united states: A policy statement from the american heart association. Circulation. Heart failure. 2013;6:606-619

5. Feiten en cijfers hart- en vaatziekten. Dutch Heart Foundation. 2017; https://www.hartstichting.nl/hart-vaten/cijfers 



\section{Dankwoord}





\section{Dankwoord}

De afgelopen 4 jaar was een periode die gepaard ging met diepte en, gelukkig veel, hoogtepunten. Gedurende deze periode heb ik veel mensen ontmoet, omgevingen ervaren en uitdagende leermomenten beleefd. Dit boekje en de ontwikkeling die ik heb doorgemaakt als mens en onderzoeker zijn vorm gegeven door veel verschillende mensen en deze wil ik hier graag voor bedanken.

Als eerste wil ik graag mijn promotor Stephane en co-promotores Blanche en Marc hartelijk bedanken. Tijdens mijn master senior stage ben ik in aanraking gekomen met dit lab, resulterend in een enthousiasme en passie voor cardiologisch microRNA onderzoek. Jullie hebben me de kans gegeven om dit onderzoek, in binnen- en buitenland, uit te voeren met de nodige ruimte om het zelf aan te sturen en daarin fouten te maken. Dankzij jullie supervisie en opbouwende kritiek heb ik me kunnen ontwikkelen tot de onderzoeker die ik nu ben. Geen enkel hoofdstuk zou tot stand zijn gekomen zonder jullie input en feedback. Hartelijk bedankt voor alles en hopelijk blijven we elkaar in de toekomst tegenkomen!

De leden van de leescommissie, die de energie erin gestoken hebben mijn proefschrift te lezen en te beoordelen, wil ik hier ook graag bedanken: Prof. dr. Harry Crijns, Prof. dr. Mauro Giacca, Prof, dr. Jan de Boer, Dr. Ebba Brakenhielm en Dr. Joris Hoeks.

Het verloop van de afgelopen jaren heb ik te danken aan alle collega's die op hun eigen manier, direct of indirect, hebben bijgedragen. Gedurende de start van mijn PhD traject heeft de "oude generatie" AIO's, Tim, Wouter, Georg en Marieke, een belangrijke rol gespeeld bij het opstarten van mijn onderzoek. Tim, ik wil jou met name bedanken voor de geweldige begeleiding tijdens mijn tijd als stagiair. Je hebt me geleerd zorgvuldig en gestructureerd te werk te gaan in het lab en daarnaast heb je mij een eerlijk beeld gegeven van de onderzoekswereld. Jij hebt een indrukwekkende basis gelegd voor het miR-221/222 project, waarbij ik alleen nog maar de eindjes aan elkaar hoefde te verbinden. Heel veel succes met je verdere carrière en vooral veel geluk met je gezin! Wouter, jouw gezelligheid en onvermoeibare optimisme zijn een voorbeeld voor mij geweest. Zelfs tijdens de insolventie periode bij Cenix wist jij mij ervan te overtuigen dat we het onderzoek tot een goed einde gingen brengen. Gelukkig hebben we ondanks de grote tijdsdruk voor het uitvoeren van de screens nog genoeg tijd gevonden om meerdere Schweinehaxen te proeven in de verschillende Bräuhauser. Samen hebben we een mooie tijd gehad in Dresden, resulterend in een prachtig onderzoek en Ik hoop dat je nog lang van deze stad kunt genieten! Tevens was het een eer om samen met Georg als paranimf te fungeren op jouw grote dag. Georg, mijn dank voor alle onbenullige vragen over printers, Wifi, de share, "bla-bla-bla", "yada yada" en "science and stuff". Of het nu ging over het maken van een 3D-plot van een principal component analyse, of het jaartal wanneer Sharknado 2 was uitgekomen, jij kon mijn vragen altijd beantwoorden. Ik wens je heel veel succes in de toekomst, in Maastricht of waar dan ook in de wereld. Marieke, bedankt voor de wetenschappelijke adviezen en het benadrukken van de klinische translatie van basaal onderzoek. Jouw presentatie vaardigheden zijn een voorbeeld voor mij geweest. 
Tevens wil ik graag de "nieuwe generatie" AIO's, Monika, Steffie, Lena en Annika hartelijk bedanken. Jullie hebben me vergezeld gedurende het promotie traject en stonden altijd klaar als ik mijn vreugde of frustratie wilde delen. Voornamelijk gedurende de laatste maanden toen de stress toenam hebben jullie me erdoorheen gesleept. Monika, we could understand each other's frustration when science was not fair or not progressing at the pace we intended. More importantly, we shared many enjoyable and memorable moments in the lab and at the ski slopes (PIÔÔOÔOÔN!). Grazie mille for the help in the lab, the discussions about science, and all the rest. During our SSF project, you really enjoyed producing a scientific deliverable to improve cardiac health care. Therefore, I hope that you will find all that you are looking for in your future career in industry. But first, I wish you all the best during your finishing period of your PhD. Steffie, ik was blij dat we een kantoor hebben gedeeld om over alle zin en onzin in de wetenschappelijke wereld te praten. En niet alleen tijdens werkuren, ook tijdens het nuttigen van een sjoes in Maastricht of een "Les Diablerets" in Zwitserland ben je geweldig gezelschap. Ik hoop dat je bereikt wat je wilt bereiken de resterende maanden van je promotie traject en de daarop volgende carrière.

Lena, although we did not work together for such a long period, your passion and drive is remarkable. Keep your spirit and enthusiasm high, than I am confident you will have a bright future in science. Annika, tijdens je stage heb je hard gewerkt onder de begeleiding van Monika en een goede indruk nagelaten bij het lab. Nu ben je begonnen aan je eigen PhD-avontuur. Bedankt dat je verder wilt werken aan het miR-151 project en ik ben ervan overtuigd dat je dit naar een succesvol eind zult brengen.

Geen enkel van de experimenten beschreven in deze thesis zou uitgevoerd zijn geworden zonder de ondersteuning van onze deskundige technicians: Rick, Wouter en Kevin. Rick, hartelijk bedankt voor alle technieken die je me bijgebracht hebt. Met name het opzetten en uitvoeren van de cardiomyocyte isolatie in Cenix zou niet zijn gelukt zonder jouw ondersteuning. Tevens ben ik erg blij dat je de afgelopen jaren zowel de professionaliteit in het lab als het stipte moment van lunch gewaarborgd hebt met grote precisie. Gelukkig hebben we ook veel momenten gedeeld waarbij je je professionaliteit liet voor wat het was om te praten over het weer, "het mannetje", "cornetto's", of onderwerpen van een nog lager niveau. Ik hoop dat je met veel passie de uitdagingen aan blijft gaan in je werk de komende jaren. Wouter, het was een genoegen om met je samen te werken en wetenschap te bediscussiëren. Als stagiair en als PhD-student kon ik altijd rekenen op een sarcastisch of cynisch antwoord op mijn onkundige vragen om mezelf aan het denken te zetten. Gedurende de tijd dat wij een kamer hebben gedeeld, heb ik naast de verschillende lab-technieken veel geleerd over de essentie van onderzoek. Je hebt me getriggerd om met een kritische blik naar mijn eigen werk, het werk van anderen, en de wetenschap in het algemeen te kijken. Kevin, gedurende mijn stage bij cardiologie was geen vraag jou teveel. Je eindeloze passie en enthousiasme in het lab stimuleerde mij en alle andere collega's. Het was een plezier om samen te werken en te feesten. Ik hoop dat je met dezelfde drive je werk kunt blijven verrichten. 
Stagiaires Moritz en Stan, ik heb met het grootste plezier jullie begeleid tijdens jullie stages. Functioneren als supervisor was soms tijdrovend maar heeft mijn onderzoek en mijn ontwikkeling veel opgeleverd. Hartelijk bedankt voor al het werk dat jullie verzet hebben.

Barbara and Lilian, hartelijk bedankt voor het beantwoorden van al mijn onwetende vragen. Met name dank voor alle hulp de laatste maanden van mijn PhD als ikjullie kantoor binnen kwam rennen voor verschillende formulieren die ondertekend moesten worden. En natuurlijk hartelijk bedankt voor het organiseren van de geslaagde activiteiten en de heerlijke diners tijdens het "Cardio Dagje Uit" of de kerstborrels. We hebben genoten!

Daarnaast wil ik graag alle leden van onze groep bedanken (gedeeltelijke) werkend in Leuven: Anna, Sophie, Julie, Ilona en Quentin. Paolo, hierbij wil ik voornamelijk jou bedanken voor het deskundig organiseren en uitvoeren van de verschillende in vivo studies. Heel veel succes de komende periode met je eigen PhD.

During the first 1,5 years of my PhD I worked at the beautiful city Dresden. I could not have whished for a better "foreign family" who welcomed me with open arms. I am happy and honoured I was a member of the Cenix family. Making it even more regretful that this company has found such a sad ending. Special thanks to Birte and Kerstin for all their supervision and coordination while setting up and performing the high throughput microRNA screening. Sarah, Arend, Alex, Julia, and Kartini thank you for all the practical help in the lab and all the food, beers, and concerts afterwards. Steffen, Andrew, and Christophe thank you for the data analysis in Definiens, Knime, and all other software that was new to me. Gisela, thank you very much for arranging all important affairs concerning housing and living in Dresden. Thanks to you guys I experienced my stay at Dresden as a second home far away from home which I will never forget. I hope all of you are having, and will continue to have a succesfull career with such a warm environment as in Cenix.

Furthermore, I would like to acknowledge additional members of the big cardio lab: Leon, Paul, Paola, Ellen, Servé, Roel, Sandrine, Burcu, Vincenza, and Martina. Especially Rio, Andrea, Lara, Mora, Christina, and Beatrice, thanks for bringing the warm, lively, alcoholic, and especially loud atmosphere to our Dutch lab and our parties. Daarnaast wil ik graag de kliniek bedanken: Mark, Jort, Arantxa, Job en Kasper.

Naast alle collega's wil ik verschillende mensen bedanken die een cruciale rol gespeeld hebben in mijn leven. Om te beginnen wil ik mijn vrienden: Jordi, Yannick, Roelof, Donald, Dennis, Casper, Vedad, Tom, Luc en Ralph, hartelijk bedanken. Jongens bedankt dat wij samen zo'n mooie groep vormen. Aangezien het woord "fotosynthese" al genoeg is om menig hoofd van jullie op hol te doen laten slaan, ben ik blij dat ik met jullie over alles behalve werk kan praten. We wonen verspreid door het land maar ik hoop dat we de tijd blijven vinden om elkaars leven met onzin en plezier te vullen!

Mijn grote broer Nick, jou wil ik ook graag bedanken voor het voorbeeld wat je altijd bent geweest en zult zijn. Als ik dezelfde passie en discipline kan stoppen in mijn werk als jij in het handballen zullen er geen hartziekten meer bestaan over 10 jaar. Ik hoop alleen dat 
je master niet zo voorspoedig zal verlopen, zodat wij de kans hebben om de keuken van ieder restaurant in Maastricht te kunnen proeven. Ik wens jou samen met je vrouw Ines, en je prachtige dochters Eline en Ida, het allerbeste!

Mijn ouders, Vicky en Peter, wil ik bedanken voor alle discipline en motivatie die jullie me samen hebben meegegeven om het maximale te bereiken. Mam, jou wil ik speciaal bedanken voor alles wat je in je eentje hebt klaar gespeeld zodat ik al mijn doelen kon najagen. Dit boekje is daarom ook voor jullie geschreven, hopend dat mijn onderzoek enig effect zal hebben op het opsporen en behandelen van hartziekten.

Lieve Rosanne, jij bent voor mij de belangrijkste persoon geweest de afgelopen jaren. Jij hebt me altijd gesteund, zelfs als ik besloot om voor een langere periode in Dresden of Triëst te gaan werken. Wanneer ik het werk overdreef door vast te roesten achter mijn laptop was jij daar om mij tegen mezelf te beschermen. Maar ik wil je vooral bedanken voor al de liefde en geluk wat wij gedeeld hebben de afgelopen jaren. Hopelijk kunnen we nog lang zo door gaan. Dankjewel, je bent de allerliefste. 




\section{Curriculum Vitae}





\section{Curriculum Vitae}

Robin Verjans was born on the $5^{\text {th }}$ of March 1990 in Heerlen. In 2008, he graduated from his secondary education at the Graaf Huyn College in Geleen, the Netherlands. He started his B.Sc. study Health Sciences at Maastricht University with a major in Bioregulation and a minor in Movement Sciences. During his B.Sc. studies, Robin completed a research internship at Maastricht University, department of Human Biology. The topic of this internship was the influence of C/EBP 3 isoforms LIP and LAP on ApoA-1 production in HepG2 cells. Element of this internship was writing the literature review: HDL Functionality as Protective Factor for Future Cardiac Diseases.

In 2011, he started the M.Sc. study Biomedical Sciences. During his first year, he completed his junior internship at the department of Pathology at the Academic Hospital Maastricht, under the supervision of Dr. Judith Sluimer. During his junior internship, the effect of reoxygenating carbogen treatment on efferocytosis efficiency and hypoxia in murine atherosclerotic plaques was studied. During the final year, he completed his senior thesis entitled "A Crucial Role for microRNAs in Heart Failure: Identifying the molecular mechanism" at the department of Cardiology at Maastricht University. He received his master's degree with a specialisation in Cardiovascular Biology and Medicine in 2013.

Subsequently, he commenced his PhD trajectory at the department of Cardiology at Maastricht University under the supervision of promoter Prof. Dr. Stephane Heymans and co-promoters Dr. Blanche Schroen and Dr. Marc van Bilsen. The main focus of this trajectory was to study the regulatory role of microRNAs in cellular processes that drive the development of heart failure. In the context of the European CardiomiR project, Robin was seconded from October 2013 to January 2015 to RNA-interference company: Cenix BioScience GmbH, Dresden Germany. During this secondment he designed and performed a high-throughput screening to determine the function of a large subset of heart failureassociated microRNAs.

In August 2017, Robin was granted the CARIM Postdoctoral Talent Fellowship for the project: "Prevention of Cardiomyocyte Cell Cycle Re-entry via miR-125a Protects the Heart from Detrimental Remodeling". This fellowship enables him to perform his postdoctoral research at the International Centre for Genetic Engineering and Biotechnology (ICGEB), Trieste Italy, as well as at Cardiovascular Research Institute Maastricht (CARIM), Maastricht the Netherlands. 